\title{
How relations, time \& size matter in medical education
}

Citation for published version (APA):

Hommes, J. E. (2014). How relations, time \& size matter in medical education. [Doctoral Thesis, Maastricht University]. Datawyse / Universitaire Pers Maastricht. https://doi.org/10.26481/dis.20140226jh

Document status and date:

Published: 01/01/2014

DOI:

10.26481/dis.20140226jh

Document Version:

Publisher's PDF, also known as Version of record

\section{Please check the document version of this publication:}

- A submitted manuscript is the version of the article upon submission and before peer-review. There can be important differences between the submitted version and the official published version of record.

People interested in the research are advised to contact the author for the final version of the publication, or visit the DOI to the publisher's website.

- The final author version and the galley proof are versions of the publication after peer review.

- The final published version features the final layout of the paper including the volume, issue and page numbers.

Link to publication

\footnotetext{
General rights rights.

- You may freely distribute the URL identifying the publication in the public portal. please follow below link for the End User Agreement:

www.umlib.nl/taverne-license

Take down policy

If you believe that this document breaches copyright please contact us at:

repository@maastrichtuniversity.nl

providing details and we will investigate your claim.
}

Copyright and moral rights for the publications made accessible in the public portal are retained by the authors and/or other copyright owners and it is a condition of accessing publications that users recognise and abide by the legal requirements associated with these

- Users may download and print one copy of any publication from the public portal for the purpose of private study or research.

- You may not further distribute the material or use it for any profit-making activity or commercial gain

If the publication is distributed under the terms of Article $25 \mathrm{fa}$ of the Dutch Copyright Act, indicated by the "Taverne" license above, 


\section{Juliette Hommes}

\section{HOW RELATIONS, \\ TIME \& SIZE MATTER}

in medical education

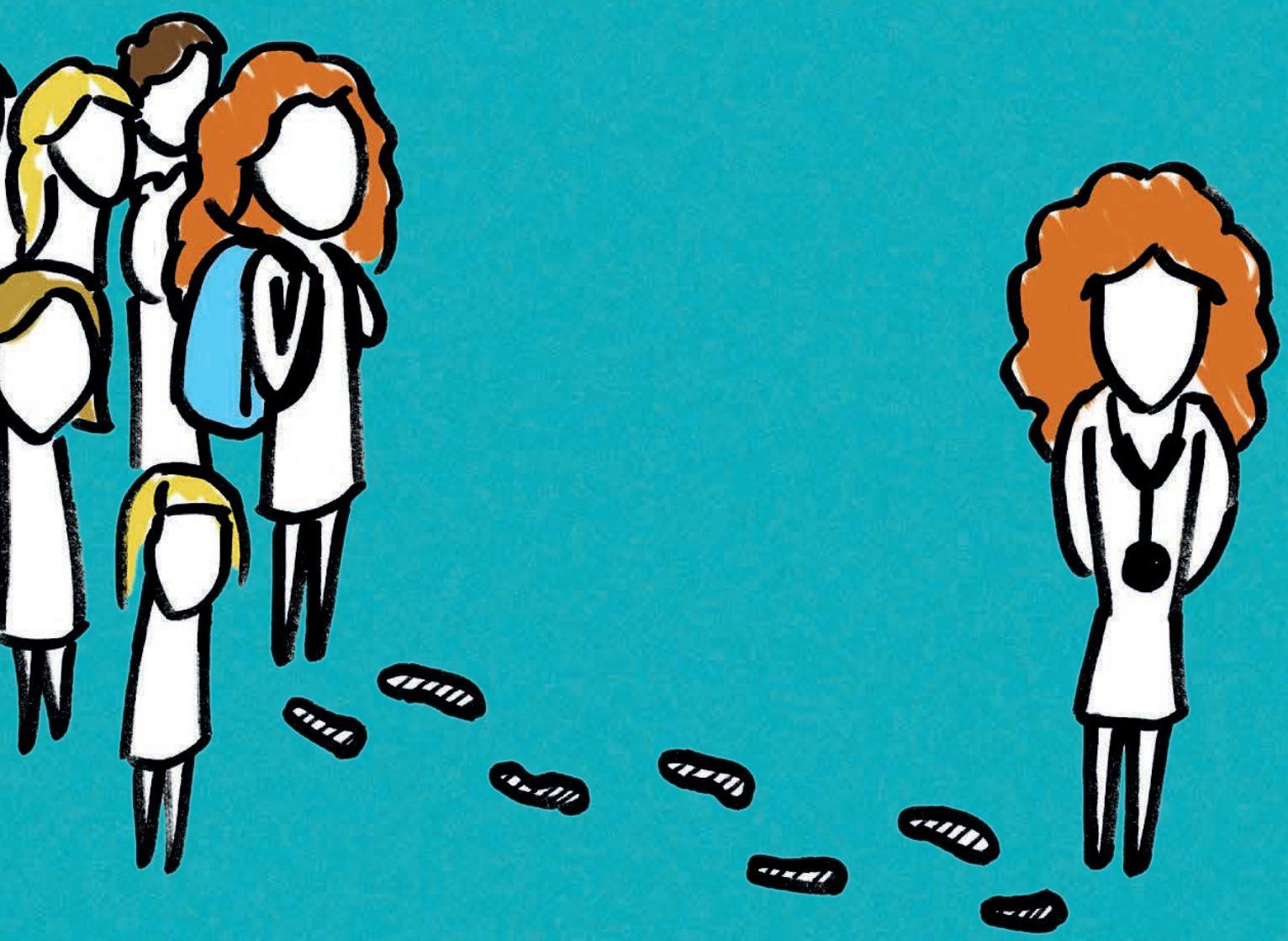



HOW RELATIONS, TIME \& SIZE MATTER IN MEDICAL EDUCATION 
The research reported in this dissertation was carried out at

\section{Maastricht University in Learning!}

In the School of Health Professions Education

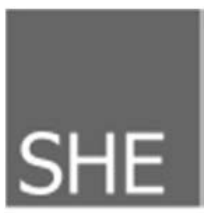

(C) Juliette Hommes, Maastricht 2014

Coverillustration: DJOZDESIGN

Production: Datawyse | Universitaire Pers Maastricht

ISBN 9789461593078 


\title{
How relations, time \& size matter in medical education
}

\author{
Proefschrift \\ Ter verkrijging van de graad van doctor aan de Universiteit Maastricht \\ op gezag van de Rector Magnificus, Prof. Dr. L.L.G. Soete, \\ volgens het besluit van het College van Decanen \\ in het openbaar te verdedigen \\ op woensdag 26 februari 2014 om 16:00 uur
}

door

Juliette Eva Hommes

geboren op 6 februari 1986 te Gorinchem

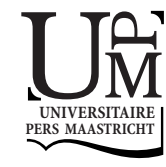




\section{Promotores:}

Prof. Dr. A.J.J.A. Scherpbier

Prof. Dr. L.W.T. Schuwirth

Prof. Dr. G.M.J. Bos

\section{Copromotor:}

Dr. W. de Grave

\section{Beoordelingscommissie:}

Prof. Dr. D. Dolmans, voorzitter

Prof. Dr. T. Dornan

Prof. Dr. W. Gijselaers

Prof. Dr. A. Jaarsma

Prof. Dr. M. De Laat 


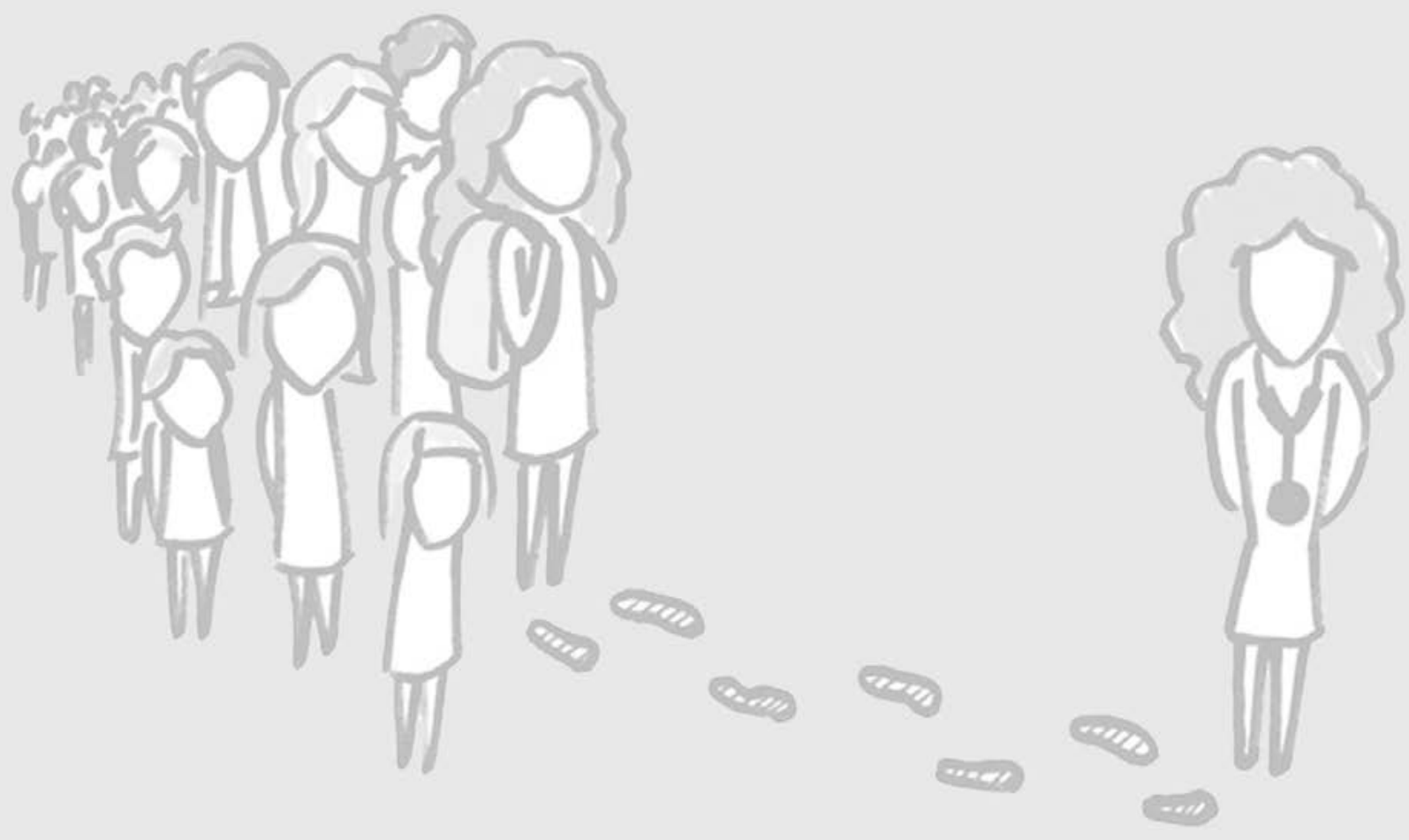



The very substance of the ambitious is merely the shadow of a dream.

Shakespeare 



\section{Contents}

Chapter 1 Introduction

Chapter 2 Understanding the effects of time on collaborative learning processes in a Problem-Based Learning setting: a mixed methods study

Chapter 3 Visualising the invisible: A network approach to reveal 49 the informal social side of student learning

Chapter 4 The impact of the instructional design on informal learning with fellow students over time

Chapter 5 Medical students perceive better learning processes 99 when classes are made to seem small

Chapter 6 General discussion

Chapter 7 Summary

Samenvatting

Chapter 8 Dankwoord

Chapter 9 Curriculum vitae 141

Chapter 10 SHE Dissertation series 



\section{CHAPTER 1}
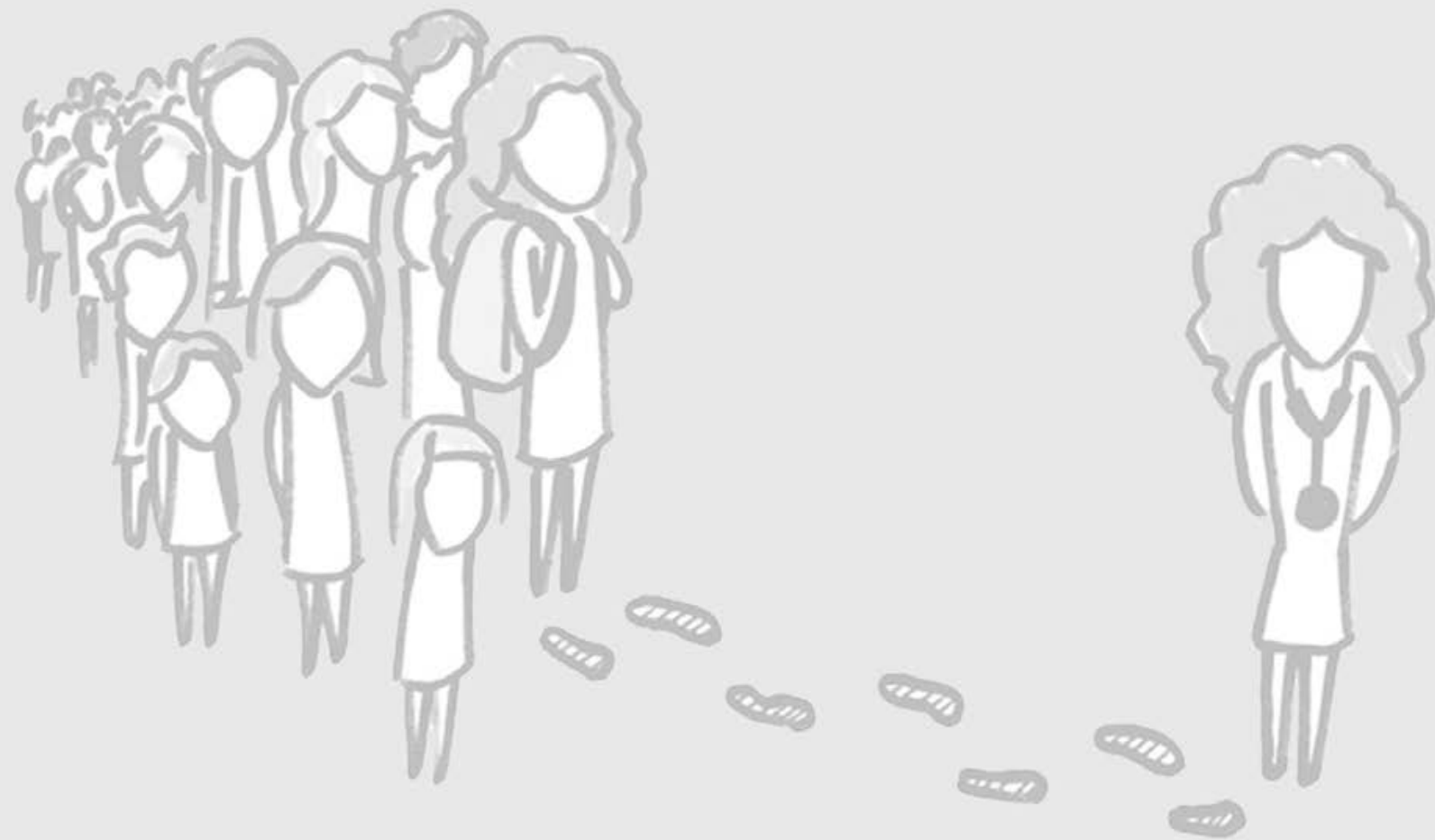


\section{Introduction}

\section{POWERFUL LEARNING ENVIRONMENTS}

Powerful Learning Environments are designed to help students acquire high-quality learning, transfer of knowledge and skills, and become self-directed learners (Konings, Brand-Gruwel, \& van Merrienboer, 2005). These instructional practices were developed on the finding that graduates were not sufficiently ready to apply knowledge and solve complex problems in practice (Gijbels, van de Watering, Dochy, $\&$ van den Bossche, 2006). These instructional designs were intended to provide the environment and tools to help students achieve learning (Gijbels et al., 2006; Konings et al., 2005). Although various studies have described the umbrella term Powerful Learning Environments slightly differently from one another, three characteristics have reached most consensus in higher education.

* Small collaborative learning groups constitute the first characteristic of Powerful Learning Environments. Collaboration is characterised by mutually striving towards common goals, without dividing the work or responsibilities (Barkley, Cross, \& Major, 2005). Various studies have showed that the interactional processes of collaboration facilitate negotiation through which learning takes place (van Boxtel, van der Linden, \& Kanselaar, 2000; van den Bossche, Gijselaers, Segers, \& Kirschner, 2006). Moreover, collaboration skills are a core competence in the future workplace (Betalden, Leach, Swing, Dreyfus, \& Dreyfus, 2002).

* Problems to be elaborated by a student's prior knowledge are the second characteristic of powerful learning contexts. A problem serves as the basis to acquire knowledge and skills. Search strategies and metacognition are needed to acquire high quality knowledge (Veenman, van Hout-Wolters, \& Afflerbach, 2006). Preferably, these problems are formulated to best mirror a real-life situation at the appropriate level of authenticity as this has been demonstrated to facilitate learning, retention and access to the learned subject matter (La Rochelle et al., 2011; Rotgans \& Schmidt, 2011; Taylor \& Miflin, 2008).

* Self-regulated learning is the third characteristic and is believed to be an important aspect of learning. Self-regulated learning is an umbrella term used to describe - amongst others - the learner's motivation, goal orientation, planning, self-observation and self-reinforcement (Zimmerman, 1989, 2002). Students need to be able to cope with a continuously changing environment and practice. Especially in the medical domain in which practice changes continuously, students need to be able to become life-long learners (van Hout-Wolters, Simons, $\&$ Volet, 2000) to be(come) 'up-to-date' medical professionals.

Contrary to the traditional classrooms, Powerful Learning Environments do not view 
learning as a predominantly individual activity, consisting of memorising knowledge and skills transmitted by a teacher or textbook (Hanley, 1994; Shepard, 2000). In the current constructivist views of learning (Simons, van der Linden, \& Duffy, 2000) learning is considered an active process of constructing one's individuals cognitive schemas (Adams, 2006; Colliver, 2002; Fosnot, 2005; Kanselaar, 2002; Powell \& Kalina, 2009; Reynolds \& Miller, 2003). Furthermore, in new learning environments information processing is dependent on the social context in which they are involved (van der Linden, Erkens, Schmidt, \& Renshaw, 2000). For example, communication with others or 'social interaction' makes contradictions, inconsistencies and limitations of one's own explanations clear and thus it allows one to consider his or her conceptualisations from a different angle. The key element in new learning is, therefore, interaction among students (Simons et al., 2000). In other words, learning is a social process, taking place in a social context. This view is in line with the sociocultural perspective of learning in which knowledge is considered a social entity (Powell \& Kalina, 2009; Reynolds \& Miller, 2003).

The success of these new powerful learning environments over the traditional individual learning has been shown in various studies and meta-analyses see for example Hmelo-Silver (2004), Michaelsen \& Richards (2005), Springer et al (1999) or Tynjala (1999). These studies demonstrate enhanced cognition, represented as higher achievement, higher-level reasoning, better problem solving skills and transfer of knowledge and more frequent generation of new ideas or solutions. Behaviour is also affected, such as increased student motivation to do difficult tasks and more positive attitudes of students towards the subject matter. Finally, modern medics are expected to possess good collaboration skills to provide best patient care. This was clearly acknowledged by a variety of medical professions worldwide representing collaboration as a competence (Betalden et al., 2002; Epstein \& Hundert, 2002; Frank \& Danoff, 2007; Frank et al., 2010). In the Dutch medical programmes, collaboration is also one of the seven competences that need to be learned by the medical students, see the guideline of the Dutch Federation of University Medical Centres (van Herwaarden, Laan, \& Leunissen, 2009).

\section{Problem-BASED LeARNING}

The concept of Powerful Learning Environments is applied in a variety of instructional approaches (Gerjets \& Hesse, 2004), for example: situated learning (Lave \& Wenger, 1991), Problem-Based Learning (Schmidt, 1984), anchored instruction (Bransford, Sherwood, Hasselbring, Kinzer, \& Williams, 1990) or discovery learning (Hammer, 1997). Because this dissertation took place in a Problem-Based Learning (PBL) context and since this type of learning context is the best-known example of a Powerful Learning Environment (Gijbels et al., 2006), we will continue to elaborate on this type of instructional design to provide a deeper understanding on how learning is stimulated in this context and the problems faced by students, teachers and educational designers. 
Problem-Based Learning is based on ideas originated by a variety of researchers amongst others Dewey (1938) and Piaget (1954). In Canada this instructional method was developed for medical training at McMaster University (Barrows, 1996; Gijbels, Dochy, van den Bossche, \& Segers, 2005; van Berkel, Scherpbier, Hillen, \& Van der Vleuten, 2010). Since then, many universities worldwide, have applied this model, amongst others the Maastricht medical school in 1974 (Graaff \& Post, 1985; van Berkel et al., 2010).

\section{MECHANISMS HOW PBL PROMOTES LEARNING}

Carefully constructed problems serve as a stimulus for learning and collaboration in the PBL groups. These problems are presented at the beginning of the learning sequence, before any preparation or study has occurred (Gijbels et al., 2005). Problems should be contextual to drive learning by generating situational interest. In turn, a higher level of situational interest, related to higher levels of achievement (Rotgans \& Schmidt, 2011). In other words, to be intrinsically motivating, problems should provide students with a proximal and tangible goal of applying their knowledge to solve a concrete problem (Hmelo-Silver, 2004). Thus for medical students clinical scenarios are used to stimulate learning.

Collaboration between students in a small group in the PBL system is intended to activate prior knowledge, share expertise and discuss or negotiate irregularities in the argumentation when solving a problem. The constructive nature of learning is used in PBL as a method of learning. Early studies on the cognitive steps when problem solving found that groups in the initial phase of discussing a problem activated previously learned knowledge (Schmidt, De Grave, De Volder, Moust, \& Patel, 1989). Compared to individual problem analysis, there is a larger effect when solving problems in a group (De Grave et al., 1985). Students are better able to construct new knowledge when they can relate it to what they already know (Bransford et al., 2005). Elaboration of the problems in small groups furthermore facilitated processing of problems and added to the long-term memory (van Blankenstein, Dolmans, van der Vleuten, \& Schmidt, 2009). Through these steps, research suggests that the small group discussions and debate in PBL sessions enhances problem solving, higher order thinking and promotes shared knowledge construction e.g. Blumenfeld et al (1996). Besides construction of knowledge, distribution of knowledge or cognitive load is another reason why it is beneficial to work in groups, especially when tasks become rather complex (Hmelo-Silver, 2004; Kirschner, Paas, \& Kirschner, 2009; Schmidt, Loyens, van Gog, \& Paas, 2007).

\section{CONTEXT DESCRIPTION}

In PBL as it is applied at the medical school of Maastricht University, students learn in groups of eight to twelve students. These groups are provided clinical scenarios. A facilitator, the tutor, guides the group of students through the 'seven step process' (Gijbels et al., 2005; Hmelo-Silver, 2004; Schmidt, 1984) summarised in Table 1. In our university, students meet twice a week for two hours. Students are stimulated to activate their prior knowledge when discussing the problem in the tutorial group sessions. Next, the students need to identify knowledge gaps and to formulate 
Table 1: Seven-step procedure

1 Clarification of terminology in the clinical scenario

2 Synthesis of problems

3 Brainstorm on all problems raised in step 2

4 Problem analysis to identify knowledge gaps

5 Formulation of learning goals

6 Self-directed learning

7 Elaboration on the learning goals specific learning goals. Following the first tutorial session, the students study independently to acquire the knowledge and skills required prior to the next tutorial session. In this next session, the groups elaborate on the knowledge acquired; allowing students to critically ask one another questions and discuss contrasting ideas.

In the Maastricht University Medical School, the first two curriculum years form part of the preclinical curriculum. The curriculum is organised in modules of six to twelve weeks. The basic element in the preclinical curriculum is the tutorial groups. Lectures, skill trainings and anatomy sessions complement the tutorial groups. In contrast to other higher educational systems, the modules are offered only once a year as the modules build onto one another. In the first curriculum year, students are involved in approximately 10.5 hours per week of formally organised activities by the medial school (e.g. tutorial group sessions, lectures etc.). In the second curriculum year this decreased slightly towards approximately 10 hours per week. This leaves sufficient time for students for independent study. The extent of learning in PBL does not result from either group collaboration or individual knowledge acquisition in isolation: both activities contribute equally to learning in PBL in a cumulative fashion (Yew \& Schmidt, 2010). An example of a week schedule is represented in Table 2.

Table 2: Week schedule

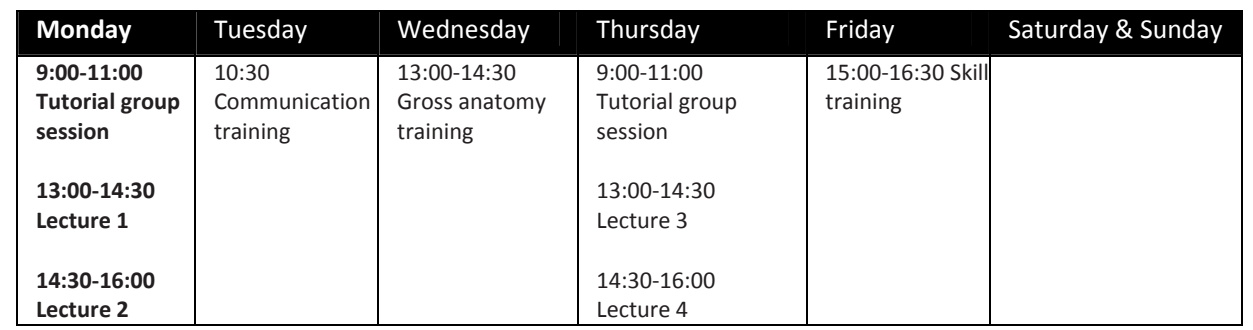

\section{THE GAP BETWEEN THEORY \& PRACTICE}

Some authors attribute problems that are experienced in these Powerful Learning Environments to a gap between educational theory and practice (De Corte, 2000; Gijbels et al., 2006). The majority are problems of the process of collaborative learning. For example in PBL, students were found to skip the brainstorm and elaboration phases resulting in a suboptimal structuring of prior knowledge which in turn led to less efficient information acquisition (Moust, Berkel, \& Schmidt, 2005). The main reason for this behaviour was the failure of students to perceive the value 
and necessity of interaction and elaboration for construction of knowledge (Visschers-Pleijers, Dolmans, Wolfhagen, \& Van der Vleuten, 2005). Other studies also mentioned problems in students' social motivation, mainly feelings of anonymity, the occurrence of 'free riding' or 'social loafing' phenomena which in turn reduced collaboration in these groups (Bornstein, 1992; E. Johnson, 1975; Kelly, 2008; Latane, Williams, \& Harkins, 1979; Moust et al., 2005; Salomon \& Bloberson). To cease the occurrence of these problems, we first need to know what effective collaborative learning is exactly.

\section{EFFECTIVE COLLABORATIVE LEARNING}

The quality of interaction is a key element for learning (van der Linden et al., 2000). How the interaction process with other students results in knowledge acquisition has been the focus of many studies (Dillenbourg, Baker, Blaye, \& O'Malley, 1996; Jeong \& Chi, 1997). As explained earlier, sharing knowledge and negotiation of meaning are primary aspects to collaboratively construct knowledge in cognitive schemas. However, groups of individuals will not automatically engage in interaction when placed in close proximity to others (D. Johnson \& Johnson, 2002; Roschelle \& Teasley, 1995). Beliefs, values, attitudes and motivation among group members are known to induce or inhibit interaction within a group (Goodman \& Dabbish, 2011; Harrington \& Fine, 2006). For example in cooperative learning contexts, Slavin (1996) suggested that feelings of social cohesion stimulated group members to contribute actively to the interaction process. Social cohesion was defined as the shared liking or attraction within the group. Another example is interdependence in the group, based on Deutsch's (Deutsch, 1949, 1962) social interdependence theory. Interdependence described by Johnson and Johnson' (2002) as mutual responsibility and dependency among group members makes students interact to maximize learning and share knowledge with all group members. Therefore, feelings of interdependence among group members are viewed as one of the key elements in the collaborative process. But, despite the large number of studies on group learning, it is still largely unknown why some groups fail while others succeed over time (Barron, 2003). In a thorough review on the literature on team learning, Decuyper et al (2010) identified two important gaps in our understanding how groups learning: the lack of knowledge on time or development of the learning process and a gap in the understanding how students learn from other students with whom he is not formally involved with.

\section{TIME AND COLLABORATIVE LEARNING}

Time is a variable through which universities direct learning. For example, the time spend per subject is thought to be linear with the performance on the subject (Scheerens, Hendriks, Luyten, Sleegters, \& Cees, 2013). A correlation was indeed shown between the number of hours spent studying and achievement in medicine, but this relationship was rather weak (van den Hurk, Wolfhagen, Dolmans, \& van der Vleuten, 1998). Thus, time spent on task does not have a clear linear relationship with learning. The quality of instruction, tasks and resources as well as group processes, self-directed learning skills, motivation and many other variables directly confound the learning process over time. The influence of time on learning is 
therefore still a subject that demands further research (Scheerens et al., 2013).

Problem-Based Learning stimulates students to maximise learning for all group members from the first tutorial group session onwards. However, it is likely that groups need to develop or change over time before they can become effective. In the field of education rather sparse evidence is available on the dynamic side of groups. In other words, there is little knowledge about what the influence is of time on group learning (Cronin, Weingart, \& Todorova, 2011; Goodman \& Dabbish, 2011; Roe, 2008). Published studies on collaborative group processes are all cross-sectional (Fransen, Weinberger, \& Kirschner, 2013) and therefore did not incorporate changes in the group processes over time or development within the life-cycle of the groups. In contrast, organisational sciences have focussed on how groups develop over time. Consensus in this discipline is that it takes time before the members merge into an effective group (Mathieu, Maynard, Rapp, \& Gilson, 2008). An example of such a developmental process is psychological safety. Edmondson et al $(1999,2003)$ have repeatedly shown that feelings of psychological safety need to 'grow' within a group. If there is a lack of these feelings of safety, groups show less effective learning behaviour. In medical education, it is also probable that it takes time before groups become effective.

\section{FORMAL VERSUS INFORMAL COLLABORATIVE LEARNING}

Apart from the question how collaboration develops over time in formally organised educational activities there is also paucity in the literature on how collaboration develops in informal settings. This is rather surprising since collaborative educational designs such as PBL leave plenty of time for students to learn in a self-directed fashion or 'informally'. It is highly plausible that "students don't stop learning when stepping outside the classroom door" (Morone \& Taylor, 2004) and that this type of informal interaction among students contributes towards the students' learning processes. Especially, because the business literature finds that, in work situations, colleagues are regarded as one of the most valuable sources of information, even better than books, internet or resources provided by the employer (Cross, 2000). In medicine, the importance of informal learning was also illustrated by Coleman et al. (1966) who found that the diffusion of a new tetracycline-based medication among physicians was mainly based on the physician's social network; the stronger the ties of a particular physician, the more likely the physician was to be an early user of this new drug. This study was recently replicated (Jippes et al., 2010). In all, it may be concluded that there may be a lack of viewing learning between groups of students (Decuyper et al., 2010). This gap should be bridged to fully understand the social learning process of students. 


\section{OVERVIEW OF THIS DISSERTATION}

This dissertation aims to gain more understanding of the social process of learning and increase its effectiveness to help students learn better. These aims are investigated in four studies, described in the next four chapters.

In the second chapter (first study) a mixed-methods study was applied to gain insights into how groups develop their collaborative learning over a period of 1,5 curriculum years. The first research question focussed on development of group processes such as psychological safety, cohesion, social interdependence and group learning behaviour over time when involved in the same group. The second research question studied to what extent group processes over time developed when students progressed through the curriculum and became members of new groups. The last research question applied qualitative methods to explore in detail how learning processes developed over time.

The third and fourth chapter cover informal collaborative learning among students. First, in the third chapter, a social network study was described. In social network analyses information flow among students in the class is represented as a network, see Figure 1. In this chapter, two research questions were addressed. First, to what extent do social networks increase student learning? And second, how does the effect of social networks on students' learning relate to confounders such as academic motivation, social integration and prior performance?

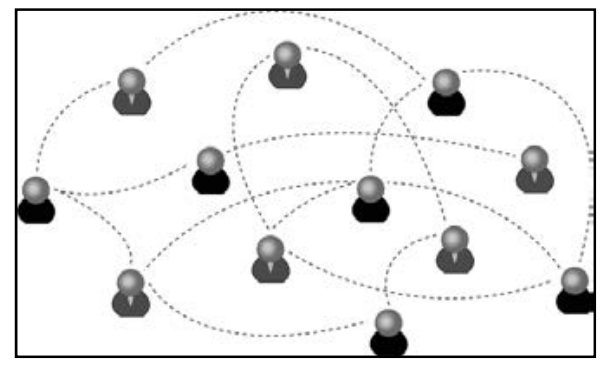

Figure 1 is a graphical representation of a social network among students. The information flow among students is represented with dotted lines

In the next chapter, informal learning among students was explored in further detail focussing on the development of informal learning over time. Again, a mixed methods study was conducted over two curriculum years applying both a longitudinal social network analyses and semi-structured interviews with students. Three research questions were explored. First, what is the pattern of development of informal learning over time? Then second, what is the influence of formal structures of groups on the development of informal learning networks? And finally, how and why do students develop their informal learning network over time?

Our last aim was to improve the collaborative process. In line with the essential learning conditions of Powerful Learning Environments students need to be involved 
in small groups. However in our curriculum, due to large class sizes and a changing group composition every module again, that students have to learn with new peers every 6-8 weeks again as a consequence. We expected this design feature of the learning context to have a negative impact on students' group learning process for three reasons. First, sharing knowledge in the collaborative process incurs an implicit cost, while the expected returns of relevant new knowledge and/or expertise are uncertain. Some students are, therefore, less willing to share knowledge than others. Group member familiarity might reduce costs of sharing information among students (Gruenfeld, Mannix, Williams, \& Neale, 1996; Harrison, Mohammed, McGrath, Florey, \& Vanderstoep, 2003). Second, groups must invest time and energy in collaborating in a group before the process can become effective (Mathieu et al., 2008). Changing the composition of groups too quickly might prevent groups from reaching the beneficial group processes. Finally, if students will not become interdependent of each other in a group, social loafing or free-riding in future groups may be stimulated, further reducing high-quality interaction in groups. For these three reasons, it is plausible to assume that collaboration with a limited number of students over time will increase group processes and thus group learning.

Therefore, in the fifth chapter, a randomised trial was conducted in which the class of approximately 322 students was subdivided in a control group $(n=102)$ and two intervention groups ( $\&$ \& ) containing 50 students in each group. The remaining students $(n=120)$ were mixed with the control group to compose a large subset compared to the intervention groups of $n=50$ students each. These subsets of the class were used to compose formal tutorial groups every module again. In the intervention groups, students frequently met again in a tutorial group and were more familiar to the group members. The primary outcome measure of this trial was a difference in the collaborative group processes. The secondary outcome measures explored the influence of the intervention on informal learning networks and the perceived (positive and negative) effects of the intervention through interviews.

\section{REFERENCES}

Adams, P. (2006). Exploring social constructivism: Theories and practices. Education 34(3), 243-257.

Barkley, E. F., Cross, K. P., \& Major, C. H. (2005). Collaborative Learning Techniques. San Francisco: Jossey Bass.

Barron, B. (2003). When smart groups fail. The journal of the learning sciences, 12(3), 307-359.

Barrows, H. S. (1996). Problem-Based Learning in Medicine and Beyond: A Brief Overview. Teaching and learning, 68(winter), 3-9.

Betalden, P., Leach, D., Swing, S., Dreyfus, H., \& Dreyfus, S. (2002). General competencies and accreditation in graduate medical education. Health Affairs, 21(5), 103-111.

Blumenfeld, P. C., Marx, R. W., Soloway, E., \& Krajcik, J. S. (1996). Learning with peers: From small group cooperation to collaborative communities. Educational Research, 25(8), 37-40.
Bornstein, G. (1992). The Free-Rider Problem in Intergroup Conflicts Over Step-Level and Continuous Public Goods. Journal of Personality and Social Psychology, 62(4), 597-606.

Bransford, J., Sherwood, R., Hasselbring, T., Kinzer, C., \& Williams, S. (1990). Anchored instruction: Why we need it and how technology can help. New Jersey: Lawrence Erlbaum Assocates.

Bransford, J., Vye, N., Stevens, R., Kuhl, P., Schwartz, D., Bell, P., ... Sabelli, N. (2005). Learning theories and education: Toward a decade of synergy. In P. Alexander \& P. Winne (Eds.), Handbook of educational psychology (2nd ed.). Mahway, NJ: Erlbaum.

Coleman, J. S., Katz, E., \& Menzel, H. (1966). Medical Innovation: A diffusion study. Indianapolis, USA: the Bobbs-Merril Company, Inc. 
Colliver, J. A. (2002). Constructivism: The view of knowledge that ended philosophy or theory of learning and instruction. Teaching and learning in medicine, 14(1), 49-51.

Cronin, M. A., Weingart, L. R., \& Todorova, G. (2011). Dynamics in groups: Are we there yet? The academy of management annals, 5(1), 571-612. doi: 10.1080/19416520.2011.590297

Cross, R. (2000). More than an answer: How seeking information through people facilitates knowledge creation and use. Paper presented at the Academy of management conference, Toronto, Canada.

De Corte, E. (2000). Marrying theory building and the improvement of school practice: a permanent challenge for instructional psychology. Learning and instruction, 10, 249-266.

De Grave, W., Schmidt, H. G., Belie, N. J. J., Moust, J. H. C., De Volder, M. L., \& Kerkhofs, L. M. M. (1985). Effecten van verschillende typen van activatie van voorkennis of recall, gemeten met een aanvultoets (Effects of different types of activation of prior knolwege on recall, measured with a completeion procedure). Paper presented at the Onderwijs Research Dagen, Tilburg.

Decuyper, S., Dochy, F., \& van den Bossche, P. (2010). Grasping the dynamic complexity of team learning: An integrative model for effective team learning in organisations. Educational Research Review, 5, 111133. doi: 10.1016/j.edurev.2010.02.002

Deutsch, M. (1949). A theory of cooperation and competition. Human Relations, 2, 129-152.

Deutsch, M. (1962). Cooperation and trust: Some theoretical notes. Lincoln: NE: University of Nebraska Press.

Dillenbourg, P., Baker, M., Blaye, A., \& O'Malley, C. (1996). The evolution of research on collaborative learning. In E. Spada \& P. Reiman (Eds.), Learning in humans and machine: Towards an interdisciplinary learning science (pp. 189-211). Oxford: Elsevier.

Edmondson, A. (1999). Psychological safety and learning behaviour in work teams. Administrative science quarterly, 44, 350-383.

Edmondson, A. (2003). Speaking up in the operating room: How team leaders promote learning in interdisciplinary action teams. Journal of management studies, 40(6), 1419-1452.

Epstein, R. M., \& Hundert, E. M. (2002). Defining and assessing professional competence. JAMA, 287(2), 226-235.

Fosnot, C. T. (2005). Constructivism revisited: implications and reflections. The Constructivist, 16(1).

Frank, J. R., \& Danoff, D. (2007). The CanMEDS initiative: implementing an outcomes-based framework of physician competencies. Medical Teacher, 29, 642647.

Frank, J. R., Mungroo, R., Ahmad, Y., Wang, M., Rossi, S. d., \& Horsley, T. (2010). Toward a definition of competency-based education in medicine: a systematic review of published definitions. Medical Teacher, 32, 631-637.
Fransen, J., Weinberger, A., \& Kirschner, P. A. (2013). Team Effectiveness and Team Development in CSCL. Educational psychologist, 48(1), 9-24. doi: 10.1080/00461520.2012.747947

Gerjets, P., \& Hesse, F. (2004). When are powerful learning environments effective? The role of learner activities and of students' conceptions of educational technology. International journal of educational Research in higher education, 41(6), 445-465. doi: 10.1016/j.ijer.2005.08.011

Gijbels, D., Dochy, F., van den Bossche, P., \& Segers, M. (2005). Effects of Problem-Based Learning: a metaanalysis from the angle of assessment. Review of Educational Research, 75(1), 27-61. doi: 10.3102/00346543075001027

Gijbels, D., van de Watering, G., Dochy, F., \& van den Bossche, P. (2006). New learning environments and constructivism: The students' perspective. Instructional Science, 34, 213-226.

Goodman, P. S., \& Dabbish, L. A. (2011). Methodological issues in measuring group learning. Small group research, 42, 379-404. doi: $10.1177 / 1046496410385471$

Graaff, d. E., \& Post, G. J. (1985). Farewell Maastricht the evaluation ex-students after six years problembased education (Vol. II). Maastricht: Network of community-oriented educational institutions for the health sciences, Rijksuniversiteit Limburg.

Gruenfeld, D. H., Mannix, E. A., Williams, K. Y., \& Neale, M. A. (1996). Group composition and decision making: How member familiarity and information distribution affect process and performance. Organizational behavior and human decision processes, 67(1), 1-15.

Hammer, D. (1997). Discovery Learning and Discovery Teaching. Cognition and instruction, 15(4), 485-529. doi: 10.1207/s1532690xci1504_2

Hanley, S. (1994). On constructivism. In M. c. f. t. preparation (Ed.): The university of Maryland.

Harrington, B., \& Fine, G. A. (2006). Where the Action Is: Small Groups and Recent Developments in Sociological Theory. Small group research, 37(1), 419. doi: $10.1177 / 1046496405284356$

Harrison, D. A., Mohammed, S., McGrath, J. E., Florey, A. T., \& Vanderstoep, S. W. (2003). Time matters in team performance: effects of member familitary, entrainment, and task discontinuity on speed and quality. Personnel Psychology, 56(3), 663-669.

Hmelo-Silver, C. E. (2004). Problem-based learning: What and how do students learn? Educational psychology review, 16(3), 235-266.

Jeong, H. W. N., \& Chi, M. T. H. (1997). Construction of shared knowledge during collaborative learning. Paper presented at the Proceedings of the 2nd international conference on Computer support for collaborative learning, Toronto, Ontario, Canada.

Jippes, E., Achterkamp, M. C., Brand, P. L. P., Kiewiet, D. J., Pols, J., \& van Engelen, J. M. L. (2010) Disseminating educational innovations in health care practice: Training versus social networks. Social science \& medicine, 70, 1509-1517. 
Johnson, D., \& Johnson, R. (2002). Social interdependence theory and university instruction: Theory into practice. Swiss journal of psychology, 61(3), 119-129.

Johnson, E. (1975). Increasing teacher effectiveness within normal budget restraints. The journal of economic education.

Kanselaar, G. (2002). Constructivism and socioconstructivism.

Kelly, P. (2008). Achieving desirable group-work outcomes through the group allocation process. Team Performance Management, 14(1/2), 22-38.

Kirschner, F., Paas, F., \& Kirschner, P. A. (2009). A cognitive load approach to collaborative learning: United brains for complex tasks. Educational psychologist review, 21, 31-42.

Konings, K. D., Brand-Gruwel, S., \& van Merrienboer, J. J. G. (2005). Towards more powerful learning environments through combining the perspectives of designers, teachers, and students. British Journal of Educational Psychology, 75, 645-660. doi: 10.1348/000709905X43616

La Rochelle, J. S., Durning, S. J., Pangaro, L. N., Artino, A. R., Van der Vleuten, C. P. M., \& Schuwirth, L. (2011). Authenticity of Instruction and Student Performance: A Prospective Randomized Trial. Medical Education, 45, 807-817. doi: 10.1111/j.1365-2923.2011.03994.x

Latane, B., Williams, K., \& Harkins, S. (1979). Many hands make light the work: The causes and consequences of social loafing. Journal of personality and social psychology, 37(6), 822-832.

Lave, J., \& Wenger, E. (1991). Situated learning: Legitimate peripheral participation. Cambridge, UK: Cambridge university press.

Mathieu, J., Maynard, M. T., Rapp, T., \& Gilson, L. (2008). Team effectiveness 1997-2007: A review of recent advancements and a glimpse into the future. Journal of Management, 34(3), 410-476. doi: 10.1177/0149206308316061

Michaelsen, L. K., \& Richards, B. (2005). Drawing conclusions from the team-learning literature in health-sciences education: A commentary. Teaching and Learning in Medicine, 17, 85-88.

Morone, P., \& Taylor, R. (2004). Knowledge diffusion dynamics and network properties of face-to-face interactions. Journal of evolutionary economics, 14, 327-351. doi: 10.1007/s00191-004-0211-2

Moust, J. H. C., Berkel, H. J. M., \& Schmidt, H. G. (2005). Signs of erosion: Reflections on three decades op problem-based learning at Maastricht University. Higher Education, 50, 665-683.

Powell, K. C., \& Kalina, C. J. (2009). Cognitive and social constructivism: Developing tools for an effective classroom. Education, 130(2), 241-250.

Reynolds, W. M., \& Miller, G. E. (2003). Current Perspectives in Educational Psychology. In I. B. Weiner, W. M. Reynolds \& G. E. Miller (Eds.), Handbook of Psychology (Vol. 7, pp. 4-18). Hoboken, New Jersey: John Wiley \& Sons Inc.

Roe, R. A. (2008). Time in Applied psychology. European psychologist, 13(1), 37-52. doi: 10.1027/10169040.13.1.37
Roschelle, J., \& Teasley, S. D. (1995). The construction of shared knowledge in collaborative problem solving. In C. E. O'Malley (Ed.), Computer supported collaborative learning (pp. 69-197). Berlin: SpringerVerlag.

Rotgans, J. I., \& Schmidt, H. G. (2011). Situational interest and academic achievement in the activelearning classroom. Learning and instruction, 21(1), 58-67. doi: 10.1016/j.learninstruc.2009.11.001

Salomon, G., \& Bloberson, T. When teams do not function the way they ought to.

Scheerens, J., Hendriks, M., Luyten, H., Sleegters, P., \& Cees, G. (2013). Productive time in education: A review of the effectiveness of teaching time at school, homework and extended time outside school hours. Twente: University of Twente Publications.

Schmidt, H. G. (1984). Introduction. Maastricht, The Netherlands: Van Gorcum.

Schmidt, H. G., De Grave, W., De Volder, M. L., Moust, J. H. C., \& Patel, V. L. (1989). Explanatory models in the processing of science text: the role of prior knolwege activation through small-group discussion. Journal of Educational Psychology, 81, 610-619.

Schmidt, H. G., Loyens, S. M. M., van Gog, T., \& Paas, F. (2007). Problem-Based Learning is Compatible with Human Cognitive Architecture: Commentary on Kirschner, Sweller, and Clark (2006). Educational psychologist, 42(2), 91-97.

Shepard, L. A. (2000). The role of assessment in a learning culture Educational researcher, 29(7), 4-14.

Simons, R.-J., van der Linden, J., \& Duffy, T. (2000). New learning. Dordrecht, the Netherlands: Kluwer Academic Publishers.

Slavin, R. E. (1996). Research on cooperative learning and achievement: What we know, what we need to know. Contemporary educational psychology, 21, 43-69.

Springer, L., Stanne, M. E., \& Donovan, S. S. (1999). Effects of Small-Group Learning on Undergraduates in Science, Mathematics, Engineering, and Technology: A Meta-Analysis. Review of Educational Research, 69(1), 21-51.

Taylor, D., \& Miflin, B. (2008). Problem-based learning: Where are we now? Medical Teacher, 30, 742-763. doi: 10.1080/01421590802217199

Tynjala, P. (1999). Towards expert knowledge? A comparison between a constructivist and a traditional learning environment in the university. International journal of educational research, 31, 357-442.

van Berkel, H. J. M., Scherpbier, A., Hillen, H., \& Van der Vleuten, C. P. M. (2010). Lessons from ProblemBased Learning. Oxford: Oxford University Press.

van Blankenstein, F. M., Dolmans, D. H. J. M., van der Vleuten, C. P. M., \& Schmidt, H. G. (2009). Which cognitive processes support learning during smallgroup discussion? The role of providing explanations and listening to others. Instructional Science, 32(2), 1-16. doi: 10.1007/s11251-0099124-7 


\section{2 | Chapter 1}

van Boxtel, C., van der Linden, J., \& Kanselaar, G. (2000). Collaborative learning tasks and the elaboration of conceptual knowledge. Learning and instruction, 10, 311-330.

van den Bossche, P., Gijselaers, W. H., Segers, M., \& Kirschner, P. A. (2006). Social and cognitive factors driving teamwork in collaborative learning environments: Team learning beliefs and behaviors. Small Group Research, 37(5), 490-521. doi: $0.1177 / 1046496406292938$

van den Hurk, M. M., Wolfhagen, H. A. P., Dolmans, D. H. J. M., \& van der Vleuten, C. P. M. (1998). The relation between time spent on individual study and academic achievement in a problem-based curriculum. Advances in Health Sciences Education, 3, 43-49.

van der Linden, J., Erkens, G., Schmidt, H. G., \& Renshaw, P. (2000). Collaborative learning. London: Kluwer Academic Publishers.

Raamplan Artsopleiding 2009 (2009).

van Hout-Wolters, B. H. A. M., Simons, R.-J., \& Volet, S. (2000). Active learning: Self-directed learning and independent work. Dorderecht, The Netherlands: Kluwer Acacemic Publishers.
Veenman, M. V. J., van Hout-Wolters, B. H. A. M., \& Afflerbach, P. (2006). Metacognition and learning: conceptual and methodological considerations. Metacognition learning, 1, 3-14. doi: 10.1007/s11409-006-6893-0

Visschers-Pleijers, A. J. S. F., Dolmans, D. H. J. M., Wolfhagen, H. A. P., \& Van der Vleuten, C. P. M. (2005). Student Perspectives on Learning-Oriented Interactions in the Tutorial Group. Advances in Health Sciences Education, 10, 23-35.

Yew, E. H. J., \& Schmidt, H. G. (2010). Is learning in problem-based learning cumulative? Advances in Health Sciences Education. doi: 10.1007/s10459010-9267-y

Zimmerman, B. J. (1989). A social cognitive view of selfregulated academic learning. Journal of educational psychology, 81(3), 329-339.

Zimmerman, B. J. (2002). Becoming a self-regulated learner: an overview. Theory into practice, 41(2), 64-70. 


\section{CHAPTER 2}
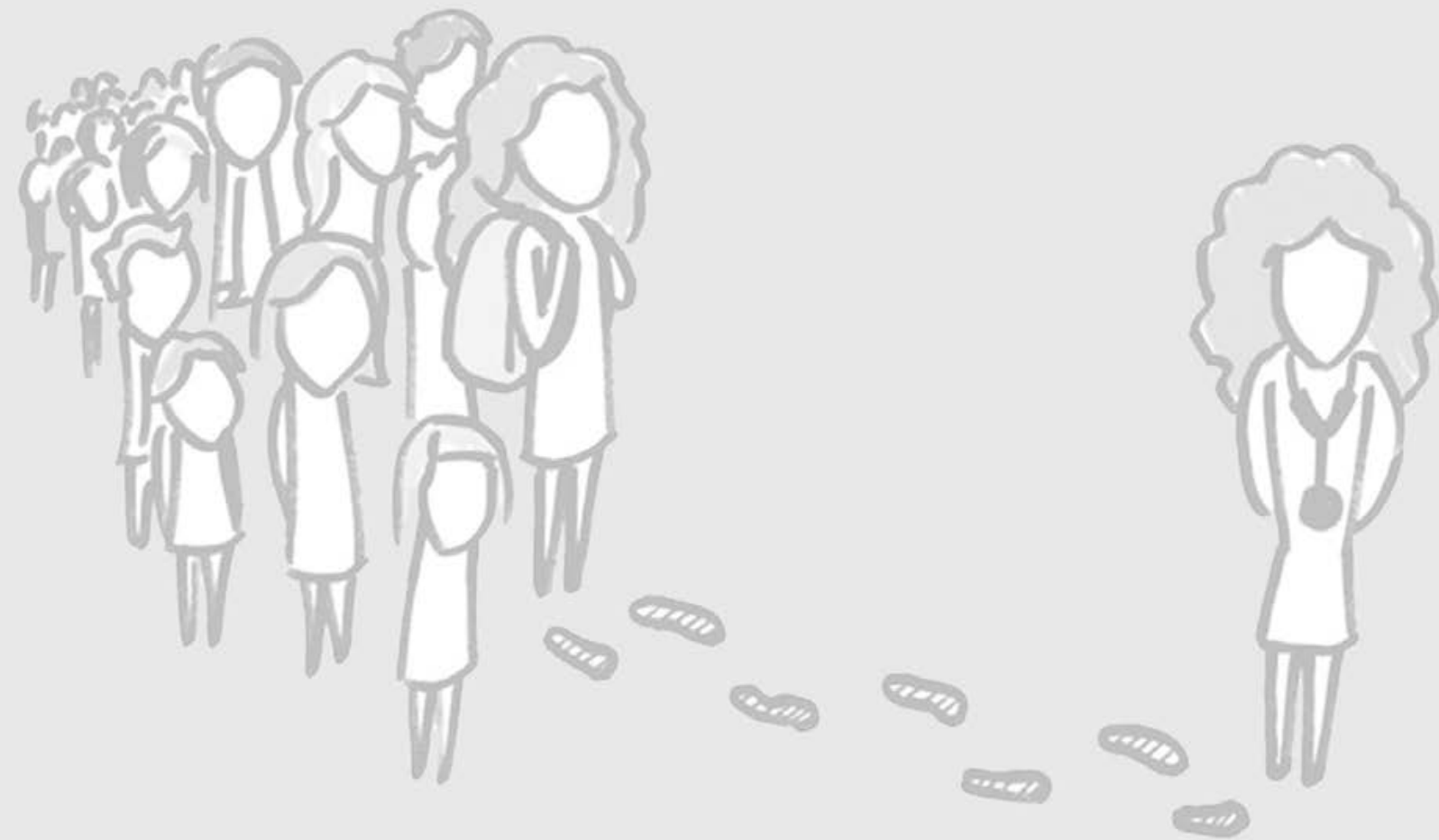


\section{Understanding the effects of time on collaborative learning processes in Problem-Based Learning: a mixed methods study}

J. Hommes ${ }^{1}$, P. Van den Bossche $e^{2,3}$, W. de Grave ${ }^{1}$, G. Bos ${ }^{1,4}$, L. Schuwirth ${ }^{5}$, A. Scherpbier ${ }^{1}$.

1) Department of Educational Development and Research, Faculty of Health Medicine and Life Sciences, Maastricht University, The Netherlands.

2) Department of Educational Research \& Development, School of Business \& Economics, Maastricht University, The Netherlands.

3) Institute of Education \& Information Sciences, University of Antwerp, Belgium.

4) University Hospital Maastricht, Department of Internal medicine, Haematology, The Netherlands.

5) Flinders Innovation and Clinical Education, Flinders Medical School, Flinders University, Adelaide, Australia. 


\section{ABSTRACT}

OBJECTIVE: Little is known how time influences collaborative learning groups in medical education. Therefore a thorough exploration of the development of learning processes over time was undertaken in an undergraduate PBL curriculum over eighteen months.

METHODS: A mixed-methods triangulation design was used. First, the quantitative study measured how various learning processes developed within and over three periods in the first 1,5 study years of an undergraduate curriculum. Next, a qualitative study using semi-structured individual interviews focused on detailed development of group processes driving collaborative learning during one period in seven tutorial groups.

RESULTS: $\quad$ The hierarchic multilevel analyses of the quantitative data showed that a varying combination of group processes developed within and over the three observed periods. The qualitative study illustrated development in psychological safety, interdependence, potency, group learning behaviour, social and task cohesion. Two new processes emerged: 'transactive memory' and 'convergence in mental models'.

CONCLUSION: The results indicate that groups are dynamic social systems with numerous contextual influences. Future research should thus include time as an important influence on collaborative learning. Practical implications are discussed.

\section{INTRODUCTION}

Increasingly, groups are the units in which learning takes place in modern learning environments in medical education. Theoretical foundations arise from studies viewing groups as complex social systems interacting within their environment (Arrow \& Cook, 2008) and competence directed education (Schmidt, 1996; van der Vleuten \& Schuwirth, 2005). Despite the great number of studies on groups, rather sparse evidence exists on the dynamic side of groups, in other words the influence of time on group learning (Cronin, Weingart, \& Todorova, 2011; Goodman \& Dabbish, 2011; Roe, 2008). Studies on collaborative group processes are cross-sectional (Fransen, Weinberger, \& Kirschner, 2013), for example Dolmans \& Schmidt (2006), Visschers-Pleijers et al. (2006) and Olivera \& Straus (2004). As such, these studies do not incorporate changes in the group processes over time or development within these groups. This lack of including time as an important variable in groups, can be traced back to the foundations of group learning with for example Slavin (1996) who uses an input-process-output model, ignoring the influence of time. On the other hand, the Johnson and Johnson's social interdependence model of collaborative learning (2002) emphasizes the role of feedback in the group, but ignores how individuals in groups learn over time when changing from one group to another group. The evidence that students learn from their collaborative learning groups over time was clearly shown in a recent study by Hillyard et al (2010) who showed a very 
strong relationship with students past experience with group work and (current) attitudes toward group work. If students perceived their group work experiences negative in an undergraduate institution, their attitudes concerning group work remained negative, regardless of the experience in the graduate programme.

In contrast to the available evidence, the educational literature merely adheres to a general consensus that groups develop or change over time e.g. Benson et al (2001). In other words, groups learn how to learn in a group (Sweet \& Michaelsen, 2007). In contrast to the educational literature, the organisational sciences have focussed strongly on group development, resulting in a variety of models. Three major categories might be described: linear progressive models, cyclical models and nonsequential models (Carabajal, LaPointe, \& Gunawardena; Fransen et al., 2013; Mennecke, Hoffer, \& Wynne, 1992). One of the most well known developmental models is Tuckman' forming-storming-norming-performing' stages of development (1965), an example of linear progressive models in which groups specifically develop in one direction. Cyclical models emphasise the terminal phase resulting in groups that dissolute or generate into another cycle in which phases re-emerge. Nonsequential models take into account prior experiences and environmental factors respectively without the focus on sequential events. As the previous authors point out the evidence that these models can be applied to collaborative learning groups is rather marginal due to the wide variety of groups used, the settings in which the groups were studied, the disciplines in which these groups were studied, the number of groups that were explored and most importantly the length of time groups were studied (Fransen et al., 2013; Hare, reprinted 2010; Smith, 2001). The consensus reached in organisational sciences is that it takes time before the members merge into an effective group (Mathieu, Maynard, Rapp, \& Gilson, 2008). This might also be translated to the educational settings (Fransen et al., 2013). Therefore this study will explore how group processes develop in a medical programme in which students participate in a sequential number of groups over the curriculum.

Theoretical foundations of group learning arise from research viewing individuals' knowledge structures and information processing as dependent on the social context in which they are involved. Interaction among learners is the key element for learning (van der Linden, Erkens, Schmidt, \& Renshaw, 2000). How the interaction process with other students results in knowledge acquisition has been the focus of many studies (Dillenbourg, Baker, Blaye, \& O'Malley, 1996; Jeong \& Chi, 1997). Several studies identified a pattern of interaction to represent group learning in collaborative learning groups starting with construction of knowledge, followed by co-construction between group members which can lead to constructive cognitive conflict (van Boxtel, van der Linden, \& Kanselaar, 2000; Visschers-Pleijers, Dolmans, Wolfhagen, \& van der Vleuten, 2004). However, groups of individuals will not necessarily involve in interaction when placed in close proximity to others (Johnson \& Johnson, 2002; Roschelle \& Teasley, 1995), and this leaves the question what really drives students to learn collaboratively?

Antecedent processes such as beliefs, values, attitudes and motivation between group members are acknowledged to drive or inhibit interaction within a group 
(Goodman \& Dabbish, 2011; Harrington \& Fine, 2006). For example, in collaborative learning contexts, Slavin (1996) opted that feelings of social cohesion stimulated group members in (small) groups to contribute actively to the interaction process. Social cohesion was defined as the shared liking or attraction within the group. Another example is Johnson and Johnson' (2002) social interdependence, positing that interdependence between group members in collaborative groups is the most central aspect driving students to collaborate. At last, psychological safety has been shown to be an essential condition potentiating collaboration in groups (Edmondson, 1999). Therefore, in studies exploring how groups learn over time, these processes have to be included to fully understand the group's learning processes.

Finally, learning processes are primarily used in the literature as a group phenomenon only. This is in sharp contrast to the conceptual framework of groups viewing the participants as the first level to compose the group. The top level is the context in which the groups take place, causing groups to be multi-level construct (Cronin et al., 2011; Kozlowski, Chao, \& Jensen, 2010). Individual and contextual factors can both influence processes on the group level. For example a dominant student can have a negative influence on psychological safety in the group. In turn, contextual factors such as the tutor facilitating the tutorial group (de Grave, Dolmans, \& van der Vleuten, 2002) or methods of assessment (Gijbels, van de Watering, Dochy, \& van den Bossche, 2006) have been shown to be a large influence on group processes. Unfortunately, in process studies, the multilevel construct of groups was largely ignored or restricted (Kozlowski et al., 2010; Mathieu \& Tesluk, 2010). Therefore, there is a need to include the multilevel construct of groups when studying group processes.

To conclude these paragraphs, despite the use of small groups as the learning units in medical education worldwide, time to develop into an effective group has not been taken into account explicitly in collaborative group research. Therefore, our aim was to understand the development of group learning processes over time in a Medical Programme applying Problem-Based Learning through posing three research questions. Our first research question focussed on development of group processes such as psychological safety, cohesion, social interdependence and group learning behaviour over time when students were involved in the same group. As students were expected how to learn in consequential groups over time, our second research question studied to what extent group processes over time developed when students progressed through the curriculum and became members of new groups. Previous studies in organisational and educational sciences have a strong quantitative orientation (Cronin et al., 2011). However, these methods strongly rely on theory build by previous research (Edmondson \& McManus, 2007). Since the theory on group development is still being constructed in educational settings, our third research question applied qualitative methods to explore how learning processes over time developed in detail. By triangulation of these research methods in the discussion we believe that the results merge towards a better understanding of group learning over time. 


\section{MethODS}

\section{RESEARCH DESIGN}

A mixed-methods triangulation design (Creswell, 2009) was employed. First a quantitative repeated measures study was used to investigate the development of learning processes involved in six observations over three tutorial groups in the first and second study year (see figure 1 for an overview). Within this timeframe, the second qualitative study was used to establish a view of social cognitive learning processes encompassing group learning in seven tutorial groups within one period.

\section{SetTing}

The studies took place at Maastricht University medical school in The Netherlands in the cohort of 2010-2011. This school offers a six-year undergraduate-entry medical course with a Problem-Based Curriculum. Problem-Based Learning is a collaborative learning context in which students in small groups are provided with a problem to be solved (Schmidt, Rotgans, \& Yew, 2011). Lectures, skill trainings and anatomy sessions complement these tutorial groups.

The first three years in this medical school are organised in modules of six to ten weeks. The tutorial groups consist of eight to twelve students, randomly re-assigned to a new tutorial group every module again, with the exception of the first two modules. In these first two modules, the students stay within the same tutorial group, while the tutor changes. The overview of both studies is illustrated in figure 1 . We will call the first two modules period one (P1) In the third module, students were randomly re-assigned to new tutorial groups with a new tutor and we will refer to this as the second period (P2). This process of being re-assigned to a new tutorial group at the start of each new module continues throughout the first two study years. In the second module of the second study year, students were invited to participate again in this study. Therefore, this period will be called P7.
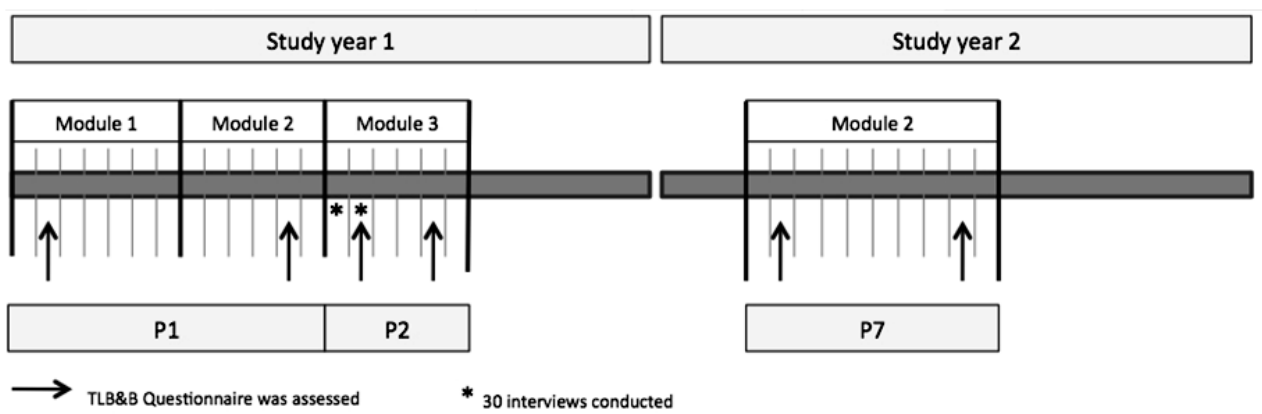

P7

Figure 1: Overview when the observations for the quanitative study were conducted as well as the interviews. 


\section{QUANTITATIVE STUDY}

\section{TESTS AND MEASUREMENTS}

Group learning processes were assessed by a reduced, translated and adapted version of the Team Learning Beliefs \& Behaviors Questionnaire (van den Bossche, Gijselaers, Segers, \& Kirschner, 2006), comprised of 33 questions regarding group learning behaviour, interdependence, psychological safety, social and task cohesion and group potency, ranging from (1) 'I do not agree at all' to (7) 'I fully agree'. This questionnaire is based on scales taken from validated questionnaires, for further details cf. Van den Bossche et al (2006).

Group learning behaviour was conceptualized by the pattern of conversational actions. Nine items measured group learning behaviour, composed of construction of knowledge (Stahl, 1994), co-construction between group members (Baker, Hansen, Joiner, \& Traum, 1999; Barron, 2000) and constructive cognitive conflict (PerretClermont \& Schubauer-Leoni, 1981). The scale was based on the questionnaires on the questionnaires of Edmondson (1999), van Offenbeek (2001) and VisschersPleijers et al. (2003).

Interdependence between students in the tutorial group was measured using an abbreviated version of the questionnaire designed by van der Vegt \& van de Vliert (1998). Two items measured the degree of perceived task interdependence (e.g., "I depend on my team members for information and advice."). Two items measured outcome interdependence (e.g., "When my team members succeed in their jobs, it works out positively for me.").

Psychological safety was measured using a seven-items scale designed by Edmondson (1999) questionnaire. An example of an item is "No one in this tutorial group would deliberately act in a way that undermines my efforts".

Social cohesion was measured using a scale developed by Sargent \& Sue-Chan (2001), composed of four items. Sample items include, "I like my team" and "I feel a sense of belongingness to my tutorial group". Task cohesion was operationalized using a scale from Carless \& De Paola (2000). This scale consists of four items, including "This team is united in trying to reach its goals for performance".

At last, group potency was measured using an adapted version of the scale formulated by Guzzo et al. (1993), previously used by Sargent \& Sue-Chan (2001) and Gibson et al (2000). This is an adapted version from a scale originally formulated by. An example of one of the six items is "This tutorial group has confidence in itself".

\section{PROCEDURE}

We approached the students during the tutorial groups. If students were absent in their group, they received an invitation to fill in the questionnaire online. Four sessions were planned in study year one, and two more in study year two, see Figure 1. Each survey was planned to take ten minutes. First, written information about the aims of the research was given, followed by a description of the survey. Students were assured that the data collected would remain strictly confidential used for research purposes only. Second, students filled in written informed consent. 


\section{STATISTICAL ANALYSES}

Students were nested in their tutorial groups. Since the tutorial group composition changed (randomly) between P1, P2 and P7, the data shape a crossed hierarchical multilevel model (Rasbash \& Goldstein, 1994), schematically illustrated in Figure 2. The STATA software package (STATACORP, 2010) was used for data preparation and analyses.

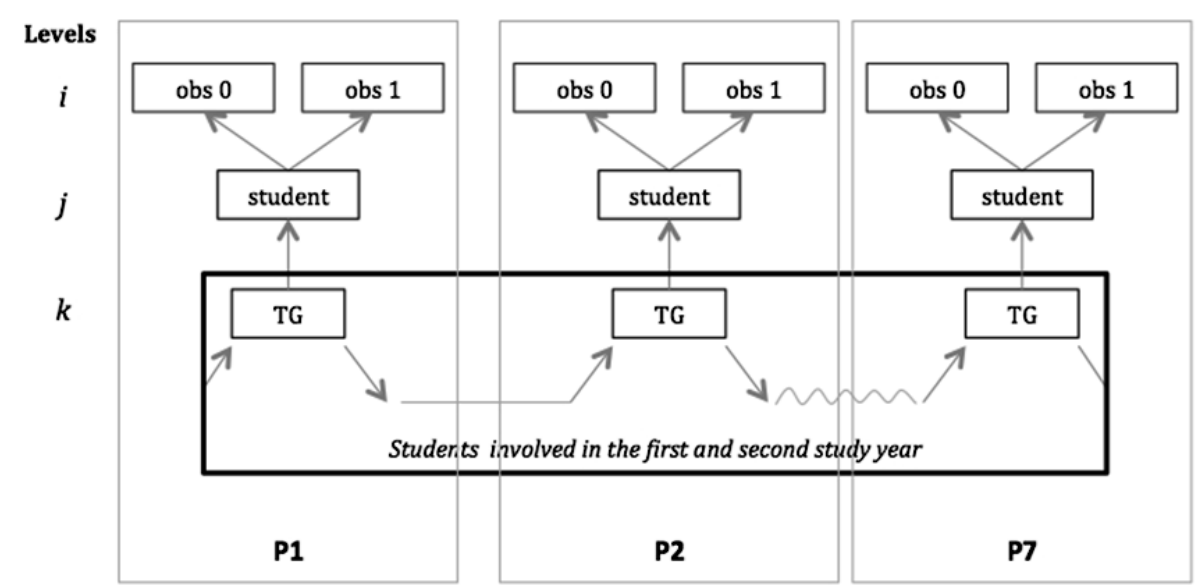

Figure 2: The quantitative study has a multi-level structure: $k$ represents the tutorial groups, which is composed of students (j). Each student fills in the TLB Questionnaire twice (i).

RQ 1: TO WHAT EXTENT DO THE VARIOUS GROUP PROCESSES CHANGE WITHIN EACH PERIOD?

We analysed how students developed the various group processes within their tutorial groups over the two observations in P1. A three-level random intercepts random slopes model fitted the hierarchical multilevel analysis. As such the group processes were the dependent variables and the observations (nested in students and tutorial groups) formed the random intercept. These analyses were repeated for P2 and P7.

RQ 2: TO WHAT EXTENT DO THESE PROCESSES DEVELOP OVER THE PERIODS WHEN STUDENTS PROGRESS IN THEIR CURRICULUM?

The group processes between the P1, P2 and P7 were compared to study how students within their groups would change over time. A multilevel crossed model was fitted using the xtmixed command in STATA. First we compared differences in the dependent variables (group processes) at observation 0 (starting points) in P1 versus $\mathrm{P} 2$. This was followed by comparisons of the processes between $\mathrm{P} 2$ and $\mathrm{P} 7, \mathrm{P} 1$ and P7. The same was done with the slope between observation 0 and 1 between all periods students.

\section{QUALITATIVE STUDY}

Semi-structured individual interviews were conducted to explore students' individual perceptions which group processes caused collaborative learning in their tutorial 
group, focussing on the multilevel construct and the development of these group processes. To reduce errors of omission and commission, all interviews were conducted in the two weeks following the end of the first period (see Figure 1). Of the 22 tutorial groups, one group was excluded from this study because students entered late in the medical programme. From the 21 tutorial groups, seven were randomly selected of which students were randomly invited to participate in this study. We estimated that interviewing $50 \%$ of the students in each tutorial group would provide a reasonable description of the group processes in the seven tutorial groups. In the end $n=30$ students participated from the seven selected tutorial groups. The desired number of students participating in the study was reached in all but one tutorial group, in which three students were interviewed.

Three assistant interviewers were trained to conduct the interviews. Assistant interviewers (students from other faculties) were chosen instead of staff members, to minimise the chance of the interviewees to withhold negative opinions and to discuss freely with the participants on group dynamics.

\section{PROCEDURE}

First, the intentions of the interview were expounded, followed by explaining the voluntary and confidential nature of participation of this study. All students agreed to participate before continuing the interview.

In the first part of the interview, students were asked what processes drove collaborative learning in their tutorial group. The interviewers explored the definitions of the processes raised by the students such as "equal participation". The students' definitions were maintained throughout the interview. The second part consisted of exploring the developmental nature of the group processes that students had brought up. To facilitate the description of development of processes in the group, students were asked to start drawing their perception of 'effectiveness' of their tutorial group in a graph. The X-axis represented time: seven weeks in the first module and then six weeks in the second module. The Y-axis consisted of a scale of (0-10) to indicate the 'effectiveness'. The (psycho)graph guided the interview. Next, the other processes that were mentioned by the students in the first part of the interview were added to the graph and further described by students. The interviews were audio taped and lasted approximately one hour. All transcripts were transcribed verbatim. Two pilot sessions revealed that this design was feasible.

\section{ANALYSIS}

Template analysis was applied to analyse the transcripts (see (King, 1998, 2004) for an overview). This technique encompasses thematic analyses of qualitative data based on a-priori defined themes or codes, described in the template. This template is iteratively modified carefully when applying it to the data. The initial template for this study consisted of learning processes defined by the social cognitive literature: group learning behaviour, psychological safety, interdependence, group potency, task cohesion and social cohesion. Using the software programme Atlas t.i. (Atlas.tiCompany, 2012) these learning processes were identified and coded. When 
applying these 'codes' to the data, the difference between a developmental and a static process as well as the multilevel construct was noticed. For example, the initial template defined group potency as solely a group construct, while interviewed students and the original literature (Bandura, 1977; Guzzo et al., 1993) viewed potency as an individual and group construct. Some concepts of the various processes were too narrowly defined in the template. As such, the definitions were modified based on the description of the process described by the students. Two processes were added to the template as the a-priori described group processes did not cover these processes, elaborated in the results section. Following the coding process of the transcripts, interrelations among the group learning processes were added. In order to analyse the developmental aspects of these processes and the multilevel construct of groups, an overview was created of all transcripts.

\section{Roles of researchers}

$\mathrm{JH}$ and WdG constructed the initial template. Both authors independently coded seven manuscripts after which the first modifications were made in the template. This processes was repeated five times before the final template was completed. The other authors ( $A S$, LS GB and PvdB) provided critical analyses of the template construction and analyses process to minimise biases on the interpretation of the transcripts. After reaching consensus on the template with the complete research team, the final template was applied to all transcripts.

\section{RESULTS}

\section{DEMOGRAPHICS OF THE QUANTITATIVE DATA}

Table 1 summarizes the demographics in all observations over all periods. Between $\mathrm{n}=173$ and $\mathrm{n}=204$ students participated over all six observations, resulting in missing between $3.0 \%$ and $15.3 \%$ of the participants.

The internal consistencies of the scales 'group learning behaviour', 'psychological safety', 'social cohesion' and 'group potency' ranged from 0.72 to 0.90 in all observations, which is in line with previous reports (van den Bossche et al., 2006). The internal consistency of the items in the scales 'interdependence' and 'task cohesion', were lower than expected (0.47-0.60 and 0.14-0.40 respectively). Correcting for the number of items per scale using the Spearman Brown formula, the scale measuring interdependence became acceptable (0.66-0.75), while task cohesion did not (0.27-0.60). As can be seen in Table 1, there was no restriction of range that could explain the low internal consistency among these participants in the scale task cohesion. Results of the qualitative study indicated that students inserted a different interpretation to task cohesion than the questionnaire approached this process. As such, we omitted this scale in the further analyses of this quantitative study. 
Table 1: Demographics of the quantitative data.

\begin{tabular}{|c|c|c|c|c|c|c|c|c|c|c|c|c|}
\hline & & & 1 & & & & 2 & & & & 7 & \\
\hline & $a b$ & 50 & & $s 1$ & $o b$ & 50 & & s 1 & & so & $o b s$ & \\
\hline Participants (n) & $n=192$ & & $n=17$ & & $n=20$ & & $n=20$ & & $n=18$ & & $n=177$ & \\
\hline (missing \% of total (n)) & $(3.0 \%)$ & & $(12.6 \%$ & & $(11.5 \%$ & & $(7.3 \%$ & & $(13.4 \%$ & & (15.3\%) & \\
\hline Female (\%) & 60.9 & & 61.9 & & 61.0 & & 60.7 & & 61.9 & & 61.0 & \\
\hline Age (yrs) & 19.4 & & 19.7 & & 19.7 & & 19.8 & & 20.5 & & 20.6 & \\
\hline & Mean & SD & Mean & SD & Mean & So & Mean & SD & Mean & so & Mean & SD \\
\hline Group learning behaviour & 5.32 & 0.76 & 5.41 & 0.76 & 5.05 & 0.71 & 5.24 & 0.76 & 5.05 & 0.73 & 5.26 & 0.85 \\
\hline Psychological Safety & 5.37 & 0.79 & 5.55 & 0.81 & 5.26 & 0.75 & 5.35 & 0.81 & 5.22 & 0.82 & 5.52 & 0.82 \\
\hline Social cohesion & 5.04 & 0.98 & 5.82 & 1.00 & 4.43 & 0.98 & 4.90 & 1.04 & 4.80 & 0.79 & 5.27 & 0.97 \\
\hline Task cohesion & 3.69 & 0.75 & 3.56 & 0.78 & 3.75 & 0.72 & 3.73 & 0.78 & 3.69 & 0.65 & 3.56 & 0.76 \\
\hline Group potency & 4.68 & 0.74 & 5.04 & 0.89 & 4.71 & 0.76 & 4.81 & 0.85 & 4.70 & 0.78 & 5.06 & 0.93 \\
\hline Interdependence & 4.38 & 0.80 & 4.46 & 0.74 & 4.22 & 0.84 & 4.36 & 0.79 & 4.15 & 0.81 & 4.32 & 0.88 \\
\hline
\end{tabular}

\section{RQ 1: TO WHAT EXTENT DO THE VARIOUS GROUP PROCESSES CHANGE WITHIN EACH PERIOD?}

As is illustrated in figure 3 and table 2, all group processes developed during the tutorial group, although not within all periods (P1, P2 or P7). For example, the perceived "group learning behaviour" did not increase within period one ( $\beta 0.07$ $(0.05) p<0.05)$, but did increase in P2 ( $\beta 0.21(0.06) p<0.05)$ and P7 ( $\beta 0.22$ (0.07), $p<0.05)$. The results illustrated in table 2 show an overall pattern of a positive development in the scales "psychological safety", "group potency" and "social cohesion" in P1. In P2, "group learning behaviour" and "interdependence" developed, as did social cohesion. In P7 all scales developed.

Between groups students differed in their perception of the four group processes over time within the period. For example in the case of group learning behaviour in P1, between group variance at observation null was $23.6 \%$, decreasing towards $<0.01 \%$ at observation one. Similarly the between-student (within tutorial group) variance in $\mathrm{P} 1$, decreased from $40.1 \%$ at observation null to $2.1 \%$ at observation 1 . Similar patterns were demonstrated for the other three group processes within all periods. These variances show that both students and groups became more similar over time in their perception of the processes in their tutorial group. 
Table 2: Within-period development of the five group processes.

\begin{tabular}{|c|c|c|c|c|c|c|}
\hline & & $\begin{array}{c}\text { Group learning } \\
\text { behaviour }\end{array}$ & $\begin{array}{c}\text { Psychological } \\
\text { safety }\end{array}$ & Social cohesion & Group potency & Interdependence \\
\hline P1 & \begin{tabular}{|l}
$\beta$ \\
$\sigma^{2}\left(V_{0 K}\right)$ \\
$\sigma^{2}\left(V_{1 K}\right)$ \\
$\sigma^{2}\left(U_{0, K K}\right)$ \\
$\sigma^{2}\left(U_{1, K}\right)$
\end{tabular} & \begin{tabular}{|l}
$.05(0.05)$ \\
$23.6 \%$ \\
$<0.01 \%$ \\
$40.1 \%$ \\
$2.1 \%$ \\
\end{tabular} & $\begin{array}{l}0.15^{*}(0.05) \\
17.6 \% \\
<0.01 \% \\
42.7 \% \\
4.1 \% \\
\end{array}$ & \begin{tabular}{|l|}
$0.76 *(0.08)$ \\
$2.1 \%$ \\
$2.8 \%$ \\
$48.0 \%$ \\
$<0.01 \%$ \\
\end{tabular} & $\begin{array}{l}0.35 *(0.08) \\
16.9 \% \\
8.8 \% \\
24.3 \% \\
6.0 \% \\
\end{array}$ & \begin{tabular}{|l|}
$0.05(0.07)$ \\
$12.0 \%$ \\
$2.4 \%$ \\
$34.8 \%$ \\
$<0.01 \%$ \\
\end{tabular} \\
\hline P2 & $\begin{array}{l}\beta \\
\sigma^{2}\left(V_{0 K}\right) \\
\sigma^{2}\left(V_{1 K}\right) \\
\sigma^{2}\left(U_{0, K}\right) \\
\sigma^{2}\left(U_{1 J K}\right)\end{array}$ & $\begin{array}{l}0.21 *(0.06) \\
0.5 \% \\
4.0 \% \\
53.3 \% \\
0.6 \% \\
\end{array}$ & $\begin{array}{l}0.11(0.06) \\
<0.01 \% \\
2.0 \% \\
46.5 \% \\
3.4 \% \\
\end{array}$ & $\begin{array}{l}0.48 *(0.08) \\
5.5 \% \\
1.2 \% \\
38.9 \% \\
3.6 \% \\
\end{array}$ & $\begin{array}{l}0.11(0.07) \\
<0.01 \% \\
7.1 \% \\
50.9 \% \\
<0.01 \% \\
\end{array}$ & \begin{tabular}{|l|}
$0.15^{*}(0.06)$ \\
$4.6 \%$ \\
$1.1 \%$ \\
$40.7 \%$ \\
$<0.01 \%$ \\
\end{tabular} \\
\hline P7 & $\begin{array}{l}\beta \\
\sigma^{2}\left(V_{0 K}\right) \\
\sigma^{2}\left(V_{1 K}\right) \\
\sigma^{2}\left(U_{0, K}\right) \\
\sigma^{2}\left(U_{1, K}\right)\end{array}$ & $\begin{array}{l}0.22 *(0.07) \\
10.0 \% \\
7.9 \% \\
26.9 \% \\
4.6 \%\end{array}$ & $\begin{array}{l}0.32 *(0.07) \\
3.9 \% \\
2.2 \% \\
34.7 \% \\
<0.01 \%\end{array}$ & $\begin{array}{l}0.49 *(0.07) \\
8.8 \% \\
<0.01 \% \\
14.3 \% \\
15.7 \%\end{array}$ & $\begin{array}{l}0.37 *(0.08) \\
11.9 \% \\
9.1 \% \\
22.5 \% \\
8.6 \%\end{array}$ & $\begin{array}{l}0.18 *(0.06) \\
0.6 \% \\
3.4 \% \\
55.4 \% \\
2.6 \%\end{array}$ \\
\hline
\end{tabular}

RQ 2: TO WHAT EXTENT DO THESE PROCESSES DEVELOP OVER tHe PERIODS WHEN STUDENTS PROGRESS IN THEIR CURRICULUM?

Figure 3 and table 3 illustrate how the five observed group processes differed between P1 versus P2 and P7. The perception of group learning behaviour starting in a tutorial group (observation null) is highest in P1 compared to P2 ( $\beta-0.28$ (0.07) $p<0.05)$ and $P 7(\beta-0.25(0.07) \quad p<0.05)$, while these perceptions hardly differed between P2 and P7 $(\beta-0.02(0.07) \quad p<0.05)$. The development of group learning behaviour within one period was lowest in $\mathrm{P} 1$.

A different pattern was found for psychological safety. Students indicated highest perception of psychological safety in the beginning of P1 compared to P2. However, the development within P7 was steeper than in P1. Social cohesion was perceived highest in the beginning of P1. Within P1 the development of social cohesion also showed the steepest slope compared to P2 and P7. Group potency did not differ significantly at the start of all periods. However, the development within P2 had a much shallower slope compared to P1 and P7. Finally, interdependence was perceived highest in P1 (versus P2 and versus P7. Furthermore, between all periods, only P7 had a significantly sharper slope than P1. 
Table 3: Between-period development of the five group processes.

\begin{tabular}{|c|c|c|c|c|c|c|}
\hline & & $\begin{array}{l}\text { Group learning } \\
\text { behaviour }\end{array}$ & $\begin{array}{l}\text { Psychological } \\
\text { safety }\end{array}$ & Social cohesion & Group potency & Interdependence \\
\hline \multirow{3}{*}{$\begin{array}{l}\text { Differences in } \\
\text { starting point } \\
\text { (obs } 0)\end{array}$} & $P 1$ vs $P 2$ & $-0.28 *(0.07)$ & $-0.13^{*}(0.07)$ & $-0.63 *(0.09)$ & $0.02(0.07)$ & $-0.15 *(0.07)$ \\
\hline & $P 1$ vs $P 7$ & $-0.25 *(0.07)$ & $-0.15^{5}(0.08)$ & $-0.25 *(0.10)$ & $0.04(0.08)$ & $-0.24 *(0.08)$ \\
\hline & P2 vs P7 & $-0.02(0.07)$ & $-0.04(0.07)$ & $0.34 *(0.09)$ & $0.01(0.07)$ & $-0.10(0.07)$ \\
\hline \multirow{3}{*}{$\begin{array}{c}\text { Differences in } \\
\text { slopes ( } \beta \text { ) }\end{array}$} & P1 vs $P 2$ & $0.17 *(0.07)$ & $-0.02(0.07)$ & $-0.26 *(0.10)$ & $-0.22 *(0.08)$ & $0.12(0.09)$ \\
\hline & P1 vs $P 7$ & $0.18 *(0.08)$ & $0.19 *(0.09)$ & $-0.25 *(0.11)$ & $0.02(0.09)$ & $0.17 *(0.09)$ \\
\hline & P2 vs P7 & $0.05(0.08)$ & $0.25 *(0.09)$ & $0.03(0.11)$ & $0.25 *(0.09)$ & $0.02(0.08)$ \\
\hline
\end{tabular}

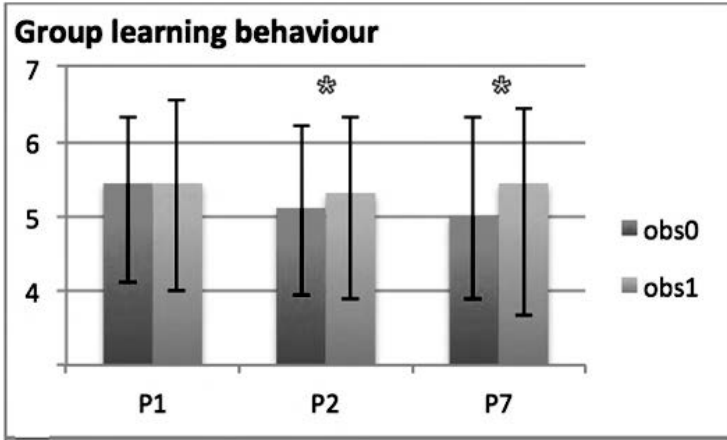

\section{Psychological safety}

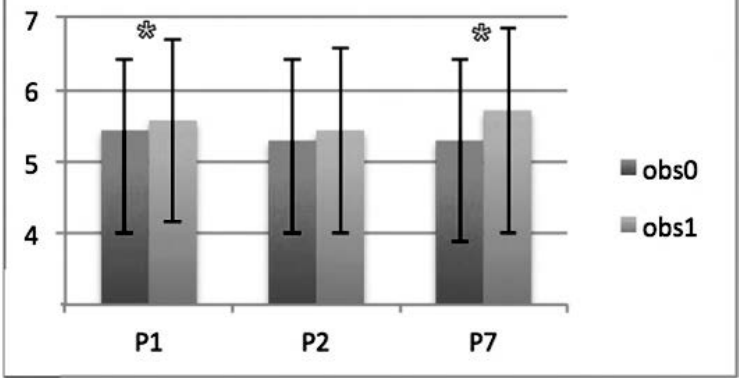

\section{Social cohesion}

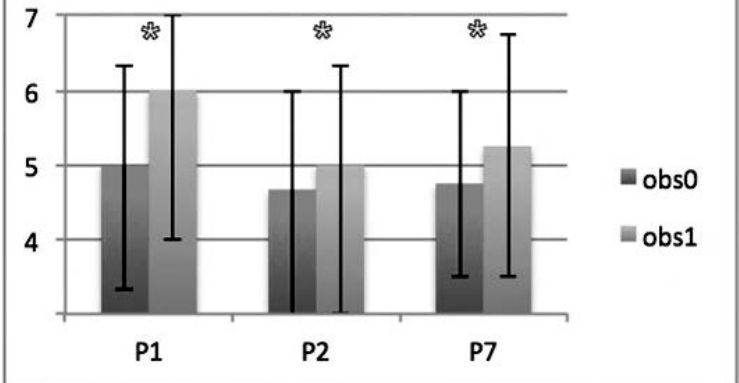

Figure 3: Visualisation of the dynamics of the five group processes over time. 


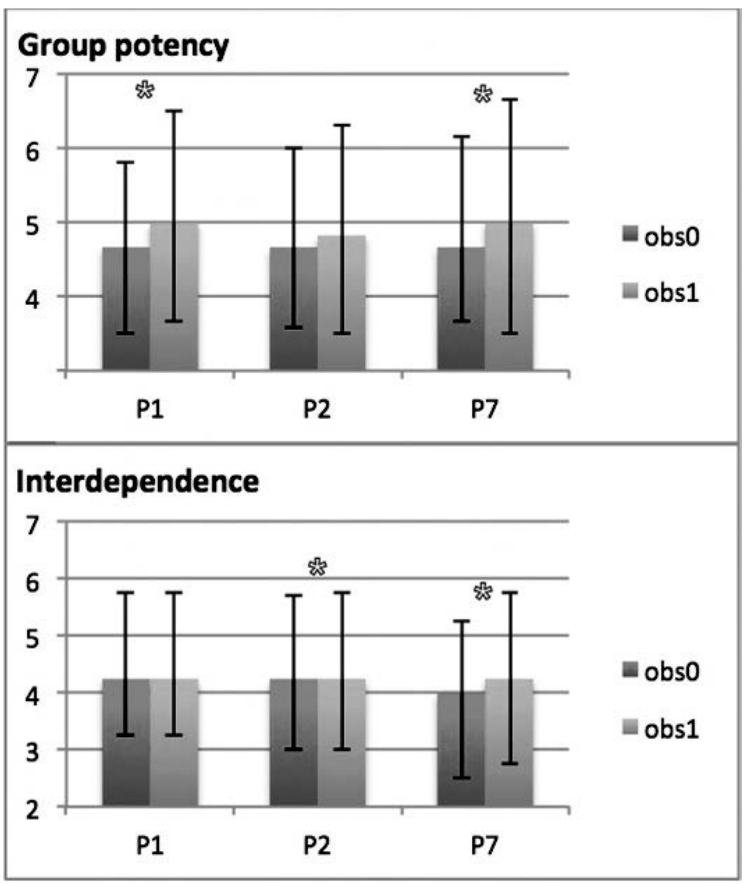

RQ 3: HOW DO GROUP LEARNING PROCESSES DEVELOP OVER TIME?

A description of the derived (multilevel) process will be given based on all interviewed students, followed by a global description of its development.

GROUP LEARNING BEHAVIOUR

This process was described as sharing information, building onto the ideas of group members and if conflicting ideas come across, applying logical reasoning to structure the contrasting ideas and to understand where the contrast occurs. All students indicated that group learning behaviour was a group level construct, starting from the first tutorial group. The seven-step-procedure in PBL played an important role on group learning behaviour as it stimulated students to share information from the first session and might also facilitate construction and constructive cognitive conflict in the tutorial group. Some students clearly indicated a stepwise developmental process in the various domains of learning behaviour, starting with construction of knowledge during the first tutorial groups and ending with constructive cognitive conflict. However, not all groups reached the last 'step'. (S1) In the beginning of P1 a group member would read whatever he prepared for the tutorial group session. The listeners nodded to show they had read the same literature. No further questions were asked and nobody else added information. Fortunately, towards the beginning of the second module in P1, we developed into a group in which frequent discussions were held on subject that we had studied. 
INTERDEPENDENCE

Feelings of interdependence between students in the tutorial group were one of the key indicators for successful group learning. However, students differed in their concepts of interdependence. Most students described interdependence as 'equal participation'. Many silent students were mentioned as a problem in collaborative learning as these students were experienced as social loafing on the 'active' members of the group. Differences in personality, for example 'being shy', 'not being used to participate in groups' and 'not preparing', were all reasons for students to be silent. Getting to know one another -see 'convergence of mental models'- led to more insights in how to deal with these students; for example shy students were frequently explicitly called on by the chair in the tutorial group to increase equal participation. 'Socializing' outside the tutorial group was also important to increase interdependence.

Several students viewed 'source' interdependence as another description of interdependence and a key element of group learning. This was directly linked to the effectiveness of the group learning process: (S2) We all studied the same tasks but explored slightly different angles and studied with a varying degree of details. In the tutorial group sessions we were able to add these different details resulting in a richer understanding of the subjects that we all had studied. Other students underlined the importance of interaction in a group to view conceptualisations from a different point of view. None of the students mentioned 'outcome' interdependence as important in the group as was described by Johnson \& Johnson (2002) as the key element in collaborative learning.

Overall, interdependence ('equal participation' and 'seeing differences in a point of view') was conceptualised as a group phenomenon, emerging once involved in a tutorial group, while 'source' interdependence emerged when students had been involved in the group for some time and sufficient feelings of safety were reached to rely on the groups' knowledge base.

\section{PSYCHOLOGICAL SAFETY}

'Feeling safe' within a tutorial group was the second key element before successful group learning could occur. In all groups, students did not feel safe from the start. Convergence of mental models caused students to get used to one another (communication, roles in the group) and the PBL system (expectations and roles in PBL groups). As such, this process was described as an emerging group phenomenon, strongly dependent on the group phenomenon 'convergence of mental models' but also 'personal factors' such as previous experience in collaboration within groups, ease to speak in public. In turn, psychological safety is a pre-requisite for interdependence and social cohesion and group learning. (S3) A good atmosphere is important in the group for effective collaboration. For example when involved in the brainstorming session, if group members would react 'no way, that's not true' the student that offers explanations is likely to feel rejected and stop his participation. Fortunately in our tutorial group, it was very safe although everyone was scared in the beginning to say something... Scared to be perceived as dumb or to tell others something that is not true. In the end, all group members were respectful towards 
one another and corrections were made while carefully bearing in mind the feelings of all group members.

SOCIAL COHESION

Social cohesion between students was another emerging group phenomenon that was ascribed as very important for the tutorial groups. Various students described it as showing respect to one another or labelled it as 'openness' or 'pleasantness' in the tutorial group. Collaborating or 'socializing' outside tutorial groups or extracurricular activities was mentioned frequently as a strong influence of feelings of relatedness or attraction to the tutorial group or to individual students. Finally, students described a close relationship between psychological safety and social cohesion, developing strongly in the first weeks being in a tutorial group. (S4) Increasingly, all members do practical training sessions together, and sit together in the lecture hall. This way, we all got to know one another well. In the beginning this process proceeds rapidly towards a constant value. So far, we have had dinner twice in the group and had a night out. Now we are in module 3, we still meet every week to keep up with one another. One of the group members now experiences low motivation in her group. That's a difficult situation, but through our meetings I hope we are helping to keep up with our groups.

\section{TASK COHESION}

Students stressed the importance of task cohesion in the process of collaborative learning. This process was mostly defined by motivation to study, which is an individual construct. Students relied on the expression of motivation, indicated by preparation and involvement in the tutorial group sessions. Task cohesion was also socially influenced or 'contagious' within the group, giving rise to a bottom-up influence of motivation to a group process of task cohesion. (S5) If it is fun in the group, you are also more willing to come to the tutorial group and prepare for the sessions. Otherwise it's easier to Google the subjects instead. Enthusiasm to study medicine, an individual construct, was strongly present in most groups. Hesitation towards the effectiveness of PBL (an individual construct) was also reflected in the group's task cohesion (group construct). (S6) Sometime in the second module we discovered that half of the group members did not want to study in this university because of the PBL system. These group members did not try hard at all to learn in the group.

POTENCY

Potency was a concept that was not clearly defined by most students as an important process in collaborative learning. However, this process did develop over time and had influence on the group's learning behaviour or other socio-cognitive processes involved in collaborative learning. For example, various students mentioned that their self-efficacy (individual construct) grew while getting used to the PBL learning context (convergence of mental models). Performance of individuals and members of the group on the test was also a strong indicator of self-efficacy or group potency as 
was the tutor: (S7) It is nice if the tutor confirms that the group has tackled all subjects in the tutorial group session(s).

TRANSACTIVE MEMORY

'Knowing where the knowledge and expertise is' was a process that developed over time in the tutorial groups. Students described an active and passive process of familiarising towards one another's expertise. This type of getting to know one another in turn improved the groups' cognition. (58) Especially in the second module we collaborated effectively in the group. We really got to know one another well. In the tutorial group we took advantage of one another by having certain things explained by one student, while other things explained by another student that had obtained more expertise in a particular subject. This process did not only take place within tutorial groups. Social interaction outside tutorial groups was an essential element in this emergent process. Various students described that a network among students who shared expertise (including some members of the tutorial group) increased feelings of interdependence and social cohesion during the tutorial group sessions.

CONVERGENCE OF MENTAL MODELS

Getting used to the PBL system increased 'group learning behaviour' through 'task cohesion', 'group potency' or 'self-efficacy', 'interdependence' and 'psychological safety'. The tutor and group members with previous experience had a strong positive influence on the development of this process. Overall, this phenomenon of not knowing what to do in the group and in the university shows a rapid improvement; most students indicated that at the end of the first module, all members of the group got used to the PBL system. (S9) We had to get used to the PBL system. Especially how to prepare was quite difficult in the first few weeks. It resulted in excellent preparation quality in the second week before the test was held. Some students described it as a continuing process finishing only when the group ended (module 2). These students differed slightly in their interpretation of getting used to collaborative learning; focussing not only how PBL influenced students and the group, these students also focused on a growing understanding of the behaviour of their group members. (S10) We had one group member, a girl who hardly participated in the group process. However, if she participated, the information provided was rather good. She explained that she had chosen for the PBL system since she was shy and wanted to learn how to interact better and more frequent. Therefore, we knew that she wanted to be actively approached without forcing her to participate. These students viewed convergence of mental models as 'cross understanding' of communication of individuals instead of understanding what type of knowledge and skills a group member brings to the group.

As both phenomena (getting used to PBL and a growing understanding the communication of group members) have to do with getting used to the group in its context, we have added this process and labelled it 'convergence of mental models'. As described previously, the participants described how this emergent group phenomenon is a driving factor for all listed socio-cognitive processes. Moreover, 
convergence of mental models resulted in adaptation of the groups' behaviour to facilitate collaborative learning for all members. One group mentioned adding possible learning resources for every learning goal to structure the literature search during the self-study period. Various groups indicated striving towards equal participation through actively inviting group members to participate in a tutorial group session. Again, the tutor using scheduled group reflections actively encouraged students in this process of understanding one another's behaviour and how to improve the use of the group to increase learning. A great disturbance of the groups' mental model could be the addition of a new student in the group. (S7) A male student was added to our group. He acted rather dominantly, pretending if he knew everything what we needed to learn. This was a pity since the other group members clammed up completely. This resulted in a group in which there was no collaboration at all. Fortunately, in some groups the new students had a positive influence on some members of the group.

\section{Discussion}

PRINCIPAL FINDINGS AND MEANING

This study explored how group processes developed over time using a mixedmethods design. The quantitative study clearly showed the dynamics of learning groups over time. Overall, the four tested group processes developed (positively) within the three observed periods, confirming the general consensus that groups develop over time (Benson et al., 2001; Fransen et al., 2013; Mathieu et al., 2008). At the same time, students converged towards each other in their perception of the groups process, emphasizing the social nature of learning (Levine \& Resnick, 1993). It was striking that social cohesion showed the sharpest increase when involved in the same tutorial group over all three periods. This finding underlines Slavin's finding (1995) that social cohesion is a rather important process in collaborative learning contexts. At the same time, feelings of interdependence seemed to be not as important, being perceived overall as 'neutral' in the beginning of the periods with very shallow slopes over time. This finding is a rather large contrast with the Johnson and Johnson' theory of social interdependence (2002) which posits social interdependence as the crucial element of collaborative learning in groups.

Finally, differences in development between the periods indicate that students learn how to learn in a group. Students perceived most positive group processes in their first tutorial group (P1). This could be due to the importance of the first tutorial group in which students learn to learn in a PBL curriculum during a rather exciting or even stressful time in life for students. This could also explain the rather negative perceptions of the group learning processes when starting the second period in a new tutorial group. Considering the gap between P2 and P7, it is surprising that not all learning processes show a steeper increase in P7 than P2. 
While the first study aimed to understand group processes within and over various periods over time, the qualitative study explored how students experienced these learning processes and their impact on learning; allowing us to focus on the involvement on individual level constructs influencing group level phenomena and the contextual influences on group processes. At the same time, the development was illustrated in detail including fluctuation between the two quantitative observations within one period. Students clearly described that all group processes 'social cohesion', 'task cohesion', 'psychological safety', 'interdependence', 'potency' and 'group learning behaviour' were perceived important for collaboration in groups. These findings are in line with cross-sectional quantitative studies in a similar context (Dolmans \& Schmidt, 2006; van den Bossche et al., 2006) and theoretical models of collaborative learning (Johnson \& Johnson, 2002; Slavin, 1983). However, the interpretation of the process differed between students and the literature. For example interdependence represented 'equal participation', 'seeing a different point of view' or 'source interdependence' by students, instead of 'outcome interdependence' stated as the most essential element of collaborative learning by Johnson and Johnson (2002). This might explain why in the quantitative data, interdependence appeared to not play an important role in their collaborative learning process, whereas in the qualitative study it was perceived as very important by students. Rather similar was the description of 'task cohesion', which was expressed by students in the quality of preparation for the tutorial group session, whereas in the questionnaire it was assessed as shared attraction to the task. All these processes had a varying time of onset and a difference in being a group and/or individual phenomenon influenced by contextual factors (e.g. tutor, test) or other processes (e.g. safety and social cohesion are related strongly). Two additional processes were described, labelled as 'transactive memory' and 'convergence in mental models' among students. The former process represents that students learn where to locate knowledge from other students during and outside the tutorial groups, rather similar to the Transactive Memory System described in the organisational sciences (Ellis, Porter, \& Wolverton, 2008). The latter process refers to both getting used to PBL from both the student and group perspective, as well as getting to understand how group members behave in the group. This description is similar to the process of convergence of mental models described in organisational sciences (Huber \& Lewis, 2010; Mohammed \& Dumville, 2001). However, this process has been described in a wide variety of definitions (Klimoski, 1994) some of which shows overlap with transactive memory. Convergence of mental models as students defined it in the interviews, was a starting point of all other socio-cognitive processes (causing feelings of psychological safety, self-efficacy etc.) and facilitated the group in making adaptions to increase collaborative learning. Another key difference with previous literature is the directionality of how processes influence each other. Van den Bossche et al (2006) clearly describe psychological safety, group potency, task and social cohesion and social interdependence as antecedent processes for group learning behaviour, which is in the end driving shared mental models in the group. These qualitative data suggest that the context (tutor) and the attitudes of the students, especially expressed as psychological safety drive 
behaviour such as social cohesion, convergence towards the PBL, social interdependence, which drive group learning behaviour. However, time and experience in the problem based learning sessions make cycles of group processes recur or proceed on another level. Socialising with the students outside the formal activities make process cycles accelerate or delay formal group learning. Potency, transactive memory and convergence of mental models are processes that occur later on the curriculum. Contextual factors have a great influence on group processes, for example approaching the module tests, makes students collaborate differently in the tutorial group sessions. Therefore, the qualitative data suggest that a nonsequential development model approaches group development in a Problem Based Learning setting best, supporting the hypothesis of Fransen et al (2013).

IMPLICATIONS FOR PRACTICE AND FUTURE RESEARCH

Thorough understanding on how collaborative learning processes develop over time goes beyond solely enriching our insights into group learning in Problem Based Learning environments. Both teachers and students can benefit from these insights directly. First of all, as was shown, there is quite some variance between students in the same tutorial groups. This variance indicates that students could use some training to be more aware of group dynamics in the current tutorial group. Furthermore, having this knowledge, students could be trained to take an active role in the group to change the dynamics to increase group efficacy. Sweet \& Michaelsen (2007) stated that "Students need to learn how to learn". This might seem straightforward, but most universities don't teach this to students as was noted quite some time ago by Hounsell (1979). In collaborative learning contexts, the 'teaching' how groups learn, is still marginal in most universities. Tutors can also attribute to the awareness of group dynamics to steer the dynamics in a positive direction to help groups to use the group optimally. To facilitate awareness on what happens in groups, the development of an instrument measuring the group processes might provide a good tool to visualize group dynamics and steer the direction of what to optimize to increase effectiveness.

These insights might also provide new approaches to improve our educational designs in order to optimise students' learning contexts. Most attention should be put in optimising students' group learning process in the first tutorial group as it seems that this is the period in which students learn how to learn. Another option to optimise group development is through increasing the length of the modules to facilitate group development and in the end facilitate group learning. For example in our medical curriculum students collaborate between six or ten weeks within one tutorial group. As most group processes develop over time, a period of six weeks might be much to short to reach effective dynamics in the group. Anonymity might be another danger for group processes such as convergence in mental models and transactive memory. Especially educational designs with large classes should consider if anonymity and group development in the groups do not pose a negative effect on students' learning processes in the curriculum. In the case of large classes, allocation of students to new tutorial groups every module again might decrease the development of positive group dynamics in these tutorial groups as students might 
not be able to spend a sufficient amount of time getting to know one another every module again. As such, one might think of changing the allocation strategy in such way that students know with whom they collaborate. The same holds for changing tutors over time, see Curet \& Mennin (2003).

\section{STRENGTHS AND LIMITATIONS}

The mixed methods design with the use of longitudinal observations of a variety of group learning processes using a multilevel construct of groups in the quantitative study, are strengths of this study. Especially considering the lack of these designs in (small) group research and especially in educational research. Moreover, studying students in tutorial groups in their natural educational context while still involving large numbers of participants in both studies, gives us a good view of what can occur in collaborative learning groups. This design did cause some difficulties in the analyses. As explained in the methods description of the quantitative study, the educational context brought quite a statistical challenge as we could not control for covariates such as duration of the period, contents of tutorial groups, time when tutorial groups were held during the medical curriculum. We felt that we could not change the educational context to keep these statistical covariates constant and still try to understand group dynamics and development. Further limitations are related to measuring group processes as a subjective factor in both studies, inherently to the self-reported measurements. The longitudinal design and overlapping findings in variance between the quantitative and qualitative studies, decreases the likelihood that our results are based on measurement errors. Finally, a-priori defined codes can direct the researchers' ability to discriminate processes in groups, which could favour a researcher to start with open coding schemas. However, template analysis includes a dynamic side in the analysis method allowing for modifications based on the information derived from interviews as grounds to alter the initial template. The advantage of using an a-priori template is that it directed us researchers to clearly state our views and definitions before analysing the data. We believe that rigorous qualitative data analysis should take into account the beliefs and backgrounds of the researchers, as is common in constructivist grounded theory for example (Mills, Bonner, \& Francis, 2006).

Although these results have increased our insights into group development in learning groups, this study holds some limitations. First of all, we still don't know if 'higher' developed groups, or groups with merely positive group processes, also 'learn' more or 'perform' better (e.g. more knowledge retention and translation). This association could be a very interesting direction for future research, although first a clear definition of group learning in collaborative learning groups should be developed (Goodman \& Dabbish, 2011). Furthermore, this study solely focussed on formal group processes. More limited is our understanding on how informal learning influences formal learning, although again in this study, the importance of informal learning or 'socializing outside the formal learning context' has been indicated as important for the students overall learning process, confirming previous research (Gasevic, Zouaq, \& Janzen, 2013; Hommes et al., 2012). Future studies could thus 
include the informal context to provide a more complete our understanding on how students learn over time. Finally, future research, using direct observations while not influencing the group processes over time and focussing on group processes in modules later in a curriculum, would result into a broader understanding of how group dynamics change over time during a curriculum.

\section{REFERENCES}

Arrow, H., \& Cook, J. (2008). Configuring and reconfiguring groups as complex learning systems. In V. I. Sessa \& M. London (Eds.), Work group learning: understanding, improving \& assessing how groups learn in organizations (pp. 45-71). London: Lawrence Erlbaum Associates, Taylor \& Francis Group.

Atlas.tiCompany (Producer). (2012). Atlas.ti v. 6.3. [Qualitative data analysing software]

Baker, M., Hansen, T., Joiner, R., \& Traum, D. (1999). The role of grounding in collaborative learning tasks. In P. Dillenbourg (Ed.), Collaborative learning: Cognitive and computational approaches. Saffron Walden, UK: Elsevier Science / Pergamon.

Bandura, A. (1977). Self-efficacy: Toward a unifying theory of behavioral change. Psychological review, 84(2), 191-215.

Barron, B. (2000). Achieving coordination in collaborative problem-solving groups. The journal of the learning sciences, 9(4), 403-436.

Benson, G., Noesgaard, C., \& Drummond-Young, M. (2001). Facilitating small group learning. In E. Rideout (Ed.), Transforming nursing education through problem-based learning (pp. 75 - 99). London, UK: Jones and partlett Publishers International.

Carabajal, K., LaPointe, D., \& Gunawardena, C. N. (2008). Group development in online distance learning groups. In M. G. Moore (Ed.), Handbook of distance education (2nd ed., pp. 137-148). Mahwah, New Jersey: Lawrence Erlbaum Assocates Inc.

Carless, S. A., \& De Paola, C. (2000). The measurement of cohesion in work teams. Small group research, 31(1), 71-88.

Creswell, J. W. (2009). Qualitative, quantitative, and mixed methods approaches (3 ed.). London, Thousand Oakes, New Delhi, Singapore: SAGE Publications Inc.

Cronin, M. A., Weingart, L. R., \& Todorova, G. (2011). Dynamics in groups: Are we there yet? The academy of management annals, 5(1), 571-612. doi: 10.1080/19416520.2011.590297

Curet, M. J., \& Mennin, S. P. (2003). The effect of longterm vs shortterm tutors on the quality of the tutotiral process and student performance. Advances in Health Sciences Education, 8, 117-126.

de Grave, W. S., Dolmans, D. H. J. M., \& van der Vleuten, C. P. M. (2002). Student perspectives on critical incidents in the tutorial group. Advances in Health Sciences Education, 7, 201-209.
Dillenbourg, P., Baker, M., Blaye, A., \& O'Malley, C. (1996). The evolution of research on collaborative learning. In E. Spada \& P. Reiman (Eds.), Learning in humans and machine: Towards an interdisciplinary learning science (pp. 189-211). Oxford: Elsevier.

Dolmans, D. H. J. M., \& Schmidt, H. G. (2006). What do we know about cogntive and motivational effects of small group tutorials in problem-based learning? Advances in Health Sciences Education, 11, 321-336.

Edmondson, A. (1999). Psychological safety and learning behaviour in work teams. Administrative science quarterly, 44, 350-383.

Edmondson, A., \& McManus, S. E. (2007). Methodological fit in management field research. Academy of management review, 32(4), 1155-1179.

Ellis, A. P. J., Porter, C. O. L. H., \& Wolverton, S. A. (2008). Learning to work together: an examination of transactive memory system development in teams. In V. I. Sessa \& M. London (Eds.), Work group learning: understanding, improving \& assessing how groups learn in organizations (pp. 91-115). London: Lawrence Erlbaum Associates, Taylor \& Francis Group.

Fransen, J., Weinberger, A., \& Kirschner, P. A. (2013). Team Effectiveness and Team Development in CSCL. Educational psychologist, 48(1), 9-24. doi: 10.1080/00461520.2012.747947

Gasevic, D., Zouaq, D., \& Janzen, R. (2013). “Choose your Classmates, your GPA is at Stake!" The Association of Cross-Class Social Ties and Academic Performance. American behavioural scientist, 57(10), 1460-1479. doi 10.1177/0002764213479362

Gibson, C. B., Randel, A. E., \& Early, P. C. (2000). Understanding group efficacy. Group \& organization management, 25(1), 67-97.

Gijbels, D., van de Watering, G., Dochy, F., \& van den Bossche, P. (2006). The relationship between students' approaches to learning and the assessment of learning outcomes. European journal of psychology of education, 20(4), 327-341.

Goodman, P. S., \& Dabbish, L. A. (2011). Methodological issues in measuring group learning. Small group research, 42, 379-404. doi $10.1177 / 1046496410385471$

Guzzo, R. A., Yost, P. R., Campbell, J. R., \& Shea, G. P. (1993). Potency in teams: Articulating a construct. British journal of social psychology, 32, 87-106. 
Hare, A. P. (reprinted 2010). Theories of group development and categories for interaction. Small group research, 41(1), 106-140. doi: 10.1177/1046496409359503

Harrington, B., \& Fine, G. A. (2006). Where the Action Is: Small Groups and Recent Developments in Sociological Theory. Small group research, 37(1), 419. doi: $10.1177 / 1046496405284356$

HIllyard, C., Gillespier, D., \& Littig, P. (2010). University student's attitudes about learning in small groups after frequent participation. Active learning in higher education, 11(1), 9-20. doi: 10.1177/1469787409355867

Hommes, J., Rienties, B., de Grave, W., Bos, G., Schuwirth, L., \& Scherpbier, A. (2012). Visualising the invisible: A network approach to reveal the informal social side of student learning. Advances in Health Sciences Education, 17(5), 743-757. doi: 10.1007/s10459-012-9349-0

Hounsell, D. (1979). Learning to Learn: Research and Development in Student Learning. Higher Education, 8(4), 453-469.

Huber, G. P., \& Lewis, K. (2010). Cross-understanding: implications for group cogntion and performance. Academy of management review, 35(1), 6-26.

Jeong, H. W. N., \& Chi, M. T. H. (1997). Construction of shared knowledge during collaborative learning. Paper presented at the Proceedings of the 2nd international conference on Computer support for collaborative learning, Toronto, Ontario, Canada.

Johnson, D., \& Johnson, R. (2002). Social interdependence theory and university instruction: Theory into practice. Swiss journal of psychology, 61(3), 119-129.

King, N. (1998). Template analysis In G. S. C. Cassell (Ed.), Qualitative methods and analysis in organizational research (pp. 118-134). London: Sage.

King, N. (2004). Using templates in the thematic analysis of the text. In C. Cassel, Symon, G. (Ed.), Essential guide to qualitative methods in organisational research (pp. 256-270). London: Sage.

Klimoski, R. (1994). Team mental model: Construct or metaphor? Journal of management, 20(2), 403-437.

Kozlowski, S. W. J., Chao, G. T., \& Jensen, J. M. (2010). Building an infrastructure for organizational learning: a multilevel approach. In S. W. J. Kozlowski \& E. Salas (Eds.), Learning, training, and development in organizations (pp. 363-403). New York: Routledge Taylor \& Francis Group.

Levine, J. M., \& Resnick, L. B. (1993). Social foundations of cognition. Annual review of psychology, 44, 585612.

Mathieu, J., Maynard, M. T., Rapp, T., \& Gilson, L. (2008). Team effectiveness 1997-2007: A review of recent advancements and a glimpse into the future. Journal of Management, 34(3), 410-476. doi: 10.1177/0149206308316061

Mathieu, J. E., \& Tesluk, P. E. (2010). A multilevel perspective on training and development effectiveness. In S. W. J. Kozlowski \& E. Salas (Eds.), Learning, training, and development in organizations (pp. 405-440). New York: Routledge Taylor \& Francis Group.
Mennecke, B. E., Hoffer, J. A., \& Wynne, B. E. (1992). The implications of group development and history for group support system theory and practice. Small group research, 23, 524-572. doi: 10.1177/1046496492234005

Mills, J., Bonner, A., \& Francis, K. (2006). Adopting a constructivist approach to grounded theory: implications for research design. International journal of nursing practice, 12(1), 8-13.

Mohammed, S., \& Dumville, B. C. (2001). Team mental models in a team knowledge framework: expanding theory and measurement across discipinary boundaries. Journal of Organizational Behavior, 22, 89-106.

Olivera, F., \& Straus, S. G. (2004). Group-to-individual transfer of learning: Cognitive and social factors. Small group research, 35, 440-465. doi: $10.1177 / 1046496404263765$

Perret-Clermont, A.-N., \& Schubauer-Leoni, M.-L. (1981). Conflict and cooperation as opportunities for learning. In P. Robinson (Ed.), Communication in development (pp. 203-234). London: Academic Press.

Rasbash, J., \& Goldstein, H. (1994). Efficient analysis of mixed hierarchical and cross-classified random structures using a multilevel model. American educational research association, 19(4), 337-350.

Roe, R. A. (2008). Time in Applied psychology. European psychologist, 13(1), 37-52. doi: 10.1027/10169040.13.1.37

Roschelle, J., \& Teasley, S. D. (1995). The construction of shared knowledge in collaborative problem solving. In C. E. O'Malley (Ed.), Computer supported collaborative learning (pp. 69-197). Berlin: SpringerVerlag.

Sargent, L. D., \& Sue-Chan, C. (2001). Does diversity affect group efficacy? The intervening role of cohesion and task-interdependence Small group research, 32, 426-450.

Schmidt, H. G. (1996). The development of diagnostic competence: Comparison of a problem-based, an integrated and a conventional medical curriculum. Academic medicine, 71(6), 658-664.

Schmidt, H. G., Rotgans, J. I., \& Yew, E. H. J. (2011). The process of Problem-Based Learning: what works and why. Medical Education, 45, 792-806. doi: 10.1111/j.1365-2923.2011.04035.x

Slavin, R. E. (1983). When does cooperative learning increase student achievement? Psychological Bulletin, 94(3), 429-445.

Slavin, R. E. (1995). When and why does cooperative learning increase achievement? Theoretical and empirical perspectives. In R. E. Slavin (Ed.), Cooperative Learning (pp. 145-171). Needham Heights, Massachusettes, USA: A Simon \& Schuster Company.

Slavin, R. E. (1996). Research on cooperative learning and achievement: What we know, what we need to know. Contemporary educational psychology, 21, 43-69.

Smith, G. (2001). Group Development: A Review of the Literature and a Commentary on Future Research Directions. Group facilitation: A research and applications journal, 3, 14-46. 
Stahl, R. J. (1994). The essential elements of cooperative learning in the classroom. from ERIC development team

StataCorp, L. (2010). Stata (Version 11.1). Texas, USA: Stata Corporation.

Sweet, M., \& Michaelsen, L. K. (2007). How group dynamics research can inform the theory and practice of postsecondary small group learning. Educational psychology review, 19, 31-47. doi: 10.1007/s10648-006-9035-y

van Boxtel, C., van der Linden, J., \& Kanselaar, G. (2000). Collaborative learning tasks and the elaboration of conceptual knowledge. Learning and instruction, 10, 311-330.

van den Bossche, P., Gijselaers, W. H., Segers, M., \& Kirschner, P. A. (2006). Social and cognitive factors driving teamwork in collaborative learning environments: Team learning beliefs and behaviors. Small Group Research, 37(5), 490-521. doi: $0.1177 / 1046496406292938$

van der Linden, J., Erkens, G., Schmidt, H. G., \& Renshaw, P. (2000). Collaborative learning. London: Kluwer Academic Publishers.

van der Vegt, G., Emans, B., \& van de Vliert, E. (1998). Motivating effects of task and outcome interdependence in work teams. Group \& organization management, 23(2), 124-143. van der Vleuten, C. P. M., \& Schuwirth, L. W. T. (2005). Assessing professional competence: from methods to programmes. Medical Education, 39, 309-317. doi: 10.1111/j.1365-2929.2005.02094.x

van Offenbeek, M. (2001). Processes and outcomes of team learning. European journal of work and organizational psychology, 10(3), 303-317.

Visschers-Pleijers, A. J. S. F., Dolmans, D. H. J. M., de Leng, B. A., Wolfhagen, H. A. P., \& van der Vleuten, C. P. M. (2006). Analysis of verbal interactions in tutorial groups: a process study. Medical Education, 40, 129-137. doi: 10.1111/j.13652929.2005.02368.x

Visschers-Pleijers, A. J. S. F., Dolmans, D. H. J. M., Wolfhagen, H. A. P., \& van der Vleuten, C. P. M. (2003). Development and validation of a questionnaire to identify interactions that promote deep learning in PBL. Paper presented at the 10th Euopean conference of research on learning and instruction, Padova, Italy.

Visschers-Pleijers, A. J. S. F., Dolmans, D. H. J. M., Wolfhagen, H. A. P., \& van der Vleuten, C. P. M. (2004). Exploration of a method to analyze group interactions in problem-based learning. Medical Teacher, 26(5), 471-478. doi: $10.1080 / 01421590410001679064$ 


\section{APPENDIX}

This table shows the differences in socio-cognitive processes when student progress through the curriculum. P: Period in curriculum (see figure 1). $\beta$ : Estimated slope. $\sigma^{2}\left(V_{K P}\right)$ : Variance between tutorial groups within the specified period $(P 1, P 2$ or $P 7) . \sigma^{2}\left(V_{J K}\right)$ : Variance between students within their tutorial group in the specified period (P1, $P 2$ or $\left.P 7\right)$. Standard errors are given between parentheses. P-values and confidence intervals were not added to improve simplicity, but can be calculated using these results. To ease interpretation * indicates $p \leq 0.05$.

\begin{tabular}{|c|c|c|c|c|c|c|c|}
\hline & & & $\begin{array}{c}\text { Group learning } \\
\text { behaviour }\end{array}$ & $\begin{array}{c}\text { Psychological } \\
\text { safety }\end{array}$ & Social cohesion & Group potency & Interdependence \\
\hline \multirow{17}{*}{ 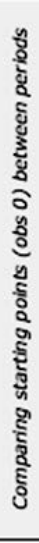 } & & $\beta$ & $-0.28 *(0.07)$ & $-0.13^{*}(0.07)$ & $-0.63^{*}(0.09)$ & $0.02(0.07)$ & $-0.15^{*}(0.07)$ \\
\hline & & $\sigma^{2}\left(V_{K D 1}\right)$ & $9.4 \%$ & $4.4 \%$ & $0.2 \%$ & $7.4 \%$ & $8.2 \%$ \\
\hline & P1 vs $\mathrm{P2}$ & $\sigma^{2}\left(V_{k}, p_{2}\right)$ & $<0.01 \%$ & $<0.01 \%$ & $2.0 \%$ & $<0.01 \%$ & $2.8 \%$ \\
\hline & & $\sigma^{2}\left(U_{* \times 1}\right)$ & $15.2 \%$ & $31.0 \%$ & $19.1 \%$ & $21.4 \%$ & $23.1 \%$ \\
\hline & & $\sigma^{2}\left(U_{\times 12}\right)$ & $4.1 \%$ & $0.1 \%$ & $<0.01 \%$ & $19.0 \%$ & $15.4 \%$ \\
\hline & & & & & & & \\
\hline & & $\beta$ & $-0.25^{*}(0.07)$ & $-0.15(0.08)$ & $-0.25^{*}(0.10)$ & $0.04(0.08)$ & $-0.24^{*}(0.08)$ \\
\hline & & $\sigma^{2}\left(V_{K}, 1\right)$ & $6.9 \%$ & $6.1 \%$ & $<0.01 \%$ & $1.1 \%$ & $8.5 \%$ \\
\hline & P1 vs P7 & $\sigma^{2}\left(V_{k p 7}\right)$ & $2.7 \%$ & $<0.01 \%$ & $3.5 \%$ & $2.0 \%$ & $0.1 \%$ \\
\hline & & $\sigma^{2}\left(U_{\times p_{1}}\right)$ & $9.8 \%$ & $9.9 \%$ & $<0.01 \%$ & $15.3 \%$ & $16.1 \%$ \\
\hline & & $\sigma^{2}\left(U_{x, p 7}\right)$ & $1.8 \%$ & $19.0 \%$ & $<0.01 \%$ & $9.9 \%$ & $7.9 \%$ \\
\hline & & & & & & & \\
\hline & & $\beta$ & $-0.02(0.07)$ & $-0.04(0.07)$ & $0.34 *(0.09)$ & $0.01(0.07)$ & $-0.10(0.07)$ \\
\hline & & $\sigma^{2}\left(V_{\times}, 2\right)$ & $2.3 \%$ & $<0.01 \%$ & $1.7 \%$ & $<0.01 \%$ & $4.3 \%$ \\
\hline & P2 vs P7 & $\sigma^{2}\left(V_{K}, 7\right)$ & $1.3 \%$ & $2.4 \%$ & $3.6 \%$ & $1.2 \%$ & $0.8 \%$ \\
\hline & & $\sigma^{2}\left(U_{\times p_{2}}\right)$ & $24.6 \%$ & $27.7 \%$ & $14.5 \%$ & $29.7 \%$ & $35.3 \%$ \\
\hline & & $\sigma^{2}\left(U_{\times p 7}\right)$ & $8.4 \%$ & $16.3 \%$ & $<0.01 \%$ & $1.7 \%$ & $<0.01 \%$ \\
\hline \multirow{16}{*}{ 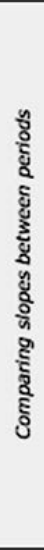 } & & $\beta$ & $0.17 *(0.07)$ & $-0.02(0.07)$ & $-0.26 *(0.10)$ & $-0.22^{*}(0.08)$ & $0.12(0.09)$ \\
\hline & & $\sigma^{2}\left(V_{K p 1}\right)$ & $0.6 \%$ & $<0.01 \%$ & $<0.01 \%$ & $1.4 \%$ & $1.4 \%$ \\
\hline & P1 Vs P2 & $\sigma^{2}\left(V_{\times p 2}\right)$ & $7.8 \%$ & $4.2 \%$ & $3.3 \%$ & $7.0 \%$ & $<0.01 \%$ \\
\hline & & $\sigma^{2}\left(U_{\times \times 1}\right)$ & $1.6 \%$ & $<0.01 \%$ & $<0.01 \%$ & $<0.01 \%$ & $<0.01 \%$ \\
\hline & & $\sigma^{2}\left(U_{\times 12}\right)$ & $<0.01 \%$ & $5.5 \%$ & $2.0 \%$ & $<0.01 \%$ & $0.6 \%$ \\
\hline & & $\beta$ & $0.18 *(0.08)$ & $0.19 *(0.09)$ & $-0.25^{*}(0.11)$ & $0.02(0.09)$ & $0.17^{*}(0.09)$ \\
\hline & & $\sigma^{2}\left(V_{\times p 1}\right)$ & $3.4 \%$ & $<0.01 \%$ & $3.9 \%$ & $5.9 \%$ & $0.6 \%$ \\
\hline & P1 vs P7 & $\sigma^{2}\left(V_{k p 7}\right)$ & $1.8 \%$ & $<0.01 \%$ & $2.7 \%$ & $3.2 \%$ & $4.0 \%$ \\
\hline & & $\sigma^{2}\left(U_{x \times 1}\right)$ & $<0.01 \%$ & $<0.01 \%$ & $<0.01 \%$ & $<0.01 \%$ & $<0.01 \%$ \\
\hline & & $\sigma^{2}\left(U_{\times p 7)}\right)$ & $7.6 \%$ & $7.2 \%$ & $<0.01 \%$ & $1.2 \%$ & $\mid<0.01 \%$ \\
\hline & & & & & & & \\
\hline & & $\beta$ & $0.05(0.08)$ & $0.25 *(0.09)$ & $0.03(0.11)$ & $0.25 *(0.09)$ & $0.02(0.08)$ \\
\hline & & $\sigma^{2}\left(V_{\times} \times 2\right)$ & $2.4 \%$ & $1.4 \%$ & $4.9 \%$ & $10.3 \%$ & $2.9 \%$ \\
\hline & P2 vs P7 & $\sigma^{2}\left(V_{x p 7}\right)$ & $4.3 \%$ & $1.4 \%$ & $2.3 \%$ & $1.1 \%$ & $0.7 \%$ \\
\hline & & $\sigma^{2}\left(U_{x \times p_{2}}\right)$ & $<0.01 \%$ & $<0.01 \%$ & $<0.01 \%$ & $<0.01 \%$ & $<0.01 \%$ \\
\hline & & $\sigma^{2}\left(U_{x, p}\right)$ & $7.4 \%$ & $3.1 \%$ & $<0.01 \%$ & $3.9 \%$ & $<0.01 \%$ \\
\hline
\end{tabular}





\section{CHAPTER 3}
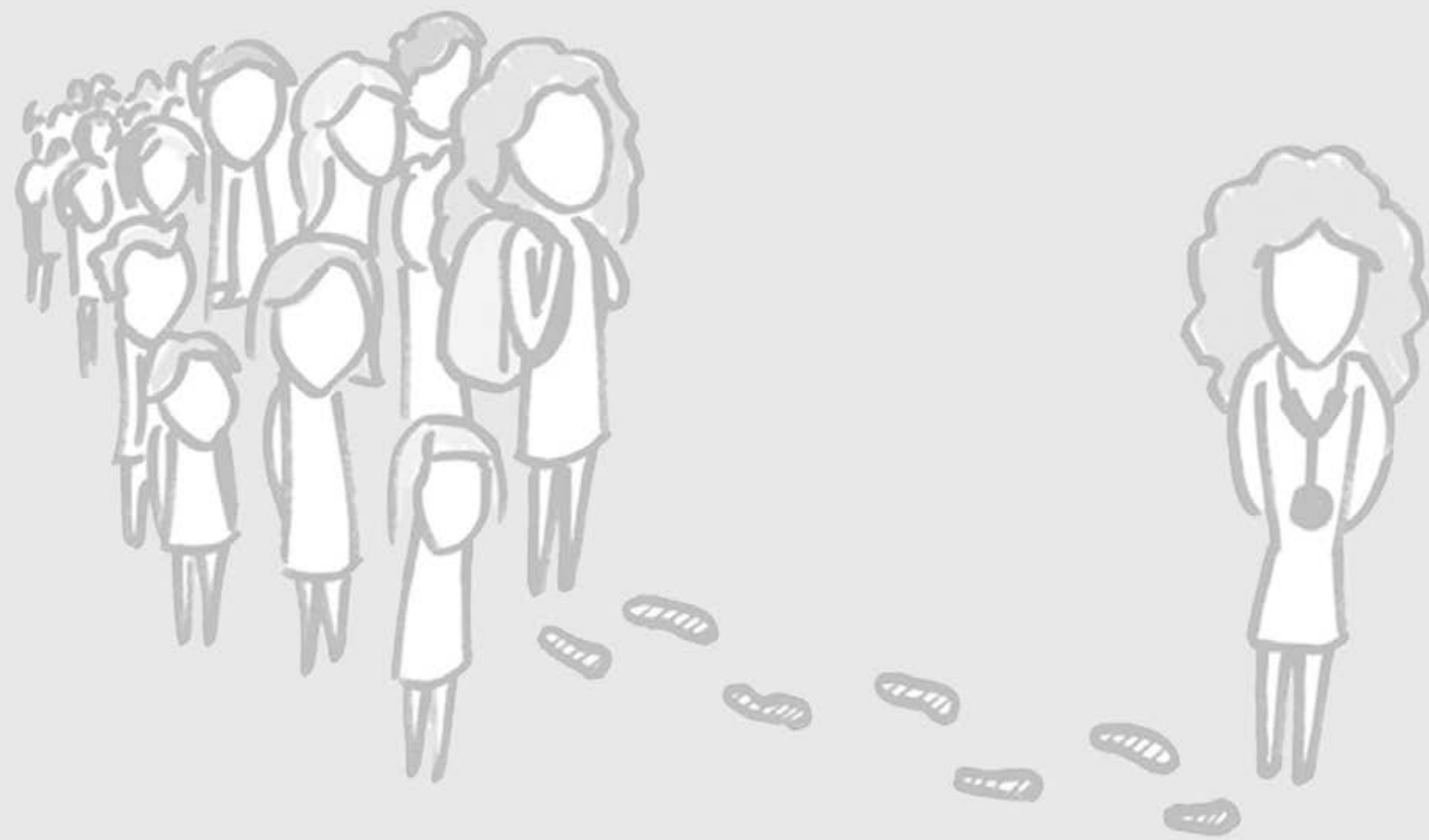


\section{Visualising the invisible: A Network approach to reveal the informal social side of student learning}

J. Hommes ${ }^{1}$, B. Rienties ${ }^{2}$, W. de Grave ${ }^{1}$, G. Bos ${ }^{1,3}$, L. Schuwirth ${ }^{1,4}$, A. Scherpbier ${ }^{1}$

1. Department of Educational Development and Research, Faculty of Health Medicine and Life Sciences, Maastricht University, The Netherlands.

2. Centre for Educational and Academic Development, University of Surrey, United Kingdom.

3. University Hospital Maastricht, Department of Internal medicine, Haematology, The Netherlands.

4. Flinders Innovation and Clinical Education, Flinders Medical School, Flinders University, Adelaide, Australia.

Published in Advances in Health Sciences Education 2012, 17(5), 743-757. 


\section{ABSTRACT}

OBJECTIVE Worldwide, universities in health sciences have transformed their curriculum to include collaborative learning and facilitate the students' learning process. Interaction has been acknowledged to be the synergistic element in this learning context. However, students spend the majority of their time outside their classroom and interaction does not stop outside the classroom. Therefore we studied how informal social interaction influences student learning. Moreover, to explore what really matters in the students learning process, a model was tested how the generally known important constructs - prior performance, motivation and social integration - relate to informal social interaction and student learning.

METHODS 301 undergraduate medical students participated in this crosssectional quantitative study. Informal social interaction was assessed using selfreported surveys following the network approach. Students' individual motivation, social integration and prior performance were assessed by the Academic Motivation Scale, the College Adaption Questionnaire and students' GPA respectively. A factual knowledge test represented student' learning.

FINDINGS All social networks were positively associated with student learning significantly: friendships $(\beta=0.11)$, providing information to other students $(\beta=0.16)$, receiving information from other students $(\beta=0.25)$. Structural equation modelling revealed a model in which social networks increased student learning $(\rho=0.43)$, followed by prior performance $(\rho=0.31)$. In contrast to prior literature, students' academic motivation and social integration were not associated with students' learning.

CONCLUSIONS Students' informal social interaction is strongly associated with students' learning. These findings underline the need to change our focus from the formal context (classroom) to the informal context to optimize student learning and deliver modern medics.

\section{INTRODUCTION}

Currently, modern learning environments in health sciences build on three elements: 'contextual', 'constructivist' and 'collaborative' learning. Research in cognitive psychology has given considerable insights on how 'contextual learning' - learning within a relevant context - and 'constructivist learning' - learning is an active constructive process - both enhance knowledge acquisition and retention (Simons, van der Linden, \& Duffy, 2000). Although considerable positive effects of collaborative learning on a variety (medical) competences were found e.g. (Johnson \& Johnson, 2009; Michaelsen, Parmelee, McMahon, \& Levine, 2008), we still have no full understanding on the mechanisms how these effects are reached. Social interaction was found to be a key element in collaborative learning among students in the formal context (see (Baker, 1999; Jeong \& Chi, 2007) for an overview). But, it is 
unlikely that this complex process of collaboration between students stops outside the "classroom" (Morone \& Taylor, 2004). In other words, social interaction outside small groups or classroom is likely to influence students' learning processes in addition to the formal education (Hafferty, 1998). Some studies have claimed that informal or non-formal learning is important, but how important it is, and in what way it can exert its influence on student learning is unfortunately still unknown (Barron, 2006; Bransford et al., 2005; Marsick \& Watkins, 2001).

Good indications that informal social interaction has a large influence on learning, can be derived from studies in anthropology, mathematics and economics, using the "network approach" (see (Katz, Lazer, Arrow, \& Contractor, 2004) for an overview). Networks are present everywhere, defined as links between telephone wires or brain cells for example (Scott, 2000). Social networks are networks between persons, with a broad range of the type of interpersonal relations, such as communication ties (who talks to whom), formal ties (who reports to who) or affective or kinship ties (who likes whom) (Hatala, 2006; Katz et al., 2004; Scott, 2000). The network approach in many contexts, which converge on the notion that a persons' behaviour is mainly the result of the web of relationships around him/her, as these relationships provide opportunities and impose constrains on people's behaviour (Katz et al., 2004; Wellman, 1988). In other words, the network approach views individuals as interdependent, taking into account a person's resources, information flow and relationships. Using this network approach, quite a few studies have confirmed that persons with many connections are also the persons that learn the most or perform better within organizations (see (Cross, 2000) for an overview). In medicine, the network approach has been used amongst others, to study the diffusion and dissemination of innovations. Coleman et al. (1966) was the first to find that the diffusion of a new tetracycline-based medication among physicians was based on the physician's social network; the stronger the ties of a particular physician, the more likely the physician was to be an early user of this new drug (Coleman, Katz, \& Menzel, 1966). More recent studies underlined the finding that social networks are critical for the sustainability of health care innovation (Fattore, Frosini, Salvatore, \& Tozzi, 2009; Jippes et al., 2010). All these studies emphasize the informal social side of learning within organizations and medical practice. Does this also apply to students? In other words, do students learn from informal social interaction, besides the formal interaction (e.g. interaction in tutorial groups) that students are involved in?

Surprisingly, researchers in the educational field have not tested this idea en masse. To the best of our knowledge, only three studies have investigated the influence of social networks in face-to-face educational programmes on student learning (Baldwin, Bedell, \& Johnson, 1997; Mayer \& Puller, 2008; Thomas, 2000). The first study (Baldwin et al., 1997) found that individuals, who had many friends among the 304 first year students within an Masters of Business Administration course, had the highest grades. The same was found for the students who asked many other students explicitly for advice or help. These results imply that social networks among 
fellow students, substantially influenced student learning in this MBA programme. Thomas (2000) studied how social networks influenced students' feelings of integration and student persistence based on Tinto's model. He found that social networks are a pool of social and academic resources for students. The most recent study, (Mayer \& Puller, 2008), studied students' "friends" or social networks on Facebook.com within their university campus. These researchers found that the average friends' grade point average (GPA) was strongly associated with his/her own GPA.

Besides not distinguishing formal and informal interaction between students, what was not addressed by the previous studies on social networks and learning is the connection with the generally known variables affecting student learning: students' social integration, academic motivation and prior performance. These variables might confound the association between social networks and learning. For example, family and friends of first-year students were found to give a feeling of "social integration" within the students' academic surroundings, which was in turn positively associated with higher performance (Severiens \& Wolff, 2008; Tinto, 1975; Wilcox, Winn, \& Fyvie-Gauld, 2005). Friendships might thus diffuse knowledge or affect student behaviour following the network theory, which was found by (Thomas, 2000). At the same time, friendships might provide social support resulting in a context that facilitates learning. Therefore, social networks might confound with feelings of social integration while researching student learning.

Students' individual motivation to learn is another strong predictor of student learning (Ryan \& Deci, 2000; Vallerand \& Pelletier, 1993). Recently, students' academic motivation was shown to be socially constructed; e.g. social relationships such as peers influence students' motivation to learn (Järvelä, Volet, \& Järvenoja, 2010; Wentzel, 2005). Another study showed that students with merely intrinsic motivation built different social networks compared to students who were mainly extrinsically motivated (Rienties, Tempelaar, van den Bossche, Gijselaers, \& Segers, 2009). As such, social networks seem to be intertwined between student learning and academic motivation.

A third confounding variable is prior performance, as this variable is an important predictor of students' university performance in medical students (Lumb \& Vail, 2004). The question remains if social networks induce learning directly, as Baldwin et al. (1997) study suggested, or if students built different social networks based on students' performance, which might be the case in Mayer and Puller (2008) study and explains why the GPA's among friends were so homogeneous.

Thus, there are several possible confounding variables that need to be taken into account while studying students' social interaction and learning. At the same time, we also need to take into the account the reciprocal relationships between social networks student learning and the confounding variables in the analyses. 
To conclude these paragraphs, there are several indications that collaboration between (medical) students in the informal context could increase student learning. However, there are socially constructed variables, e.g. motivation and integration that could have direct and indirect effects on student learning and social networks and have not been taken into account in other studies. As social networks have previously been shown to provide insights into one's social relationships and performance in other disciplines, this method seems to be very suitable to study informal learning. Hence, we researched the following two questions to increase our understanding on what really matters in the students' learning process using social network analysis: 1) To what extent do social networks increase student learning independently from academic motivation, social integration and prior performance? 2) How does the effect of social networks on students' learning relate to the previously mentioned possible confounders?

\section{Method}

\section{SETTING}

The study took place at Maastricht University medical school in The Netherlands. This school offers a six-year undergraduate-entry medical course with a Problem Based Curriculum since 1974 (Graaff \& Post, 1985). Due to the great number of students wanting to study medicine, students are selected through a national lottery system, with higher chances for students with a high Grade point average (GPA). Only students with a GPA of 8.0 or higher (range 0 to 10) can enter the medical school without having to take part in the lottery system (about $20 \%$ of the medical students). The first three years compromise the preclinical curriculum and is organised in modules of six to ten weeks. The basic element in these first three years is the tutorial groups. These groups consist of 8-11 students, resulting in a varying group composition after every module. Lectures, skill trainings and anatomy sessions complement the tutorial groups.

\section{PARTICIPANTS}

The first year students ( $n=301$ ) were asked to participate into this study, after they had completed 10 months of their first year in our medical school.

\section{TESTS AND MEASUREMENTS}

Social networks A specific methodology has been developed for social network studies. This social networks methodology defines social networks as a set of actors or individuals ("nodes") and the interrelationships ("ties"). Of course, networks can stretch almost indefenitely, therefore social network analysis requires the researchers to specify boundaries (Knoke \& Yang, 2008). For our study, we have focussed on the informal networks of first year medical students. In social network methodology, this is denoted as a closed egocentric network. 
Three network types were assessed (see Table 1) relating to friendships, giving and receiving information, while providing students with a list of names from students within the complete year group, following Marsden (Marsden, 1990). To increase validity, explicit timing was included (e.g. "during this module, I gave information to the following students"). A pilot tested the survey.

Table 1: $\quad$ The three (translated) questions to collect the relational data. Students were provided with a list of within the complete year group. Names could be added if the students were not found on this list

- Please indicate which of your fellow students are good friends of yours. For example, people with whom you go for a coffee or to the theatre with.

- Please indicate which of your fellow students have been important sources of school-related information, outside the tutorial groups, yet during the current module. Getting information from another could have occurred in various ways, for example someone gave you a summary or shared the learning goals of his/her tutorial group.

- Please indicate to which of your follow students you have given school-related information outside the tutorial groups, yet during the current module. Providing information can occur, for example, if you have answered someone else's questions.

Friendship networks explore passive information diffusion, while communication networks have a more instrumental nature (e.g. asking explicitly for help on a certain topic) (Ibarra \& Andrews, 1993; Katz et al., 2004). Two communication networks were assessed: "giving information" and "getting information". Receiving information was assessed since this directly represents information acquisition, while providing other students with information, was regarded as an active process of elaboration, which has been shown to induce learning (Webb, Troper, \& Fall, 1995).

Tie strength can cause differences in information flow (Grannovetter, 1973). For example, "being friends" as a binary representations (yes/no), might differ among students due to differences in participants' definition (Scott, 2000). Therefore, just showing the ties between persons, while not taking into account the value of these ties, might result in a loss of valuable information and could even be misleading (Freeman, 1991). Therefore, tie strength was assessed. In the communication networks, we assessed students' value of the information that was given or received, measured on a Likert scale. The range to describe the value of the information was: 'not really valuable' (1) to 'very valuable' (5). In the friendship network we assessed the same dimension. However, due to the passive nature of the information diffusion, the value dimension was termed "intensity of the friendship" with a range: 'not really intense' (1) to 'very intense' (5).

Academic motivation The students' academic motivation was measured by the Academic Motivation Scale (AMS), developed by (Vallerand et al., 1992). This scale was developed for university students and consists of 28 items. The AMS is divided into seven subscales, of which three belong to intrinsic motivation scale, three to extrinsic motivation scale and one for a- 
motivation. These scales constitute a motivational continuum reflecting the degree of self-determined behaviour. The Cronbach alpha for the seven items ranged from 0.73 to 0.85 , which is in line with previous studies (Rienties et al., 2009; Vallerand et al., 1992). A relative autonomy index (RAI) (Grolnick \& Ryan, 1987) was computed based on the seven scales. A high score reflects high autonomous academic motivation and has been used by several studies (Black \& Deci, 2000).

Social integration We used the College Adaptation Questionnaire (CAQ), originally constructed in Dutch by (Crombag, 1968). It is a self-reporting instrument and consists of 18 statements, scored on a 7-Likert scale (range: (1) 'I do not agree at all' to (7) 'I fully agree'). Ten of the items reflect poor adjustment (e.g., "I find it hard to get used to life here") and eight items reflect good adjustment (e.g., "I am glad that I came to study here"). The score for the CAQ is the sum of the items representing good adjustment, minus the sum score on the items indicating poor adjustment. Previous studies have reported the CAQ to be highly consistent, $\alpha=0.83$ (van Rooijen, 1986). In this study the Cronbach's alpha was 0.89 .

Prior performance In our study we have used the category indicator for the grade point average (GPA) achieved at the end of secondary school as a measure of prior performance.

Student learning While students were explicitly asked with whom one shared information with, during one module, student' learning was quantified by performance on the module test (1-10). This factual knowledge orientated test was a written exam, with multiple-choice questions. There were 15 themes, encompassing "unconsciousness"; including basic medical knowledge on physiology, pharmacology anatomy, clinical examination, radiology and pathology. The test items $(n=100)$ had a high reliability (Cronbach $\alpha=0.79$ ).

\section{Procedure}

We approached the students during an obligatory curricular activity: the tutorial groups. If students were absent in their group, they were contacted through email and asked to fill in the questionnaire online. We used this approach, because missing data have considerable negative effects on social network analysis (Huisman, 2007), since interpretations of social network relations rely heavily on the assumption that the presence or absence of ties are identified (Gile \& Handcock, 2006).

Two sessions, one week apart, were planned during the tutorial groups. During the first session, the academic motivation and academic integration scales were administered. In the penultimate week of the module, the social networks questionnaire was assessed. Both survey sessions lasted 15 minutes. First, written information on the aims of the research was given, followed by a description of the survey. Students were assured that the collected data were strictly confidential and 
only used for research purposes. Second, students were asked for written informed consent to participate.

Ethical approval was obtained from the educational management board of the Faculty as educational research is exempted from the Medical Ethics Committee and a national ethics committee for research in the field of medical educational was still under construction when this study commenced.

\section{StATISTiCAL ANALYSES}

Centrality is the construct we used to quantify the relatedness to other students in the social networks (Knoke \& Yang, 2008; Scott, 2000). An actor's centrality reflects one's connectivity to other actors in the network and was calculated using UCINET (Borgatti, Everett, \& Freeman, 2002), a social network software programme. From the various types of centrality that have been described in the literature, we used Freeman's degree centrality for valued data (Freeman, 1991). This type of centrality indicates that students with many \& strong relations are the prominent actors in the network (Freeman, 1978). To eliminate the effect of the network size, we used the normalised score, which divides the centrality score by the maximum number of possible connections with the other actors.

We visualised the social networks of students using Pajek (Bategelj \& Mrvar, 1996, 2010), a programme designed to graph large social networks. Using the 'KamadaKawai' algorithm, the nodes were projected in such manner that they hardly showed overlap, facilitating interpretability.

PART 1: SOCIAL NETWORKS AND STUDENT LEARNING

Once centrality was calculated for all first year students in the "friendship", "giving information" and "getting information" networks, regression analyses using STATA (StataCorp, 2010) were used to detect if centrality within the social network increased students' performance. The centrality measures in all three measures were used as the independent variables and students' performance as the dependent variable. All analyses were controlled for social integration, academic motivation, prior performance, gender and age.

PART 2: UNDERSTANDING THE ASSOCIATION BETWEEN SOCIAL NETWORKS, MOTIVATION, INTEGRATION, PRIOR PERFORMANCE ON STUDENT' LEARNING

To identify the relations between students' performance, social integration, academic motivation, prior performance and social networks, as is depicted in Figure 1 , the structural equation modelling programme Amos (Arbuckle, 1983-2008) was used. 


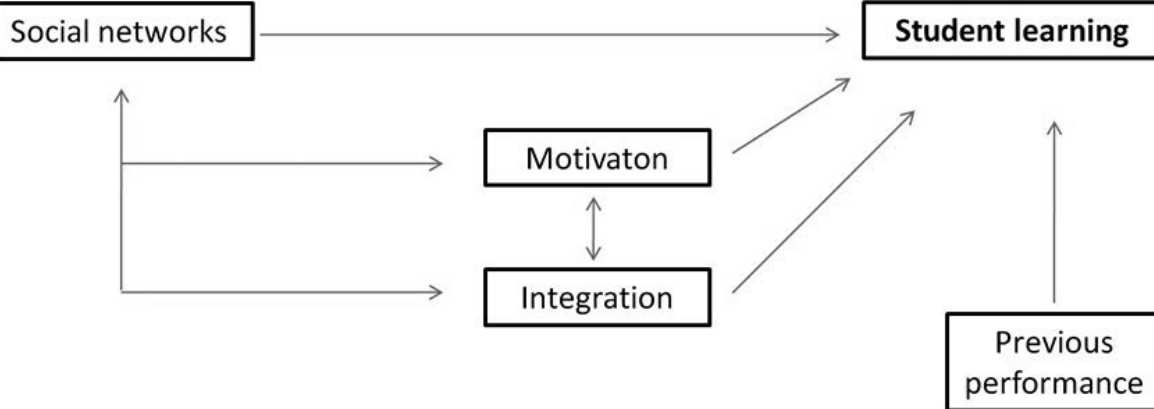

Figure 1: Social networks have been shown to increase student learning. In addition, academic motivation, social integration and prior performance have been shown increase student learning as well. In addition, motivation and social integration have shown to be socially constructed, which might cause indirect effects of social networks on student learning.

Structural equation modeling combines multiple regression and path analysis to enable testing of the causal relations in a hypothetical model (MacKinnon, 2008). Amos produces several goodness-of-fit criteria indicating how well the tested model "fits" the data, while taking into account the covariance and variance structures. The coherence of the following commonly used measures, indicated the model-fit (Humphris, 2002; Violato \& Hecker, 2007):

- $\quad$ Chi square goodness of fit value provides a level of significance (p). In order not to reject the model, the $p$-value should be higher than 0.05 .

- Chi square (minimum discrepancy) divided by the degrees of freedom (CMIN/DF) should be less than 3 and preferably close to 1 for correct models.

- Comparative fit index (CFI) compares the fit of the model under test with a model in which none of the variables are related. A CFI value of $\geq .90$ indicates that the model fits the data well.

- $\quad$ The root mean square error of approximation (RMSEA) includes the degrees of freedom, which might compensate for the effect of model complexity (Steiger, 1990). This value is required to be smaller than 0.05 .

\section{RESULTS}

From the 301 first year students (63.4\% female), 276 students (91.7\%) participated in the first session, while 260 students (85.7\%) participated in the second session. We dealt with the missing relational data following (Gile \& Handcock, 2006), treating the missing ties on the precise estimates of mutuality and other (full) network characteristics to fit from the observed data.

No data were lost. The demographics are listed in Table 2. 
Table 2: Demographics

\begin{tabular}{|lll|}
\hline & Mean & SD \\
Age (yrs) & 20.00 & 1.21 \\
Previous performance (1-5) & 3.07 & 1.19 \\
Course test results (0-10) & 7.10 & 0.99 \\
$\begin{array}{l}\text { Number of friends } \\
\text { Number of students giving } \\
\text { information to }\end{array}$ & 9.42 & 9.39 \\
$\begin{array}{c}\text { Number of students getting } \\
\text { information from }\end{array}$ & 3.73 & 3.38 \\
\hline
\end{tabular}

\section{PART 1: SOCIAL NETWORKS AND STUDENT LEARNING}

All three social networks increased students' performance on the module test, while statistically controlling for academic motivation, social integration, age, gender and prior performance (see Figure 2): Centrality within the friends-network $(\beta=0.11$, S.E. $=0.04 p=0.012$ ), centrality within the social network of providing information to fellow students $(\beta=0.16, S . E .=0.05, p=0.003)$ and centrality within the network of students receiving information $(\beta=0.25, S . E .=0.06, p<0.001)$. These findings cannot be explained by compensation behaviour of students using informal social interaction if they did not learn enough in their (formal) tutorial groups, as there was no (significant) association between the average students' perception of their tutorial group effectiveness and all three students' social network centralities.

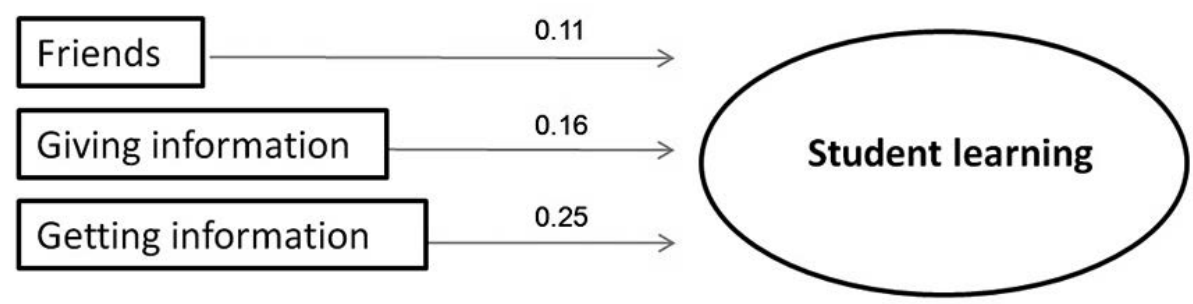

Figure 2: Centrality in the three social networks (friends, giving information and getting information from other students), increase student learning. The effects of social networks on student learning are also visually illustrated in Figure 3. 


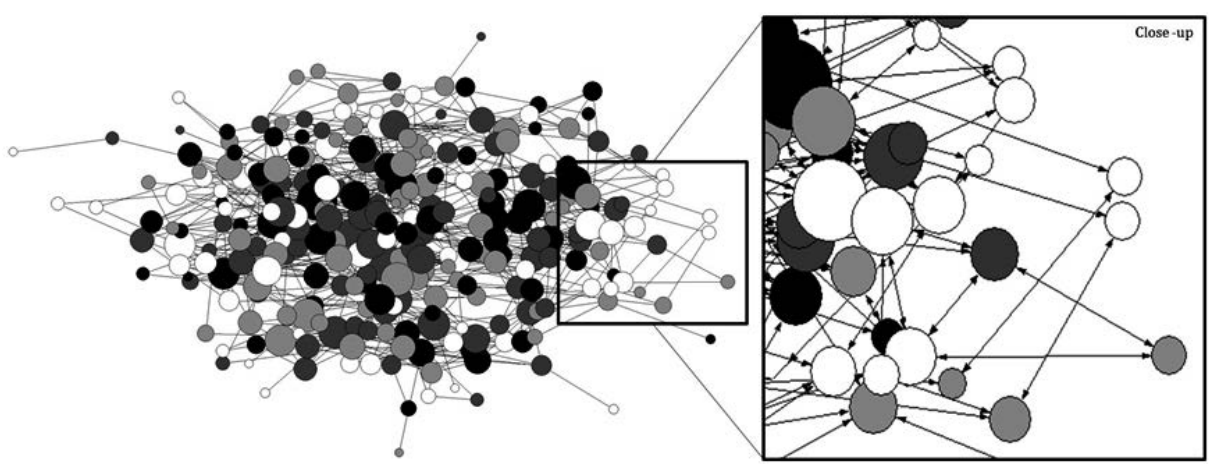

Figure 3: Visualization of how receiving information increase student learning.

This figure visualizes how students receive information from fellow students ('Get' network). Students that learned most are positioned more in the centre of the network and have more connections to others compared to students that learned less. The nodes represent the students and the arrows show the information flow among the students. The larger the node, the more information the student has gathered from other students and the more valuable the information. The colour of the node indicates the performance on the factual knowledge test. 'Black' nodes indicate the students with the highest quartile scores on the knowledge test (smart students), dark and light 'grey' represent the intermediate two quartiles and 'white' nodes represent the lowest scoring students (least smart students).

PART 2: UNDERSTANDING THE ASSOCIATION BETWEEN SOCIAL NETWORKS, MOTIVATION, INTEGRATION, PRIOR PERFORMANCE ON STUDENT' LEARNING

The model (Figure 1) consisted of paths from the independent variables social networks, academic motivation, social integration and prior performance; to the dependent variable, students' performance. The independent variable social networks represented a latent variable, composed of all three networks (friendships, giving and getting information). The model fit indicators showed that the model could use improvement $\left(\chi^{2}=31.38, p=0.003, \mathrm{CMIN} / \mathrm{df}=2.14, \mathrm{CFI}=0.95, \mathrm{RMSEA}=0.07\right)$. Modifications were made using a model trimming method (Ambramson, Rahman, \& Buckley, 2005; Ullman, 2006). First, all theoretical paths were addressed to over-fit the model. Then, one parameter at a time was changed based on the modification indexes. Modifications of the proposed model were made based on theoretical possibilities, starting with removing the associations of academic motivation and social integration on student learning. Next, academic motivation was not associated with social networks, instead it was only associated with social integration $(\rho=0.73$, $\mathrm{S} . \mathrm{E} .=0.11, \mathrm{p}<0.01)$. Finally, prior performance was found to influence not only students' performance, but also students' centrality within the social networks $(\rho=0.14$, S.E. $=0.04, p<0.001)$. The modified model, as can be seen in Figure 4 , fitted the data quite well $\left(\chi^{2}=18.91, p=0.22, \mathrm{CMIN} / \mathrm{df}=1.26, \mathrm{CFI}=0.99, \mathrm{RMSEA}=0.03\right)$. 


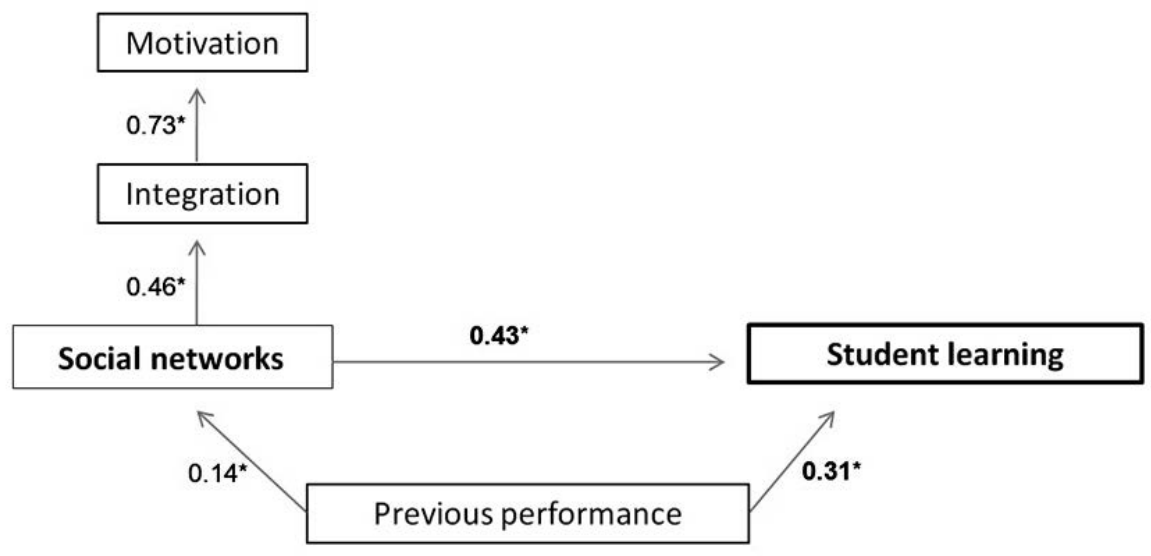

Figure 4: The modified model on the associations between social network and its confounders on students' performance. ${ }^{*} p<0.001$.

Although social networks were not associated with academic motivation, these networks did associate positively with students' social integration $(\rho=0.46$, S.E. $=0.13$, $\mathrm{p}<0.001)$. Moreover, social networks showed to have greater effects on student learning than prior performance $(\rho=0.43$, S.E. $=0.08, p<0.001$ and $\rho=0.31$, S.E. $=0.04$, $\mathrm{p}<0.001$, respectively).

\section{Discussion}

Worldwide education in health sciences involves collaborative learning techniques. While positive effects have been reported of this learning context, we researched the informal side of group interaction and student learning. In more concrete terms, this study assessed whether the informal social interaction or 'social networks' among undergraduate medical students, increased learning. A related research question was how other important influences on student learning; such as academic motivation, social integration and prior performance were related.

All three social networks increased student' learning significantly, even after controlling for academic motivation, social integration, age, gender and prior performance. This finding is not only in line with the notion that learning in inherently social (Levine \& Resnick, 1993), but more specifically with the literature stating that social interaction is a key element in the (collaborative) learning processes e.g. (Larson, 2009). Moreover, to the best of our knowledge, we are the first to quantify the impact of informal social interaction on learning. These results might make more sense while incorporating the wide variety of phenomena in which students might interact informally. Students might ask others explicitly for advice or help to complete learning goals or assignments. Yet, it might also consist of sharing 
(elaborations of) learning goals with students from other tutorial groups in order to ensure that their own group is on the right track. At the same time, passive knowledge diffusion occurs when reflecting one' activities, thoughts and university related experiences with friends.

A new model was identified in our search how the various socially important variables (academic motivation \& social integration) were associated with student learning. In this model, social networks were the strongest predictors for student learning followed by prior performance. In turn, prior performance was predictive of the strength of the social networks, indicating that the students with high prior performance were more central in the three social networks studied. In contrast to other studies (Severiens \& Wolff, 2008; Vallerand \& Pelletier, 1993), academic motivation and social integration were not predictive for student learning. Of course this could be explained by the fact that we are the first to include all variables in one model, instead of focusing on the relation between integration or motivation and student learning. This is supported by the finding that we did find a significant, but small association between academic motivation or social integration on student learning while omitting social networks in these analyses $(\beta=0.04$, S.E. $0.02, p=0.033$ and $\beta=0.09$, S.E. $0.04, p=0.023$ respectively). Another reason could be a difference in setting and participants; for example, the studies on motivation and performance were mainly based on undergraduate students within the United States and not among students in Medical school in a European setting.

Three studies have suggested associations between learning and social networks within (formal) educational contexts (Baldwin et al., 1997; Mayer \& Puller, 2008; Thomas, 2000). However, these studies did not make direct associations nor took into account other socially constructed variables, which are known to directly and indirectly influence student learning.. As such, this study has added new insights into what really matters in student learning amongst medical students, mainly emphasizing the importance of social networks and informal learning. These results are important since policy makers and curriculum designers might facilitate the development of these networks and as such might be able to influence student learning. One measure that would be supported by our findings would be increasing the frequency of collaboration with the same students to strengthen ties between students. Especially in large scale schools, with numbers of students up to $n=600$ in one class (Moust, Berkel, \& Schmidt, 2005), it is clear that students spend limited time collaborating, because they change groups frequently. At a first glance, meeting so many students during the year might seem as an advantage since students can construct very large networks. However, a network with mainly weak ties has been shown not to increase performance (Cross \& Thomas, 2008). Increasing the frequency of students meeting one another might help increasing the strength of students networks due to the fact that spending time together already causes feelings of relatedness (Baumeister \& Leary, 1995). And just these feelings of relatedness are needed to help one another (Bell, Grekul, Lamba, Minas, \& Harrell, 2001; Stewart-Williams, 2007). The implications for a collaborative learning context is 
that these feelings of interdependence among the students are essential in order to engage them in intensive collaborative learning (Johnson, Johnson, \& Smith, 2007). Besides the new insights this study has provided, it also has limitations. First, the diffusion or exchange of information amongst the first year students is measured as a subjective factor. Inherently to this self-reported measurement, three types of biases could have occurred which can reduce the reliability of the construct. First, students might have filled in the surveys according to what they thought the researcher desired them to answer. Secondly, errors of commission could have occurred by students introducing non-existent ties or over-estimations of their relationship(s). Finally, students could have forgotten to include important relations, causing an error of omission. Nonetheless, it can be argued that a self-reported measure needs to be used in this study as it captures students' perception of their social network. In order to study how (learning) behaviour is influenced by social networks it is essential to measure the perception of the (informal) social network relations, as behaviour only changes as a reaction of the perceived environment.

Instead of using valued data in the analysis, some network researchers prefer to convert the data into binary values. Furthermore, some researchers prefer other centrality measures than degree centrality such as betweenness centrality. In contrast to degree centrality, this type of centrality does not focus on the number of connections to others; it focuses on the actor's position within the network in the sense that it connects subgroups of students. In other words, if students withhold a brokers' position, these students have higher "betweenness centrality" measures (Scott, 2000). We tested if binary graphs or betweenness centrality would change our results and found that both the regression analyses as the model were similar to the described results. Next, student learning is represented as achievement by one knowledge test. This representation is, of course, too simplistic (Adams, 2006) although most universities do heavily rely on these performance measures (Kuh, Kinzie, Buckley, Bridges, \& Hayek, 2006). Since the test was acknowledged to be valid and reliable, we believe that this test was an appropriate representation of students' learning. Finally, since this research used an egocentric network (assessing only social networks among first-year students), we might have only grasped the tip of the iceberg, since most students (68.3\%) declared that they also shared information (on medical subjects) with others (e.g. family, mentor, medical students not in their first year).

Despite these empirical limitations, we feel that this study, contributes to the understanding of informal social interaction within learning. It indicates the importance of the informal side of social learning. As such, we may need to expand our focus to include the informal aspects of learning in the design and evaluation our education as was also suggested by Hafferty (1998). Future research will need to focus on how networks are constructed (why are students connected? How do students develop networks over time?) and what type of information is exchanged. At the same time, students in a PBL system are used to collaborate with fellowstudents. In a more traditional curriculum the association between informal social 
interaction and learning might be different. Insights into the influences of learning contexts might be provided when similar studies are done in another learning context. Moreover, using mixed methods or qualitative designs, studies might provide insights how informal social interaction facilitate student learning. With all these insights, it might be feasible to understand how educational institutes can influence students' social networks to increase learning. Next, studies may explore whether a change in educational design actually changes students' social networks and in the end increases student learning. Furthermore, social networks might also be used as an action research tool to increase understanding on student learning. In organizations, social networks analysis provides insights which persons hold valuable information or key positions. In education, social networks, might provide insights in which students could use some extra help to improve their learning process. Finally, in medical practice social network analysis might give valuable insights on how students or graduates learn in the workplace.

\section{CONCLUSION}

Social networks were positively associated with student learning, with greater strength than students' prior performance, academic motivation and social integration.

DECLARATION OF INTERESTS: NONE

FUNDING: NONE

\section{REFERENCES}

Adams, P. (2006). Exploring social constructivism: Theories and practices. Education 34(3), 243-257.

Ambramson, R., Rahman, S., \& Buckley, P. (2005). Tricks and traps in structural equation modelling: a GEM Australia Example Using AMOS Graphics. Paper presented at the ABBSA Conference, Cairns, Australia.

Arbuckle, J. L. (1983-2008). Amos (Version 17.0): Amos Development Corporation.

Baker, M. (1999). Argumentation and constructive interaction. In G. Rijlaarsdam, E. Esperet, P. Coirier \& J. Andriessen (Eds.), Studies in Writing (Vol. 5: Foundations of Argumentative Text processing, pp. 179-202). Amsterdam: University of Amsterdam Press.

Baldwin, T. T., Bedell, M. D., \& Johnson, J. L. (1997). The social fabric of a team-based M.B.A. program: Network effects on student satisfaction and performance. Academy of management journal, 40(6), 1369-1397.
Barron, B. (2006). Interest and self-sustained learning as catalysts of development: A learning ecology perspective. Human development, 49, 193-224.

Bategelj, V., \& Mrvar, A. (1996, 2010). Pajek: Program for analysis and visualization of large networks (Version 2.00). Ljubljana.

Baumeister, R. F., \& Leary, M. R. (1995). The need to belong: Desire for interpersonal attachments as a fundamental human motivation. The American psychological association, 117(3), 497-529.

Bell, J., Grekul, J., Lamba, N., Minas, C., \& Harrell, W. A. (2001). The impact of cost on student helping behavior. The journal of psychology, 135(1), 49-56.

Black, A. E., \& Deci, E. L. (2000). The effects of instructors' autonomy support and students autonomous motivation on learning organic chemistry: A self-determination theory perspective. Science Education, 84, 740-756.

Borgatti, S., Everett, M., \& Freeman, L. C. (2002). Ucinet: Harvard, MA: Analytic Technologies. 
Bransford, J., Vye, N., Stevens, R., Kuhl, P., Schwartz, D., Bell, P., Sabelli, N. (2005). Learning theories and education: Toward a decade of synergy. In P. Alexander \& P. Winne (Eds.), Handbook of educational psychology (2nd ed.). Mahway, NJ: Erlbaum.

Coleman, J. S., Katz, E., \& Menzel, H. (1966). Medical Innovation: A diffusion study. Indianapolis, USA: the Bobbs-Merril Company, Inc.

Crombag, H. F. M. (1968). Studiemotivatie en studieattitude. Groningen: J.B. Wolters.

Cross, R. (2000). More than an answer: How seeking information through people facilitates knowledge creation and use. Paper presented at the Academy of management conference, Toronto, Canada.

Cross, R., \& Thomas, R. J. (2008). How top talent uses networks and where rising stars get trapped. Organizational Dynamics, 37(2), 165-180.

Fattore, G., Frosini, F., Salvatore, D., \& Tozzi, V. (2009). Social network analysis in primary care: The impact of interactions on prescribing behaviour. Health Policy, 92, 141-148.

Freeman, L. C. (1978). Centrality in social networks. Conceptual clarification. Social networks, 1, 215239.

Freeman, L. C. (1991). Centrality in valued graphs: A measure of betweenness based on network flow. Social networks, 13, 141-154.

Gile, K., \& Handcock, M. S. (2006). Model-based assessment of the impact of missing data on inference for networks. Center for statistics and the social sciences, (working paper no.66). University of Washington, Seattle.

Graaff, d. E., \& Post, G. J. (1985). Farewell Maastricht the evaluation ex-students after six years problembased education (Vol. II). Maastricht: Network of community-oriented educational institutions for the health sciences, Rijksuniversiteit Limburg.

Grannovetter, M. (1973). The strength of weak ties. American journal of sociology, 81, 1287-1303.

Grolnick, W. S., \& Ryan, R. M. (1987). Autonomy in children's learning: An experimental and individual difference investigation. Journal of personality and social psychology, 52(5), 890-898.

Hafferty, F. W. (1998). Beyond curriculum reform: Confronting medicine's hidden curriculum. Academic medicine, 73(4), 403-407.

Hatala, J. (2006). Social network analysis in human resource development: A new methodology. Human resource development review, 5(1), 45-71.

Huisman, M. (2007). Imputation of missing network data: Some simple procedures. Paper presented at the International Sunbelt Social Network Conference XXVII.

Humphris, G. M. (2002). Communication skills knowledge, understanding and OSCE performance in medical trainees: a multivariate prospective study using structural equation modelling. Medical Education, 36, 842-852.

Ibarra, H., \& Andrews, S. B. (1993). Power, Social Influence, and Sense Making: Effects of Network Centrality and Proximity on Employee Perceptions. Administrative Science Quarterly, 38(2), 277-303.
Järvelä, S., Volet, S., \& Järvenoja, H. (2010). Research on Motivation in Collaborative Learning: Moving Beyond the Cognitive-Situative Divide and Combining Individual and Social Processes. Educational psychologist, 45(1), 15-27. doi: 10.1080/00461520903433539

Jeong, H. W. N., \& Chi, M. T. H. (2007). Knowledge convergence and collaborative learning Instructional science, 35, 287-315. doi: 10.1007/s11251-006-9008-z

Jippes, E., Achterkamp, M. C., Brand, P. L. P., Kiewiet, D. J., Pols, J., \& van Engelen, J. M. L. (2010). Disseminating educational innovations in health care practice: Training versus social networks. Social science \& medicine, 70, 1509-1517.

Johnson, D. W., \& Johnson, R. T. (2009). An educational psychology success story: Social interdependence theory and cooperative learning. Educational researcher, 38(5), 365-379.

Johnson, D. W., Johnson, R. T., \& Smith, K. (2007). The State of Cooperative Learning in Postsecondary and Professional Settings. Educational Psychology Review, 19, 15-29.

Katz, N., Lazer, D., Arrow, H., \& Contractor, N. (2004). Network theory and small groups. Small Group Research, 35(3), 307-332. doi $10.1177 / 1046496404264941$

Knoke, D., \& Yang, S. (2008). Social network analysis (2 ed.). Thousand Oaks CA, London, New Delhi, Singapore: SAGE publications Incl.

Kuh, G. D., Kinzie, J., Buckley, J. A., Bridges, B. K., \& Hayek, J. C. (2006). What Matters to Student Success: A Review of the Literature. Commissioned Report for the National Symposium on Postsecondary Student Success: Spearheading a Dialog on Student Success. National postsecondary education cooperative.

Larson, J. R. (2009). In search of synergy in small group performance (1 ed.). London: Psychology Press.

Levine, J. M., \& Resnick, L. B. (1993). Social foundations of cognition. Annual review of psychology, 44, 585612.

Lumb, A. B., \& Vail, A. (2004). Comparison of academic, application form and social factors in predicting early performance on the medical course. Medical education, 38, 1002-1005.

Mackinnon, D. P. (2008). Introduction to Statistical Mediation Analysis. London: Lawrence Erlbaum Associates.

Marsden, P. V. (1990). Network data and measurement. Annual review of sociology, 16, 435-463.

Marsick, V. J., \& Watkins, D. E. (2001). Informal and incidental learning. New directions for adult and continuing education, 89, 25-34.

Mayer, A., \& Puller, S. L. (2008). The old boy (and girl) network: Social network formation on university campuses. Journal of public economics, 92, 329-347.

Michaelsen, L. K., Parmelee, D., McMahon, K. K., \& Levine, R. E. (2008). Team based learning for health professions education. Sterling, Virginia, USA: Stylus Publishing, LLC. 
Morone, P., \& Taylor, R. (2004). Knowledge diffusion dynamics and network properties of face-to-face interactions. Journal of evolutionary economics, 14, 327-351. doi: 10.1007/s00191-004-0211-2

Moust, J. H. C., Berkel, H. J. M., \& Schmidt, H. G. (2005). Signs of erosion: Reflections on three decades op problem-based learning at Maastricht University. Higher Education, 50, 665-683.

Rienties, B., Tempelaar, D. T., van den Bossche, P., Gijselaers, W. H., \& Segers, M. (2009). The role of academic motivation in computer supported collaborative learning. Computers in human behavior, 25(6), 1195-1206. doi: 10.1016/j.chb.2009.05.012

Ryan, R. M., \& Deci, E. L. (2000). Self-Determination Theory and facilitation of intrinsic motivation, social development and well-being. American psychologist, 55(1), 68-78.

Scott, J. (2000). Social network analysis - A handbook (2 ed.). London, Thousand Oaks CA, New Delhi: SAGE publications Ltd.

Severiens, S. E., \& Wolff, R. (2008). Study success of ethnic minority students. In M. Tight, M. Huisman, K. H. Mok \& C. Morphew (Eds.), Handbook of higher education: Routledge.

Simons, R.-J., van der Linden, J., \& Duffy, T. (2000). New learning. Dordrecht, the Netherlands: Kluwer Academic Publishers.

StataCorp, L. (2010). Stata (Version 11.1). Texas, USA: Stata Corporation.

Steiger, J. H. (1990). Structural Model Evaluation and Modification: An interval estimation approach. Multivariate behavioral research, 25(2), 173-180.

Stewart-Williams, S. (2007). Atruism among kin vs. nonkin: effects of cost of help and reciprocal exchange. Evolution and human behavior, 28, 193198.

Thomas, S. L. (2000). Ties that bind: A social network approach to understanding student integration and persistence. The journal of higher education, 71(5), 591-615.
Tinto, V. (1975). Dropout from higher education: A theoretical synthesis of recent research. Review of educational research, 45(1), 89-125.

Ullman, J. B. (2006). Structural equation modelling: Reviewing the basics and moving forward. Journal of personality assessment, 87(1), 35-50.

Vallerand, R. J., \& Pelletier, L. G. (1993). On the assessment of intrinsic, extrinsic, and amotivation in education: Evidence on the concurrent and construct validity of the academic motivation scale. Educational and psychological measurement, 53(1), 1-10.

Vallerand, R. J., Pelletier, L. G., Blais, M. R., Brière, N. M., Senécal, C., \& Vallières, E. F. (1992). The academic motivation scale: A measure of intrinsic, extrinsic, and amotivation in education. Educational and psychological measurement, 52, 1003-1017.

van Rooijen, L. (1986). Advanced students' adaptation to college. Higher education, 15, 197-209.

Violato, C., \& Hecker, K. G. (2007). How to use structural equation modeling in medical education research: a brief guide. Teaching and learning in medicine, 19(4), 362-371.

Webb, N. M., Troper, J. D., \& Fall, R. (1995). Constructive activity and learning in collaborative small groups. Journal of educational psychology, 87(3), 406-423.

Wellman, B. (1988). Structural analysis: From method and metaphor to theory and substance. . In B. Wellman \& S. Berkowitz (Eds.), Social structures: $A$ network approach (pp. 19-61). Cambridge, England: Cambridge University Press.

Wentzel, K. R. (2005). Peer relationships, motivation, and academic performance at school. In A. J. Elliot \& C. S. Dweck (Eds.), Handbook of competence and motivation (pp. 279-296). New York: Guilford Press.

Wilcox, P., Winn, S., \& Fyvie-Gauld, M. (2005). 'It was nothing to do with the university, it was just the people': The role of social support in the first-year experience of higher education. Studies in higher education, 30(6), 707-722. doi: $10.1080 / 03075070500340036$ 


\section{CHAPTER 4}
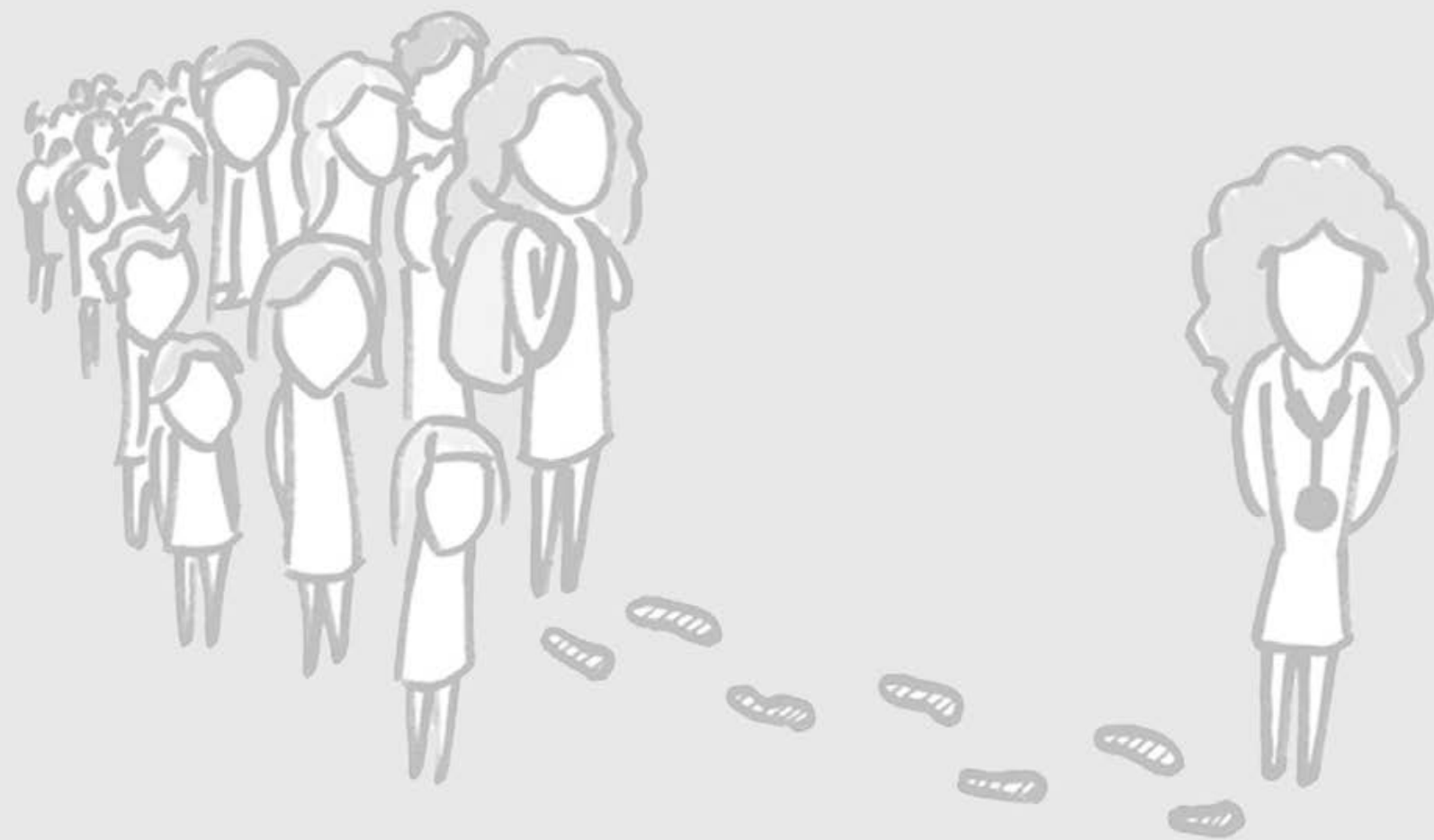


\section{The impact of the instructional design on informal learning with fellow students over time}

J. Hommes ${ }^{1}$, B. Rienties ${ }^{2}$, W. de Grave ${ }^{1}$, G. Bos ${ }^{1,3}$, L. Schuwirth ${ }^{4}$, A. Scherpbier ${ }^{1}$.

1. Department of Educational Development and Research, Faculty of Health Medicine and Life Sciences, Maastricht University, The Netherlands.

2. Centre for Educational and Academic Development, University of Surrey, Guildford, United Kingdom.

3. University Hospital Maastricht, Department of Internal medicine, Haematology, The Netherlands.

4. Flinders Innovation and Clinical Education, Flinders Medical School, Flinders University, Adelaide, Australia. 


\section{ABSTRACT}

Groups are today's learning units in modern instructional designs. Although interaction in groups can be a key enabler for the students' learning processes, limited studies have investigated how students learn within-and outside groups over time. This study explored how students learned with fellow students over time in the informal context and how the instructional design and other factors influenced with whom students interacted in informal context. An innovative mixed methods longitudinal design of repeated social network analyses depicted development of interaction amongst 322 students over a period of 22 months, which were complemented with semi-structured interviews amongst 75 students divided over two time periods. The results indicate that students' informal learning networks first increased, and then decreased in the second half of the second curriculum year. The effect of the instructional design on learning networks faded over time, whereby students developed learning relations based upon similarity and proximity. These results indicate that the power of the instructional design on group learning may be limited in time. More research is needed to understand the informal learning processes taking place outside the formal classroom.

\section{INTRODUCTION}

Groups have become today's learning units in modern educational contexts. Research has focussed on the instructional design directing students to learn within groups formally composed by the educational programme. At the same time, researchers have highlighted the importance of learning outside the formal context (Tinto, 2000). This study focuses on learning among students in the informal context, defined as learning taking place in contexts that are not organised by a formal institution, in our case our medical school.

\section{LEARNING THROUGH INTERACTION}

The synergy of groups over individual learning is ascribed to the interaction processes between group members (Larson, 2009). The precise mechanism of these interaction processes on knowledge acquisition has been the focus of many studies, e.g. van Blankenstein et al (2009), Jeong \& Chi (2007) and van den Bossche et al (2011). Meaningful cognitive discourse and negotiation were shown to be key group processes (Chan, 2001; van Boxtel, van der Linden, \& Kanselaar, 2000; VisschersPleijers, Dolmans, de Leng, Wolfhagen, \& van der Vleuten, 2006). In other words, social interaction between group members can reveal contradictions, inconsistencies and limitations of a learner's explanations (Lehtinen, Hakkarainen, Lipponen, Rahikainen, \& Muukkonen, 1998). Contemporary instructional designs apply these insights using groups as the learning units to provide a platform for social interaction to facilitate learning among students (Dochy, Segers, Van den Bossche, \& Gijbels, 2003). 
Besides enhanced cognition group learning has several positive, sometimes indirect effects on students' behaviour. First, interaction among members provide socially constructed motivation within and outside the group (Järvelä, Volet, \& Järvenoja, 2010), which is more than the sum of all participants' motivation (Hickey, 2003). Group learning designs stimulate students' intrinsic motivation to learn which in turn increases learning (Rotgans \& Schmidt, 2011). Second, groups provide a platform for the development of friendships among students (Schmidt, Rotgans, \& Yew, 2011), which might be a reason why innovative group learning instructional designs face low attrition rates (Schmidt et al., 2011; Wilcox, Winn, \& Fyvie-Gauld, 2005). Finally, positive 'extra' effects such as collaborative and communicative skills are acquired, fostering important skills needed for successful participation in the future workplace (Baldwin, Bedell, \& Johnson, 1997; Deeter-Schmelz, Norman Kennedy, \& Ramsey, 2002). Consequently, a wide variety of empirical studies indicate that groups are an effective method for the participants to learn (Decuyper, Dochy, \& van den Bossche, 2010).

Most disciplines conceptualise groups as complex and dynamic 'living' social systems (Hackman, 1992) which change over time (Arrow \& Cook, 2008; Roe, 2008). Groups are composed of participants who bring beliefs, values, attitudes and motivation which dynamically influence the groups' interaction processes (Argote, McEvily, \& Reagans, 2003; Arrow, Poole, Bouas Henry, Wheelan, \& Moreland, 2004; Dreu \& Weingart, 2003; Harrington \& Fine, 2006; Homan, van Knippenberg, van Kleef, \& de Dreu, 2007). Individuals differ over time, and so do groups (Cronin, Weingart, \& Todorova, 2011) since "groups learn how to learn" (Sweet \& Michaelsen, 2007). Finally, groups do not occur in a vacuum; instead, the social context also has a large impact on the participants and the group processes (van den Bossche, Gijselaers, Segers, \& Kirschner, 2006). For example, assessment is a contextual factor influencing a person's task motivation and at the same time, assessment can give shape to the group's interaction process (Decuyper et al., 2010; Gijbels, Dochy, van den Bossche, \& Segers, 2005).

In the quest to understand group learning, complexity arises when participants can belong to several groups at the same time, in particular when these groups of learners learn from other groups. In other words: "Students don't stop learning when stepping outside the classroom door" (Morone \& Taylor, 2004). Thus, the complex and dynamic processes of learning does not only occur within formal groups, participants can also learn from other participants or groups (i.e. informal learning) (Akkerman \& Bakker, 2011; Decuyper et al., 2010). In contrast to the typical view of (formal) groups in literature of instructional design, groups can be regarded as 'open systems'. However, not much is known about interaction and learning among students in the informal context and how the instructional design might encourage both formal and informal learning processes (de Laat \& Lally, 2003; Decuyper et al., 2010; Rienties, Hernandez Nanclares, Hommes, \& Veermans, 2013).

THE IMPORTANCE OF INFORMAL LEARNING

Research in other disciplines than education has already found substantial support for the notion of informal learning across and/or between groups and organisational 
boundaries (Akkerman \& Bakker, 2011). In the organisational sciences researchers have shown that the majority of workers learn outside formally organised learning events. Informal learning in this field is generally defined as an unstructured process that occurs continuously, the majority of learning is experiential, non-institutional, driven by people's choices, preferences and intentions (Marsick \& Watkins, 2001). Colleagues are a main source of information to learn how to solve complex problems and to perform in the work place (Cross, Borgatti, \& Parker, 2002; Cross, Laseter, Parker, \& Velasquez, 2006). In the workplace, informal learning has a larger impact on the overall learning process than formal learning, such as workshops or training programmes (Tannenbaum, Beard, McNall, \& Salas, 2010). In other words, informal learning drives the charts in firms (Krackhardt \& Hanson, 1993).

Moreover, external knowledge is crucial for innovation within organisations (Capello, 1999; Capello \& Faggian, 2005). "Knowledge spillovers" are the external inputs to groups within organisations. For example, increased transfer of information across departments was found when the participants of various departments interacted (Bresman, 2010; Edmondson, Winslow, \& Bohmer, 2003; Hsiao, Tsai, \& Lee, 2012; Levina \& Vaast, 2005; Tortoriello \& Krackhardt, 2010). Crossing boundaries between groups should thus be stimulated to increase efficacy and innovation within groups and the informal context is usually where these interrelations between groups take place (Moolenaar, Sleegers, \& Daly, 2012).

\section{INFORMAL LEARNING AMONG STUDENTS IN HIGHER EDUCATION}

Learning in the informal learning context is defined as 'out-of-class behaviour' and according to Tinto, interaction among peers in the academic society is important for persistence in university (Tinto, 2000). Although most forms of informal learning in the educational context are typically limited to the use of learning from school excursions to (science) museums which are expected to add to formal education (Gerber, 2001; Judson, 2012) and peer learning activities outside the formal context (Topping, 2005). Few studies investigated informal learning as 'out-of-classbehaviour' in higher education. For example, Tang (1993) examined students who worked collaboratively with fellow physiotherapy students and found 'spontaneous collaboration' between these students. This 'spontaneous collaboration' was neither structured by teachers nor the instructional design, but it was found to promote deep learning strategies, leading to better outcomes of assignments compared to individually preparing students (Tang, 1993). Yan and Kember (2004) furthermore found that two types of out-of-class groups were constructed; the avoider type of group, referring to groups that collaborate in order to save time and effort on assigned academic tasks, versus the engager type of groups, who cooperate and reach a better understanding on course materials (Yan \& Kember, 2004). Hommes et al. (2012) added towards this topic using social network analyses to show the impact of informal learning in a face-to-face medical programme. In this study, these authors found that medical undergraduate students who (informally) shared schoolrelated information with other students achieved higher grades.

Although informal learning in higher education might not have been extensively 
investigated theoretically and empirically, innovative instructional designs often incorporate the informal learning context in their formal design and might encourage these boundary crossing activities by providing students with sufficient time to selfstudy (Yew \& Schmidt, 2010), authentic and complex tasks enabling group learning (La Rochelle et al., 2011; Rotgans \& Schmidt, 2011; Taylor \& Miflin, 2008), and assembling groups in which students learn (Curşeu \& Pluut, 2011; Rienties, Alcott, \& Jindal-Snape, 2014; Summers \& Volet, 2008). For example, a quasi-experimental study by Rienties et al (2014) amongst 138 post-graduate business students found that students who were randomised to groups did not only develop strong relations with students in the formally composed group after collaborating for fourteen weeks, these students also interacted more with students outside these formally arranged groups. Thus formal group composition directs boundary crossing between formal study groups in both the formal and informal learning context (Rienties et al., 2014). In a study amongst 159 groups Curşeu \& Pluut (2011) also found that mixing students with different characteristics had a substantial impact how groups learned from other groups.

Thus, informal learning has not yet received much thorough evidence-based attention in the educational literature. Moreover, while groups are conceptualised as complex dynamic 'living' social systems (Hackman, 1992) which change over time (Arrow \& Cook, 2008; Roe, 2008), how time might influence the process of informal learning has not been extensively explored. Finally, the impact of instructional design on learning in the informal context with fellow students has received limited empirical attention.

\section{AIMS OF THIS STUDY}

This study aimed to increase our understanding of learning processes in the informal context in higher education, in particular in a medical school using the ProblemBased Learning environment. Therefore, the quantitative part employs a longitudinal design to gain a dynamic perspective into the development of informal learning processes over time, using the following two research questions:

R1: What is the influence of time on informal learning networks among students? R2: What is the influence of the instructional design on the development of informal learning networks among students?

To further enhance our understanding on the factors influencing the development of informal learning networks over time, a qualitative study explored our third research question:

R3: Which other factors influence the development of informal learning networks? 


\section{MethodS}

\section{RESEARCH DESIGN}

For a deeper understanding of the dynamics of informal interaction among students a combination of quantitative and qualitative studies are necessary. For example, Rienties et al (2013) explored cohesion among students in a culturally diverse class using pre- and post-test social network analyses combined with focus groups providing a richer understanding of the international classroom using a mixed methods design. In line with recommendations of Cronin et al. (2011) Daly et al (2009) and Rienties et al. (2013), this study will employ an explanatory mixedmethods design (Creswell, 2009) to gain an understanding of the development of informal learning and its relation towards the formal group structures. First, a quantitative longitudinal social-networks study observed the structure of interactions among students over time in the informal context and the association towards the formal group structures. Second, a consequential qualitative study generated an indepth understanding of the development of informal interaction among students and the dynamics of this informal interaction. In the discussion, the results of both studies will be merged to complete the interpretation on the development of informal interaction and the relation to formal group structures over time.

\section{CONTEXT AND STUDY POPULATION}

This study was conducted in class of undergraduate-entry medical students at Maastricht University. This university has been applying Problem-Based Learning (PBL) since 1974. In a PBL curriculum students learn in small groups (tutorial groups) of 10-12 students. These groups are provided with a range of medical scenarios. A facilitator, the tutor guides the group of students (Gijbels et al., 2005; Hmelo-Silver, 2004; Schmidt, 1984). In our university, students meet twice a week for two hours. Students are stimulated to activate their prior knowledge when discussing the problem in the tutorial group sessions. Next, the students need to identify knowledge gaps and to formulate specific learning goals. Following the first tutorial session, the students study independently to acquire the knowledge and skills required prior to the next tutorial session. In this next session, the groups elaborate on the knowledge acquired; allowing students to critically ask one another questions and discuss contrasting ideas.

These tutorial group sessions shape the main element of group learning. Lectures and skills training sessions complement these tutorial groups. On average, students devote sixteen hours per week to formally organised educational activities.

Students progress through the medical programme in a set chronological order; so all students were involved in the same modules during the year. Students were allocated to tutorial groups anew for every module by the educational institute, except for module 1 and module 2, whereby students remained in the same group composition. The class or study cohort was composed of 322 students ${ }^{1}$. These 
students started in September 2010 with 63.7\% female with a mean age 19.4 years. Six of the 322 students were re-takers. Progressing towards the second curriculum year, 304 students ( $n=24$ re-takers) were involved in the class, of which $63.8 \%$ was female with a mean age of 20.4 years.

\section{INSTRUMENTS}

\section{QUANTITATIVE STUDY}

Learning among students in the informal learning context was quantified by longitudinal social network analyses. These networks define student learning as interaction between a set of individuals (Scott, 2000) and have shown to be quite useful to quantify and visualise interaction patterns among students e.g. HmeloSilver \& Chernobilsky (2008). Three network types were used to assess social interaction among students outside curricular activities: friendships, giving and receiving module-related information. Friendship networks explored passive information diffusion, while communication networks had an instrumental nature (e.g. asking explicitly for help on a certain topic) (Ibarra \& Andrews, 1993; Katz, D., Arrow, \& Contractor, 2004).

Students were provided with a list of names attending the medical programme in the same class (Hommes et al., 2012; Marsden, 1990). To increase validity of the information explicit timing was included. Tie strength, the value of the information that was given or received respectively, or the intensity of friendships, was measured on a Likert scale ranging from 'not valuable' (1) to 'very valuable' (5). A previous study provided validity evidence for this method (Hommes et al., 2012).

\section{QUALITATIVE STUDY}

Two interviewers conducted semi-structured individual interviews focusing on development of students' informal learning networks. Students were randomly invited to attend an interview, whereby $n=39$ students participated at the start of the second year. To enact upon development of (informal) learning, at the end of the second year interviews were again conducted with $n=36$ other students.

Two interviewers were trained to conduct the interviews and received extensive written and oral instructions. Table 1 shows the topics addressed. The interviewers were explicitly not involved in the medical programme to minimise the chance of the interviewees withholding negative opinions on elements of the learning context.

two years. All formal educational activities were similar across all subgroups. Further details are described in the additional blinded manuscript (under review elsewhere). The (possible) influence of the intervention on the results of this study is described in the appendix, whereby the same trends were seen in both intervention groups and the control group. Therefore, we aggregated all students at the class level. 
Table 1: Questions addressed in the semi-structured interview

1. Did you exchange course related information with others besides formally organised activities?

a. If yes, with whom, how and what did you exchange?

b. Did you use social media or technology while exchanging information?

2. How did this process of interaction develop over time?

3. How did the informal interaction influence formal interaction and vice versa?

\section{Procedure}

\section{QUANTITATIVE STUDY}

Five times during a period of 22 months students were asked to fill in with whom the student had interacted outside the formal educational activities. Participation was voluntary. Three sessions were planned in curriculum year one, and two more in curriculum year two, see Figure 1. Each survey took ten minutes to complete. If students were absent, they received an invitation for an online questionnaire to provide insights into their informal learning among their peers. First, written information on the aims of the research was given, followed by a description of the survey. Students were assured that the collected data were dealt strictly confidentially and were used only for research purposes. Second, students were asked for written informed consent to participate. Response rates varied between $82.2 \%$ and $94.0 \%$ across the five observations. Three students never participated in these five observations.

\section{QUALITATIVE STUDY}

First, the goals of the interview were explained, emphasising the voluntary and confidential nature of participation of the study. All students agreed to participate and signed an informed consent before continuing with the interview. The interviews were audio taped. No data was lost. All transcripts were transcribed verbatim. Previous research (Hommes, van den Bossche, et al., 2013) revealed that this design was feasible.

Study year 1
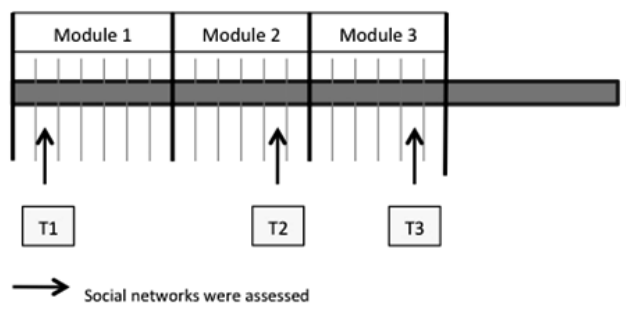

* $\quad 75$ interviews conducted

Figure 1: Timing of all five observations and interviews

\section{Study year 2}

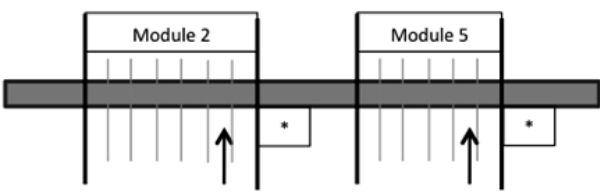

T4

T5 


\section{ANALYSES}

\section{QUANTITATIVE STUDY}

Missing data can have considerable negative effects on social network analysis (Huisman, 2007), since interpretations of social network relations rely heavily on the presence or absence of identified interrelationships. However, with an average response rate of $89.0 \%$ across the five measurements, which is well above common threshold levels of $80 \%$ (Scott, 2000), a potential bias is limited. Nonetheless, we dealt with the missing relational data following Gile and Handcock (2006), treating the missing ties as the estimates from mutuality to fit the observed data.

Univariate statistics and density were used to quantify the relatedness among students in the three networks over the five repeated observations over 22 months (Knoke \& Yang, 2008; Scott, 2000) using UCINET v6.439 (Borgatti, Everett, \& Freeman, 2002), a social network programme. These data were converted to a regular statistic software package to calculate the demographics. STATA version 11.0 was used. To understand the development in the number of ties and the value of ties over time (T1 to T5), a multilevel regression analysis using the XTREG command was used. The density of a network indicates the number of relations in the network; as it is calculated by the total number of ties divided by the total number of possible ties.

Next, QAP correlations were performed to gain insights into the interrelations between the network types and changes over time. To understand how informal learning occurred within or across the formal teams students were involved in, in line with (Rienties, Heliot, et al., 2013) the External - Internal index was used. The E-I index takes the number of ties to members of other tutorial groups (E), subtracts the number of ties to members within the same tutorial group (I), and divides it by the total number of ties in the network. The resulting index ranges from -1 (all ties are only within the group) to +1 (all ties are outside the group). This was repeated for all five observations (T1 to T5).

\section{QUALITATIVE STUDY}

Thematic analysis was applied to analyse the transcripts, see (Braun \& Clarke, 2006) for an overview. This technique encompasses iterative coding of the transcripts assembling themes emerging from the data. $\mathrm{JH}$, the first author of this study, coded all transcripts using Atlas T.I. (Atlas.tiCompany, 2012). To prevent reliance of a single researcher, WdG randomly analysed four transcripts. Next, WdG and JH compared the codes applied to four randomly drawn transcripts to encompass the same interpretation. Common to qualitative research practice (Kuper, Lingard, \& Levinson, 2008; Meyrick, 2006), differences were solved by consensus. Finally, all interviews were coded and summarised in excel using the codes in the transcripts to develop a clear overview of the answers to the three questions (table 1). 


\section{RESULTS}

\section{RQ 1: WHAT IS THE INFLUENCE OF TIME ON INFORMAL LEARNING NETWORKS AMONG STUDENTS?}

The quantitative data indicate a dynamic development of informal learning relations over time as can be seen in the univariate statistics (Graph 1 and Table 2). For example, during the first observation when students were enrolled in the medical programme for eight days, on average students developed 3.7 friends, gave medicine-related information to 3.7 students and received information from 3.8 students. The multilevel regression analyses show that, over time, students progressively and significantly made more connections to other students (Give: $\beta$ 2.64 (0.16) $p<0.001$; Get: $\beta 2.62$ (0.15) p<0.001; Friends: $\beta 3.84$ (0.17) $p<0.001$ ). However, in year two, students started to decrease the number of friends and the number of ties with whom they share information. For example, the mean number of information that was given to other students was 15.89 at T4 (6 months into year 2) and 12.77 at T5 (the end of year 2). The network also decreased in density between T4 and T5, meaning that in general students progressively made fewer connections to other students in the class. In contrast, the multilevel regression analyses show that the value of ties increased over time significantly, without a setback between T4 and T5 (Give: $\beta 0.11$ (0.02) $p<0.001$; Get: $\beta 0.11(0.02) p<0.001$; Friends: $\beta 0.12$ (0.02) $\mathrm{p}<0.001)$.

Table 2 and Graph 1:

Univariate statistics of the three networks (giving, getting and friendships) are given at all observations over time. Please note that the means of giving and getting information follow the same line. ${ }^{*} p<0.001$

\begin{tabular}{|l|ccc|}
\hline \multirow{2}{*}{ mean n ties T1 (SE) } & GIVING & GETTING & FRIENDS \\
\cline { 2 - 4 } mean n ties T2 (SE) & $3.74(3.67)$ & $3.79(3.66)$ & $3.74(3.67)$ \\
mean n ties T3 (SE) & $8.50(5.72)$ & $8.49(5.64)$ & $11.36(5.90)$ \\
mean n ties T4 (SE) & $11.53(8.31)$ & $11.47(8.27)$ & $15.69(8.51)$ \\
mean n ties T5 (SE) & $15.96(15.93)$ & $15.89(15.67)$ & $21.59(16.38)$ \\
\hline Development (T1-T5) b (SE) & $2.64(0.16)^{*}$ & $2.62(0.15)^{*}$ & $3.84(0.17)^{*}$ \\
mean value of ties T1 (SE) & $2.40(1.51)$ & $2.39(1.51)$ & $2.40(1.51)$ \\
mean value of ties T2 (SE) & $2.95(1.22)$ & $3.00(1.16)$ & $3.19(0.84)$ \\
mean value of ties T3 (SE) & $2.83(1.06)$ & $2.86(1.08)$ & $3.01(0.82)$ \\
mean value of ties T4 (SE) & $2.76(1.21)$ & $2.76(1.17)$ & $2.93(0.87)$ \\
mean value of ties T5 (SE) & $3.03(1.16)$ & $3.03(1.15)$ & $3.11(0.94)$ \\
\hline Development (T1-T5) b (SE) & $0.11(0.02)^{*}$ & $0.11(0.02)^{*}$ & $0.12(0.02)^{*}$ \\
Density T1 & 0.012 & 0.012 & 0.012 \\
Density T2 & 0.026 & 0.026 & 0.035 \\
Density T3 & 0.036 & 0.036 & 0.049 \\
Density T4 & 0.053 & 0.052 & 0.071 \\
Density T5 & 0.042 & 0.042 & 0.057 \\
\hline
\end{tabular}




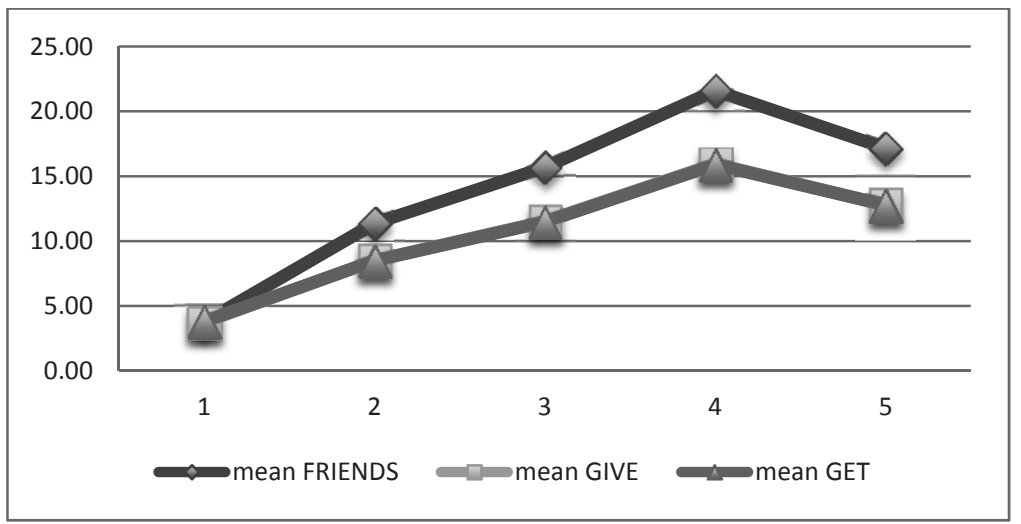

Graph 1

QAP correlation analyses (Table 3 ) indicated that the three types of students' social networks were highly correlated at the same measurement point, as well as over time. For example at $\mathrm{T} 1$, the friends network shows $\rho=1.00$. In other words, students were friends to all students that they gave information to at T1 (8 days after enrolment in the medical programme). This was repeated over time (T1 to T5), although most rhos were below common levels of multi-collinearity $(\rho<0.80)$. The social networks initiated at T1 were still important in year two. For example, friendship at T1 was significantly correlated with friendship at T2 $(\rho=0.45, p<0.001)$, T3 $(\rho=0.35, p<0.001), \mathrm{T} 4(\rho=0.30, p<0.001)$ and T5 $(\rho=0.28, p<0.001)$. The same holds for the instrumental ties (i.e. giving and getting information) over time. In other words, students over time developed more and stronger social networks over the two years of study, although towards the end a more select group of relations were used for informal learning.

RQ 2: WHAT IS THE INFLUENCE OF THE INSTRUCTIONAL DESIGN ON THE DEVELOPMENT OF INFORMAL LEARNING NETWORKS?

As illustrated in the Pearson correlation matrix (Table 4), students built their learning networks within the tutorial group they were involved in, for example giving information $\rho=0.42, p<0.001$ at $\mathrm{T} 1$ and $\rho=0.59, p<0.001$ at $\mathrm{T} 2$. Advancing through the medical programme, students did relate to new students in their tutorial groups (giving information at T3 $(\rho=0.34, p<0.001)$ ), but higher correlation indexes remained with the students with whom they were involved in their previous tutorial group (M1\&M2 $\rho=0.45, p<0.001)$. In curriculum year two, the effect of having met in a tutorial group remained eminent, with highest correlation indexes for the students met in the first tutorial group (M1 \& M2) and the concurrent tutorial group (M2 or M5 in year 2). This finding does not imply that students' social networks were matured fully at the start of the medical programme. Instead, the tutorial group composition at the time the social networks were assessed steered with whom students interacted, besides the students involved in the first tutorial group. This 
implies that the instructional design played an important role, mainly through the tutorial group composition in which students started the medical programme with. When analysing the External-Internal (E-I) group indexes as illustrated in Table 5, a progressive change in students' interaction patterns was visible with students inside and outside their formally assigned group(s), from primarily interacting with students from their tutorial group at T1 $(-0.31)$ to increasingly interacting with students outside their groups at T5 $(+0.71)$. In other words, at T1 students were $31 \%$ more likely to develop links within rather than outside their tutorial groups, whereas students primarily interacted with students outside their tutorial group from T3 and later observations, with a chance of $37-74 \%$ to have more links outside rather than inside the group. In the friendship network this shift occurred relatively faster than in both instrumental networks. 


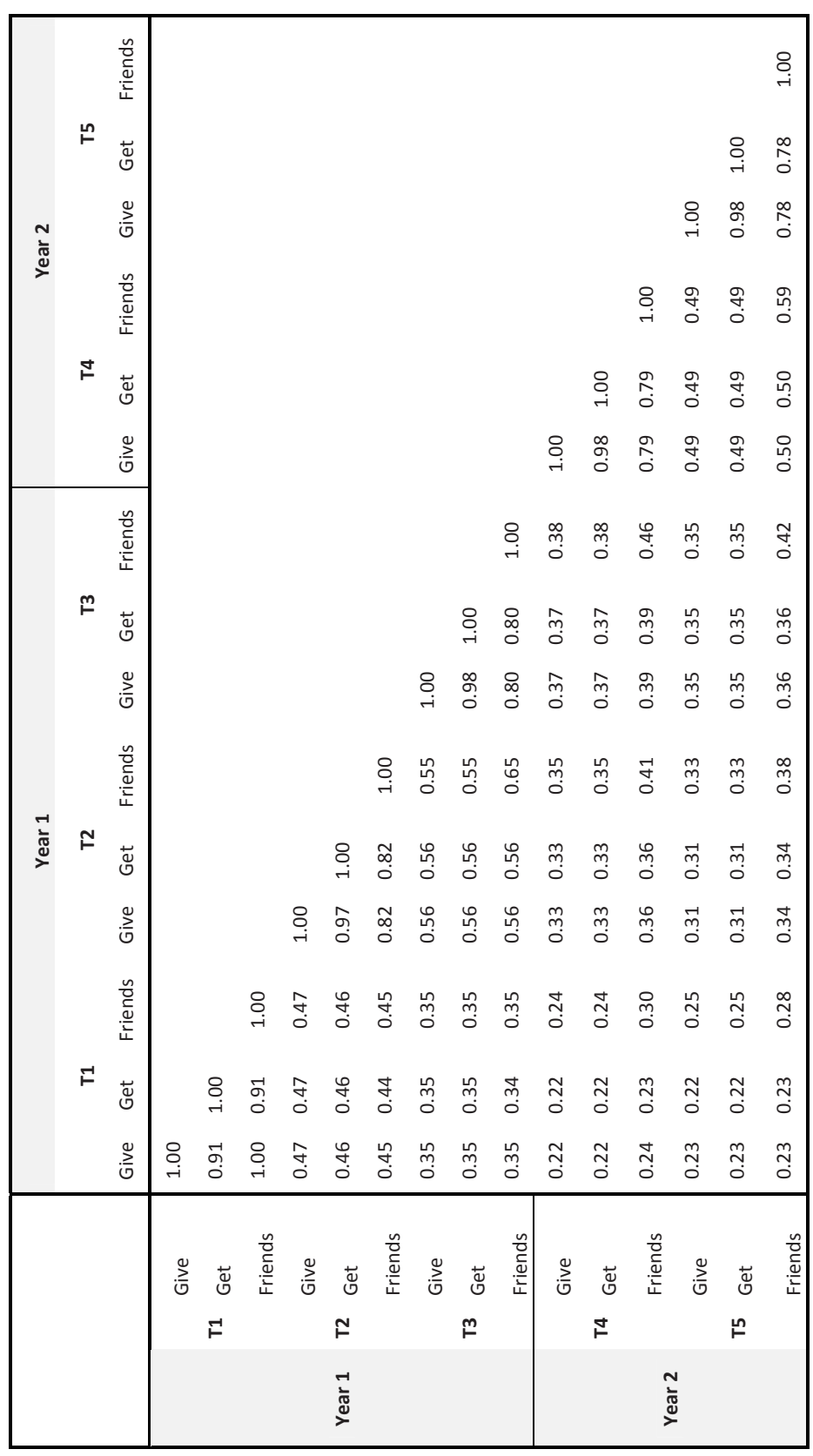




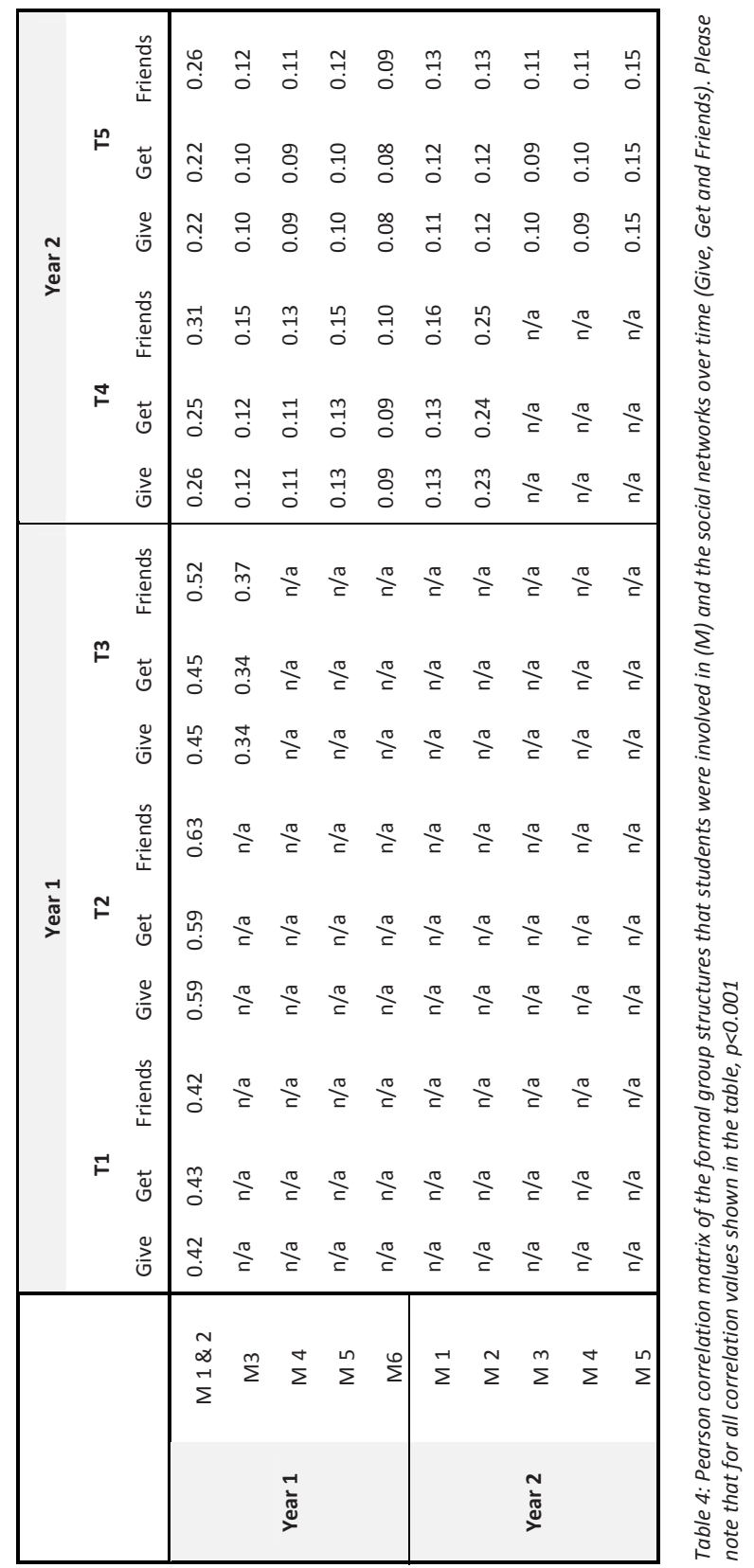


In sum, although the first tutorial group had an important (lasting) effect on how students developed friendships and instrumental learning over time, the impact of the Problem-Based Learning environment on students learning networks faded over time. Towards the end of curriculum year two, most students interacted outside the formal group structure with students who they developed (previous) informal relations.

\begin{tabular}{|l|lllll|}
\hline & T1 & T2 & T3 & T4 & T5 \\
\hline GIVING & -0.31 & -0.20 & 0.37 & 0.61 & 0.70 \\
GETTING & -0.32 & -0.21 & 0.36 & 0.61 & 0.69 \\
FRIENDS & -0.31 & -0.08 & 0.41 & 0.64 & 0.74 \\
\hline
\end{tabular}

Table 5: The E-I indexes over time in all three networks illustrate that students gradually develop mostly external ties when interacting with other students outside their tutorial groups (all p-values <0.05).

RQ 3: WHICH OTHER FACTORS INFLUENCE THE DEVELOPMENT OF INFORMAL LEARNING NETWORKS? In order to better understand how students developed relations in the informal and formal learning context over time, two interviews sessions were conducted. Of the $n=39$ students interviewed in the first interview session in year two, one student did not share information with other students in the informal context, but described some friendships among the classmates. In the end of the same year, all interviewed students ( $n=36)$ described informal learning with other students (see Figure 1 ).

FACTORS INFLUENCING INTERACTION IN THE INFORMAL CONTEXT AMONG STUDENTS

Homogeneity in characteristics

Students reported that 'matching' occurred mostly based upon similar attitudes in studying or similar interests. Students mainly interacted with co-national students. (S1) Our first tutorial group appeared to be a good match. After the first two modules in which we stayed together, we still keep in touch and exchange information two years later. In every consequent tutorial group you meet new people with whom you match and might hold onto exchanging information when the module has finished. You still meet in a lecture hall and start to exchange information to support one another. You lose track off some of these students. Information exchange appears to continue for the ones that you notice that they put in effort and participate in the formal group activities. With these 'active' students it's easy to connect on the topics that you both study. You keep in touch because this might be beneficial. In contrast, if you give something to a person that does not try hard, the chance is high that you get nothing in return. Therefore I do not support someone that does not put in any effort in studying. These students demotivate me.

\section{Proximity}

Overall, students described that sharing information occurred naturally. Talking to friends in a bar included discussing medical topics or describing module-related topics. Moreover, when waiting for the tutorial group, training session or a lecture to start, students interacted spontaneously to get to know one another. Travelling on 
the same train home or asking questions to flat mates was another frequently cited way for students to meet up and share information on a long term basis on among others module related issues. (S2) I started studying in the medical programme and had one friend from high school. With him I exchanged much information, for example while discussing cases or asking questions. Over time, I met other students and slowly I started to exchange information with these students as well. I connected easily with the group of students that all travel from the same neighbouring city by train. In the tutorial groups I also met some students who became my friends. However, the tutorial groups with which you only collaborate with the group members for one module did not result in many friendships. The first tutorial group and my friend from high school became a very close group. I still do fun stuff with this group after two years.

\section{Network size}

The number of ties with whom students frequently interacted in the informal context varied between 1 and 25 students. These wide variations might be explained by the variety in descriptions of the students whom they related to. Most students referred to friends as their main group of students with whom they learn informally. (S3) I call the students I met in tutorial group one as acquaintances and not friends due to the intensity of the relationship. If I am very close to the other, and share my whole life with them then it's a friend. However, if the relation is superficial, such as asking one another 'how are you?' etcetera without bringing it to deeper topics, then it's an 'acquaintance'. Sharing information among friends was not only personal in nature; it was an automatic process to talk about for example interesting media facts, what they have studied, how the tutorial group is behaving. (54) Sometimes we exchange too much information. Then we find ourselves in a bar while still discussing medical topics. Some students (six during first interview session and one during second interview session) only maintained instrumental ties in their class, These students reported that knowing one another from a tutorial group session was sufficient to ask for advice where to find, for example, a good medical book. These students did have friends, for example in a fraternity, student union or in their hometown, but these friends did not have anything to do with the medical programme.

\section{Methods of interaction}

Face-to-face was the common method of interaction. Some of this interaction occurred through the use of the web. Mail was important to send summaries, examples of tests, tutorial guides and other handy study material. Dropbox was sometimes used as a place where students stored and shared their own summaries, even while the subscribers of a shared folder were not all familiar to one another. One student had made a Facebook page, which the interviewed students who were members to Facebook used for university and not-university related information sharing. Students reported changes in location for lectures, posted test questions when consecutive sessions were held, discussed possible 'wrong' answers on formative tests. Interestingly, most students used the site, but the majority of the interviewed students, had never posted anything. Chatting through MSN or 
Facebook was frequently used just before a test to ask one another questions while studying.

THE INFLUENCE OF TIME

A strong development of informal learning within the formal groups was reported at the start of the medical programme. During these first months, students tended to interact strongly and almost exclusively within their formally arranged group. In contrast, after switching to a new tutorial group in the third module, students increasingly started interacting with students outside their formal group. Betweengroup interaction became more common as students progressed through the medical programme. The duration of the 'developmental phase' varied strongly among students, with some students experiencing an end to the 'development phase' after six months in year one, while others continued adjusting their interaction partners when being allocated to a new formal group. Most students reported to have developed to a relatively stable group of friends by the end of year one. (S5) Just before I started the medical programme I participated in the introduction week organised by the student union. Then I made a group of friends, of whom a part is now in my student union. With these students I still meet very frequently. I already knew one other student with whom I went to high school with. Then in year two, in the second module, I went to Italy with nine other students. We became good friends since we shared ten weeks in a foreign country. These students joined my regular friend group. And in the beginning of year two, I joined a student union through which I also made a lot of friends. Therefore I can conclude that in module one in year one, I started to develop a network, which stopped to change in the third module of year two approximately. In rare occasions you meet one other person when you collaborate with another student intensely. However, most of the times, these students don't become friends. Maybe when you connect very well and you are still looking for friends, then you might become friends that later in the medical programme.

This phenomenon of students not changing their informal networks appears to be common in the second curriculum year. (56) After the first tutorial group you are randomly allocated to a new group of students in which you don't know the others. Then you tend to meet up again [in the informal context and share information] with the students you already know. In the second year, you notice that students have formed various groups and that students in the new tutorial groups tend to stick to these groups, you don't get any invitation anymore to study or share anything with another unfamiliar student in the current tutorial group as was common in the first modules in the medical programme. Feelings of interdependence and trust were key features how students started and continued to share information over time.

THE INFLUENCE OF THE INSTRUCTIONAL DESIGN AND VICE VERSA

Students agreed that the PBL environment had a strong impact with whom students mostly interacted. After 22 months, the majority of students still interacted significantly with students they met in the first module when starting the medical programme. Students did not only meet in the tutorial groups but also through 
practical or clinical training sessions, or collaboration during assignments. The instructional design was a strong stimulator in the informal interaction process. For example, having a library where most students prepared for their tutorial group sessions, stimulated unplanned interaction with fellow students. These moments of interaction were experienced as positive for the learning process, as students felt comfortable to ask their connections for advice about which books are helpful, where to find the answer for the other learning goals, and so on. A library with rooms that students could reserve provided a space to prepare for a test with a group of students. (S7) With seven students from my first tutorial group we have made an extra 'education day' in the week before the exam. We study together in the university library from nine o'clock in the morning until nine or ten o'clock at night and discuss all cases again, all learning goals etcetera. We motivate one another to study, we check if our knowledge is correct and teach each other when we come across topics that were not discussed in some of the different tutorial groups.

Various students reported an intertwined nature of interaction in the formal and informal context. Feelings of interdependence and transactive memory grew among students in formal education and were applied in the informal context. (S8) When you meet other people, than you know what difficulties you experience yourself and whom might be able to help you and vice versa. After a while you just know who knows what, but it takes a little time. It's not only that I meet more people over time; I also get to know the others better. Knowledge gathered outside of the tutorial group was transferred back in the tutorial group (additional information achieved through an informal network was discussed in the tutorial group again). In turn, informal interaction made formal interaction safer and therefore more straightforward. (59) In the first curriculum year I was allocated to a group of strangers every module again. In this year I met many people and made a lot of friends through which I met even more people. In the second curriculum year I started to be more familiar to the students in the tutorial group. This made me feel safer in the tutorial group. It was also more fun since more and more jokes were made in these groups. The developmental period before being effective was suddenly gone in the second curriculum year, which was a relief.

\section{Discussion}

This mixed-methods study provided several unique and in-depth insights on how a large class of 322 medical students learned from other students in their informal learning context over a period of two years. In the educational literature, relatively little is known about how informal interaction occurs among students in a face-toface context. This is in sharp contrast to organisational sciences who acknowledge informal learning as a key aspect of the workers' learning process (Marsick \& Watkins, 2001; Tannenbaum et al., 2010). 


\section{PRINCIPAL FINDINGS AND MEANING}

The longitudinal social-network analyses show a strong increase of informal learning relations with other students in the first six months. The qualitative study shows that students experienced this development as a natural process. In line with studies in the organisational sciences e.g. (Cross et al., 2006), students developed strong instrumental ties with other students and therefore had the opportunity to develop inter-group learning in the informal context. Four important factors influenced the students' to build relations to students outside their formal groups.

First, reciprocal relations are rather important for sharing information. For example, being friends was for most students a pre-requisite for providing information to others, as was shown in the quantitative study and in more detail in the qualitative study. In the latter study, students indicated sharing different types of information with different types of relations with students. Acquaintances shared references, while good friends or "study mates" shared summaries and frequently asked one another questions on unclear details. Previous studies already showed that not all groups or members in particular are willing to actively share knowledge with others e.g. Casciaro (1998), Heliot \& Riley (2010) and Borgatti \& Cross (2003). In other words, sharing knowledge is an implicit cost, while expected returns of relevant new knowledge and/or expertise are uncertain; some students are less willing to share knowledge than others. Various studies in collaborative designs have shown that students (have) experienced social loafing (Dolmans, de Grave, Wolfhagen, \& van der Vleuten, 2005), which might explain a skewed group learning behaviour (Rienties, Tempelaar, van den Bossche, Gijselaers, \& Segers, 2009). Friends or member familiarity might thus reduce costs to share information (Gruenfeld, Mannix, Williams, \& Neale, 1996; Harrison, Mohammed, McGrath, Florey, \& Vanderstoep, 2003). In the interviews, various students emphasised that providing others with information was limited to friends or acquaintances from whom they received information in return. Moreover, students highlighted the importance of being able to estimate the reliability of the information that was received. This illustrates the importance of transactive memory among students, i.e. Ellis et al (2008) and London et al (2005), which is an important element for the learning process in the formally organised groups (Hommes, van den Bossche, et al., 2013).

Second, the influence of the instructional design on the students' informal learning context decreased over time. Students tended to learn within the formal group at the beginning of the first year, as was clearly illustrated in the E-I indexes. In the second study year, students interacted almost exclusively with students who were not involved in their formal group. Progressively, students started to learn outside their formal group they were assigned to by the educational programme. This 'fading' of the influence of the instructional design on informal learning, align well with literature of scaffolding whereby scaffolding is intended to fade over time when students become experts (Lajoie, 2005; Pata, Lehtinen, \& Sarapuu, 2006; Pea, 2004). Interestingly, this study shows that the students "decide" the timing of fading, raising questions on the use of the formal design by these students. Without measuring these formal and informal learning interactions over time, probably the instructional designers of this programme and the tutors moderating the groups would not have 
realised that most of their students were actually no longer exclusively learning within the formally organised groups after year one.

Third, the qualitative study enquired how students composed and managed their informal social networks over time. Students mainly interacted within their tutorial group in the first modules ( $1 \& 2$ ) as students simply did not know other students outside their formal group. Meeting one another in clinical skills trainings, in the library, through other friends, helped students to meet new potential links. Also, informal activities, such as a fraternity, or travelling on the same train home, helped students to connect. This is in support of network theorists who argue that homogeneity in characteristics (e.g. same fraternity, similarity in gender or rank in hierarchy) as well as proximity (e.g. involved in the same tutorial group or riding the same train home) encourages social network formation among people (Borgatti \& Cross, 2003; Rienties, Heliot, et al., 2013).

Fourth, the social networks were shown to be dynamic in nature. For example, in the quantitative study a decline was noted in the number of relations with other students towards the end of year two. The qualitative study provided insights into this phenomenon and showed that students perceived to have reached a sufficient and unique social network that did not change much from the beginning of year two onwards. More specifically, students were not trying to connect to others in the year two. This could be the reason why students tended to show a decline in the number of ties in the second study year as was measured in the social network analysis over time.

Finally, both methods show the intertwined nature of formal and informal learning. The quantitative study clearly shows how the first group composition was rather important in steering with whom students interact over two years. The qualitative study supports the latter finding and adds details on how informal learning encourages and ignites knowledge sharing back into the formal learning process. These findings strongly support the notion that learning is inherently social (Carley, 1986; Levine \& Resnick, 1993) and complex, with dynamics or development over time (Arrow et al., 2004), emphasizing the need to also include the informal learning context as an essential context in which students learn.

\section{LIMITATIONS}

In this study we chose to focus on the development of informal learning over time and the influence of the instructional design on this development. Informal learning was defined as inherently social, taking place as an interactive process with other students. The precise content of this interactive process was not disclosed. Future studies may need to take a different angle on group learning, for example by incorporating individual learning or learning with others than the students that participate in the same class. More in-depth associations between interaction among students in the informal and formal context might provide an additional understanding on group learning.

This study was process-oriented rather than outcome-oriented, since a previous cross-sectional study (Hommes et al., 2012) had already highlighted the importance of social networks and was supported by others (Baldwin et al., 1997; Gasevic, Zouaq, 
\& Janzen, 2013), indicating that social networks provide the most powerful predictor for academic performance. These studies did provide the need for more understanding of the dynamics of networks over time.

We believe that social network analyses are a dynamic and innovative method to provide understanding in interaction patterns among students over a long stretch of time. This was previously illustrated by various groups of authors in the field of computer supported collaborative learning (Hmelo-Silver \& Chernobilsky, 2008; Hong, Chen, Chai, \& Chan, 2010; Zhu, 2006). As informal learning occurs mostly outside formally organised activities, social networks analysis is an interesting method to visualise social networks among students for educators to stimulate students' informal learning processes. Although the longitudinal design provided reliability and a dynamic illustration of informal learning, such analyses are also more complicated than cross-sectional designs, as well as more time consuming. For example, illustrations in such large networks do not necessarily illustrate well what is happening in a network. We chose to study social networks in the first six months of year one and twice in year two. It could be argued that it would have been optimal to measure social networks before and after module, but as we were anticipating too much resistance from the students and the occurrence of participants' fatigue we decided to limit our measurement moments. As attitudes and behaviour are strongly influenced by the social and cultural context (Järvelä et al., 2010), replication of this study in another context and culture will raise interesting differences and similarities and increase insights into the external validity of these results.

The interviews provide in-depth insights in the worlds of the students. Understanding developmental patterns over a long stretch of time might have included bias, as short and long-term memory might be rather different from what had occurred. Twice during year two, interviews were planned with other students. Although, limited differences were observed between these interviews, an attractive alternative methodology is interviewing a set of students throughout two full years with more frequent observations.

Finally, both studies were subjective in nature, which could lead to errors of omission and commission. The longitudinal nature of both studies provides us with a relative strong belief that the results presented are not based on these biases.

\section{IMPLICATIONS FOR PRACTICE \& FUTURE RESEARCH}

This study supports the literature showing the importance of informal learning (Hommes et al., 2012; Marsick \& Watkins, 2001; Tannenbaum et al., 2010) and it advocates to view group learning within and between groups in both the formal and informal learning contexts (Decuyper et al., 2010). For educational practice and instructional design in particular, this provides new opportunities to understand how students learn and this might provide new tools to increase learning among students in the future.

First, a few interviewed students were not aware of the importance of social networks for their learning process. As was shown previously, students with little interaction with other students also achieved lower grades (Hommes et al., 2012). 
Therefore, students should be made aware that social interaction is also important to occur outside the tutorial groups or other formal activities. Especially for future collaboration and learning skills in the workplace, early awareness among students might facilitate learning later in the (medical) practice (Wagter, van de Bunt, Honing, Eckenhausen, \& Scherpbier, 2012).

Second, the instructional design can facilitate informal interaction among students. For example, having a library with many places for students to study in provides students a natural context to interact informally. For example, in a PBL setting students are stimulated to study from a variety of books and other media in a module, which drives students to study in the library instead of at home. Moreover, providing students with various formal groups over time provides students with an opportunity to meet new students and build new network relations. At the same time, this study indicates that a network should not be too large, since students need to maintain the network and understand the skills and knowledge of the students with whom they share information (Hommes, Arah, et al., 2013). As Allais (2013) points out, massification of education has critical downsides especially for the quality of education.

Third, the fading of the influence of the instructional design raises questions on the integration of students learning in both the formal and informal learning context. How do students balance collaboration with fellow students in the formal and informal groups? Is the informal learning context used as an additional learning situation or do students compensate with their informal social network for 'bad' formal groups? Both these scenarios could indicate that students use 'external' knowledge for their formal groups, which is recognised in the organisational sciences as a rather positive aspect of inter-team learning e.g. (Hsiao et al., 2012). However, when students learn mostly in the informal learning context, the instructional design needs to be altered to rearrange formal learning activities to efficiently facilitate student learning.

\section{CONCLUSION}

Informal learning is an essential element of group learning. Although the instructional design has an important influence on the development of informal networks, students tended to interact primarily with students outside the formal groups over time, dissolving the influence of the instructional design on learning in groups.

CONFLICT OF INTEREST: None

FUNDING: None




\section{ReferenCES}

Akkerman, S., \& Bakker, A. (2011). Boundary crossing and boundary objects. Review of educational research, 81(2), 132-169. doi: 10.3102/0034654311404435

Allais, S. (2013). A critical perspective on large class teaching: the political economy of massification and the sociology of knowledge. Higher Education, $x x(x x), x x-x x$. doi: 10.1007/s10734-013-9672-2

Argote, L., McEvily, B., \& Reagans, R. (2003). Managing knowledge in organizations: An integrative framework and review of emerging themes. Management science, 49(4), 571-582.

Arrow, H., \& Cook, J. (2008). Configuring and reconfiguring groups as complex learning systems. In V. I. Sessa \& M. London (Eds.), Work group learning: understanding, improving \& assessing how groups learn in organizations (pp. 45-71). London: Lawrence Erlbaum Associates, Taylor \& Francis Group.

Arrow, H., Poole, M. S., Bouas Henry, K., Wheelan, S. A., \& Moreland, R. (2004). Time, change, and development: The temporal perspective on groups. Small group research, 35(73), 73-105. doi: 10.1177/1046496403259757

Atlas.tiCompany (Producer). (2012). Atlas.ti v. 6.3. [Qualitative data analysing software]

Baldwin, T. T., Bedell, M. D., \& Johnson, J. L. (1997). The social fabric of a team-based M.B.A. program: Network effects on student satisfaction and performance. Academy of management journal, 40(6), 1369-1397.

Borgatti, S., \& Cross, R. (2003). A relational view of information seeking and learning in social networks. Management science, 49(4), 432-445.

Borgatti, S., Everett, M., \& Freeman, L. C. (2002). Ucinet: Harvard, MA: Analytic Technologies.

Braun, V., \& Clarke, V. (2006). Using thematic analysis in psychology. Qualitative research in psychology, 3(2), 77-101. doi: 10.1191/1478088706qp063oa

Bresman, H. (2010). External Learning Activities and Team Performance: A Multimethod Field Study. Organization science, 21(1), 81-96. doi: 10.1287/orsc. 1080.0413

Capello, R. (1999). Spatial transfer of knowledge in high technology milieur: learning versus collective learning processes. Regional studies, 33, 353-365. doi: 10.1080/00343409950081211

Capello, R., \& Faggian, A. (2005). Collective Learning and Relational Capital in Local Innovation Processes. Regional studies, 39, 75-87. doi: 10.1080/0034340052000320851

Carley, K. (1986). Knowledge acquisition as a social phenomenon. Instructional Science, 14, 381-438.

Casciaro, T. (1998). Seeing things clearly: social structure, personality, and accuracy in social network perception. Social networks, 20, 331-351. doi: 50378-8733(98)00008-2

Chan, C. K. K. (2001). Peer collaboration and discourse paterns in learning from incompatible information. Instructional Science, 29, 443-479.
Creswell, J. W. (2009). Qualitative, quantitative, and mixed methods approaches (3 ed.). London, Thousand Oakes, New Delhi, Singapore: SAGE Publications Inc.

Cronin, M. A., Weingart, L. R., \& Todorova, G. (2011). Dynamics in groups: Are we there yet? The academy of management annals, 5(1), 571-612. doi: 10.1080/19416520.2011.590297

Cross, R., Borgatti, S. P., \& Parker, A. (2002). Making invisible work visible: Using social network analysis to support strategic collaboration. California management review, 44(2), 25-46.

Cross, R., Laseter, T., Parker, A., \& Velasquez, G. (2006). Using social network analysis to improve communities of practice. California mangement review, 49(1), 32-60.

Curşeu, P. L., \& Pluut, H. (2011). Student groups as learning entities: The effect of group diversity and teamwork quality on groups' cognitive complexity. Studies in Higher Education, 38(1), 87-103. doi: 10.1080/03075079.2011.565122

Daly, A. J., Moolenaar, N. M., Bolivar, J. M., \& Burke, P. (2009). Relationships in reform: the role of teachers' social networks. Journal of Educational Administration, 48(3), 259-391. doi 10.1108/09578231011041062

de Laat, M., \& Lally, V. (2003). Complexity, theory and praxis: Researching collaborative learning and tutoring processes in a networked learning community. Instructional science, 31, 7-39.

Decuyper, S., Dochy, F., \& van den Bossche, P. (2010). Grasping the dynamic complexity of team learning: An integrative model for effective team learning in organisations. Educational Research Review, 5, 111 133. doi: 10.1016/j.edurev.2010.02.002

Deeter-Schmelz, D. R., Norman Kennedy, K., \& Ramsey, R. P. (2002). Enriching our understanding of student team effectiveness. Journal of marketing education, 24(2), 114-124.

Dochy, F., Segers, M., Van den Bossche, P., \& Gijbels, D. (2003). Effects of problem-based learning: a metaanalysis. Learning and instruction, 13, 533-568. doi: 10.1016/S0959-4752(02)00025-7

Dolmans, D. H. J. M., de Grave, W., Wolfhagen, H. A. P., \& van der Vleuten, C. P. M. (2005). Problem-based learning: future challenges for educational practice and research. Medical Education, 39, 732-741. doi: 10.1111/j.1365-2929.2005.02205.x

Dreu, C. K. W. d., \& Weingart, L. R. (2003). Task versus relationship conflict, team performance and team member satisfaction: a meta-analysis. Journal of applied psychology, 88(4), 741-749.

Edmondson, A. C., Winslow, A. B., \& Bohmer, R. M. J. (2003). Learning How and Learning What: Effects of Tacit and Codified Knowledge on Performance Improvement Following Technology Adoption. Decision sciences, 34(2), 197-223. 
Ellis, A. P. J., Porter, C. O. L. H., \& Wolverton, S. A. (2008). Learning to work together: an examination of transactive memory system development in teams. In V. I. Sessa \& M. London (Eds.), Work group learning: understanding, improving \& assessing how groups learn in organizations (pp. 91-115). London: Lawrence Erlbaum Associates, Taylor \& Francis Group.

Gasevic, D., Zouaq, D., \& Janzen, R. (2013). “Choose your Classmates, your GPA is at Stake!" The Association of Cross-Class Social Ties and Academic Performance. American behavioural scientist, 57(10), 1460-1479. doi: $10.1177 / 0002764213479362$

Gerber, B. L. (2001). Relationships among informal learning environments, teaching procedures and scientific reasoning ability. Journal of Science Education, 23(5), 535-549. doi: 10.1080/09500690116971

Gijbels, D., Dochy, F., van den Bossche, P., \& Segers, M. (2005). Effects of Problem-Based Learning: a metaanalysis from the angle of assessment. Review of Educational Research, 75(1), 27-61. doi: 10.3102/00346543075001027

Gile, K., \& Handcock, M. S. (2006). Model-based assessment of the impact of missing data on inference for networks. Center for statistics and the social sciences, (working paper no.66). University of Washington, Seattle.

Gruenfeld, D. H., Mannix, E. A., Williams, K. Y., \& Neale, M. A. (1996). Group composition and decision making: How member familiarity and information distribution affect process and performance. Organizational behavior and human decision processes, 67(1), 1-15.

Hackman, J. R. (1992). Group influences on individuals in organizations. In M. D. Dunette \& L. M. Hugh (Eds.), Handbook of industrial and organizational psychology (Vol. 3, pp. 199-267). Palo Alto, CA, USA: Consulting psychologists in press, Incl.

Harrington, B., \& Fine, G. A. (2006). Where the Action Is: Small Groups and Recent Developments in Sociological Theory. Small group research, 37(1), 419. doi: $10.1177 / 1046496405284356$

Harrison, D. A., Mohammed, S., McGrath, J. E., Florey, A. T., \& Vanderstoep, S. W. (2003). Time matters in team performance: effects of member familitary, entrainment, and task discontinuity on speed and quality. 56(663-669).

Heliot, Y., \& Riley, J. (2010). A study of indicators of willingness in the knowledge transfer process. Journal of Management \& Organization, 16(3), 399410. doi: $10.5172 /$ jmo.16.3.399

Hickey, D. T. (2003). Engaged Participation versus Marginal Nonparticipation: A Stridently Sociocultural Approach to Achievement Motivation. The elementary school journal, 103(4), 401-429.

Hmelo-Silver, C. E. (2004). Problem-based learning: What and how do students learn? Educational psychology review, 16(3), 235-266.

Hmelo-Silver, C. E., \& Chernobilsky, E. (2008). Understanding collaborative learning processes in new learning environments. Instructional Science, 36, 409-430. doi: 10.1007/s11251-008-9063-8
Homan, A. C., van Knippenberg, D., van Kleef, G. A., \& de Dreu, C. K. W. (2007). Bridging Faultlines by Valuing Diversity: Diversity Beliefs, Information Elaboration, and Performance in Diverse Work Groups. Journal of applied psychology, 92(5), 1189-1199. doi: 10.1037/0021-9010.92.5.1189

Hommes, J., Arah, O., de Grave, W., Schuwirth, L., Scherpbier, A., \& Bos, G. (2013). Medical students perceive better learning processes when classes are made to seem small. Under review.

Hommes, J., Rienties, B., de Grave, W., Bos, G., Schuwirth, L., \& Scherpbier, A. (2012). Visualising the invisible: A network approach to reveal the informal social side of student learning. Advances in Health Sciences Education, 17(5), 743-757. doi: 10.1007/s10459-012-9349-0

Hommes, J., van den Bossche, P., de Grave, W., Bos, G., Schuwirth, L., \& Scherpbier, A. (2013). Understanding the effects of time on collaborative learning processes in a Problem Based Learning setting: a mixed methods study. Accepted in Advances in Health Sciences Education.

Hong, H.-Y., Chen, F.-C., Chai, C. S., \& Chan, W.-C. (2010) Teacher-education students' views about knowledge building theory and practice. Instructional Science, 39, 467-482. doi 10.1007/s11251-010-9143-4

Hsiao, R., Tsai, D., \& Lee, C. (2012). Collaborative Knowing: The Adaptive Nature of Cross-Boundary Spanning. Journal of management studies, 49(3), 463-491. doi: 10.1111/j.1467-6486.2011.01024.x

Huisman, M. (2007). Imputation of missing network data: Some simple procedures. Paper presented at the International Sunbelt Social Network Conference XXVII.

Ibarra, H., \& Andrews, S. B. (1993). Power, Social Influence, and Sense Making: Effects of Network Centrality and Proximity on Employee Perceptions. Administrative Science Quarterly, 38(2), 277-303.

Järvelä, S., Volet, S., \& Järvenoja, H. (2010). Research on Motivation in Collaborative Learning: Moving Beyond the Cognitive-Situative Divide and Combining Individual and Social Processes. Educational psychologist, 45(1), 15-27. doi: 10.1080/00461520903433539

Jeong, H. W. N., \& Chi, M. T. H. (2007). Knowledge convergence and collaborative learning. Instructional science, 35, 287-315. doi 10.1007/s11251-006-9008-z

Judson, E. (2012). Leanring about bones at a science museum: examining the alternate hypotheses of ceiling effect and prior knowledge. Instructional Science, 40, 957-973. doi: 10.1007/s11251-0119201-6

Katz, N., D., L., Arrow, H., \& Contractor, N. (2004). Network theory and small groups. Small Group Research, 35(3), 307-332. doi $10.1177 / 1046496404264941$

Knoke, D., \& Yang, S. (2008). Social network analysis (2 ed.). Thousand Oaks CA, London, New Delhi, Singapore: SAGE publications Incl.

Krackhardt, D., \& Hanson, J. R. (1993). Informal networks: The company behind the chart. Harvard Business Review, July-August, 104-111. 
Kuper, A., Lingard, L. A., \& Levinson, W. (2008). Practice Qualitative Research: Critically appraising qualitative research. British Medical Journal, 337, 687-692. doi: 10.1136/bmj.a1035

La Rochelle, J. S., Durning, S. J., Pangaro, L. N., Artino, A. R., Van der Vleuten, C. P. M., \& Schuwirth, L. (2011). Authenticity of Instruction and Student Performance: A Prospective Randomized Trial. Medical Education, 45, 807-817. doi: 10.1111/j.1365-2923.2011.03994.x

Lajoie, S. P. (2005). Extending the scaffolding metaphor. Instructional Science, 33, 541-557. doi: 10.1007/s11251-005-1279-2

Larson, J. R. (2009). In search of synergy in small group performance (1 ed.). London: Psychology Press.

Lehtinen, E., Hakkarainen, K., Lipponen, L., Rahikainen, M., \& Muukkonen, H. (1998). Computer Supported Collaborative Learning: A Review. Retrieved from

Levina, N., \& Vaast, E. (2005). The emergence of boundary spanning competence in practice: Implications for implementation and use of information systems. MIS Quarterly, 29(2), 335-363.

Levine, J. M., \& Resnick, L. B. (1993). Social foundations of cognition. Annual review of psychology, 44, 585612.

London, M., Polzer, J. T., \& Omor. (2005). Interpersonal congruence, transactive memory, and feedback processes: an integrative model of group learning. doi: $10.1177 / 1534484305275767$

Marsden, P. V. (1990). Network data and measurement. Annual review of sociology, 16, 435-463.

Marsick, V. J., \& Watkins, D. E. (2001). Informal and incidental learning. New directions for adult and continuing education, 89, 25-34.

Meyrick, J. (2006). What is good qualitative research? Journal of Health Psychology, 11(5), 799-808. doi: 10.1177/1359105306066643

Moolenaar, N. M., Sleegers, P. J. C., \& Daly, A. J. (2012). Teaming up: Linking collaboration networks, collective efficacy, and student achievement. . Teaching and Teacher Education, 28(2), 251-262. doi: 10.1016/j.tate.2011.10.001

Morone, P., \& Taylor, R. (2004). Knowledge diffusion dynamics and network properties of face-to-face interactions. Journal of evolutionary economics, 14, 327-351. doi: 10.1007/s00191-004-0211-2

Pata, K., Lehtinen, E., \& Sarapuu, T. (2006). Interrelations of tutor's and peer's scaffolding and decision-making discourse acts. Instructional Science, 34, 313-341. doi: 10.1007/s11251-0053406-5

Pea, R. D. (2004). The social and technological dimensions of scaffolding and related theoretical concepts for learning, education and human activity. The journal of the learning sciences, 13(3), 423-451.

Rienties, B., Alcott, P., \& Jindal-Snape, D. (2014). To let students self-select or not: that is the question for teachers of culturally diverse groups. Journal of Studies in International Education, Accepted for publication.
Rienties, B., Heliot, Y., \& Jindal-Snape, D. (2013). Understanding social learning relations of international students in a large classroom using social network analysis. Higher Education, 66(4), 489-504. doi: 10.1007/s10734-013-9617-9

Rienties, B., Hernandez Nanclares, N., Hommes, J., \& Veermans, K. (2013). Understanding emerging knowledge spillovers in small-group learning settings; a networked learning perspective. In V. Hodgson, D. McConnell \& M. De Laat (Eds.), Exploring the Theory, Pedagogy and Practice of Networked Learning (pp. (in press)). The Netherlands: Springer.

Rienties, B., Tempelaar, D. T., van den Bossche, P., Gijselaers, W. H., \& Segers, M. (2009). The role of academic motivation in computer supported collaborative learning. Computers in human behavior, 25(6), 1195-1206. doi: 10.1016/j.chb.2009.05.012

Roe, R. A. (2008). Time in Applied psychology. European psychologist, 13(1), 37-52. doi: 10.1027/10169040.13.1.37

Rotgans, J. I., \& Schmidt, H. G. (2011). Situational interest and academic achievement in the activelearning classroom. Learning and instruction, 21(1), 58-67. doi: 10.1016/j.learninstruc.2009.11.001

Schmidt, H. G. (1984). Introduction. Maastricht, The Netherlands: Van Gorcum.

Schmidt, H. G., Rotgans, J. I., \& Yew, E. H. J. (2011). The process of Problem-Based Learning: what works and why. Medical Education, 45, 792-806. doi: 10.1111/j.1365-2923.2011.04035.x

Scott, J. (2000). Social network analysis - A handbook (2 ed.). London, Thousand Oaks CA, New Delhi: SAGE publications Ltd.

Summers, M., \& Volet, S. (2008). Students' attitudes towards culturally mixed groups on international campuses: impact of participation in diverse and non - diverse groups. Studies in Higher Education, 33(4), 357-370. doi: 10.1080/03075070802211430

Sweet, M., \& Michaelsen, L. K. (2007). How group dynamics research can inform the theory and practice of postsecondary small group learning. Educational psychology review, 19, 31-47. doi: 10.1007/s10648-006-9035-y

Tang, K. C. C. (1993). Spontaneous Collaborative Learning: A New Dimension in Student Learning Experience? Higher education research \& development, 12(2), 115-130. doi 10.1080/0729436930120201

Tannenbaum, S. I., Beard, R. L., McNall, L. A., \& Salas, E. (2010). Informal learning and development in organizations. In S. W. J. Kozlowski \& E. Salas (Eds.), Learning, training and development in organizations. New York: Taylor \& Francis group.

Taylor, D., \& Miflin, B. (2008). Problem-based learning: Where are we now? Medical Teacher, 30, 742-763. doi: 10.1080/01421590802217199

Tinto, V. (2000). What have we learned about the impact of learning communities on students? Assessment update, 12(2), 1-2.

Topping, K. J. (2005). Trends in Peer Learning. Educational psychology, 25(6), 631-645. doi: 10.1080/01443410500345172 
Tortoriello, M., \& Krackhardt, D. (2010). Activating crossboundary knowledge: The role of simmelian ties in the generation of innovations. Academy of management journal, 53(1), 167-181.

van Blankenstein, F. M., Dolmans, D. H. J. M., van der Vleuten, C. P. M., \& Schmidt, H. G. (2009). Which cognitive processes support learning during smallgroup discussion? The role of providing explanations and listening to others. Instructional Science, 32(2), 1-16. doi: 10.1007/s11251-0099124-7

van Boxtel, C., van der Linden, J., \& Kanselaar, G. (2000). Collaborative learning tasks and the elaboration of conceptual knowledge. Learning and instruction, 10, 311-330.

van den Bossche, P., Gijselaers, W. H., Segers, M., \& Kirschner, P. A. (2006). Social and cognitive factors driving teamwork in collaborative learning environments: Team learning beliefs and behaviors. Small Group Research, 37(5), 490-521. doi: $0.1177 / 1046496406292938$

van den Bossche, P., Gijselaers, W. H., Segers, M., Woltjer, G., \& Kirschner, P. (2011). Team learning: building shared mental models. Instructional Science, 39(3), 283. doi: 10.1007/s11251-010-91283
Visschers-Pleijers, A. J. S. F., Dolmans, D. H. J. M., de Leng, B. A., Wolfhagen, H. A. P., \& van der Vleuten, C. P. M. (2006). Analysis of verbal interactions in tutorial groups: a process study. Medical Education, 40, 129-137. doi: 10.1111/j.1365 2929.2005.02368.x

Wagter, J. M., van de Bunt, G., Honing, M., Eckenhausen, M., \& Scherpbier, A. (2012). Informal interprofessional learning: Visualizing the clinical workplace. Journal of interprofessional care, 26, 173-182. doi: 10.3109/13561820.2012.656773

Wilcox, P., Winn, S., \& Fyvie-Gauld, M. (2005). 'It was nothing to do with the university, it was just the people': The role of social support in the first-year experience of higher education. Studies in higher education, 30(6), 707-722. doi: 10.1080/03075070500340036

Yan, L., \& Kember, D. (2004). Avoider and engager approaches by out-of-class groups: the group equivalent to individual learning approaches. Learning and instruction, 14, 27-49. doi: 10.1016/j.learninstruc.2003.10.001

Yew, E. H. J., \& Schmidt, H. G. (2010). Is learning in problem-based learning cumulative? Advances in Health Sciences Education. doi: 10.1007/s10459010-9267-y

Zhu, E. (2006). Interaction and cognitive engagement: An analysis of four asynchronous online discussions. Instructional Science, 34, 451-480. doi: 10.1007/s11251-006-0004-0 


\section{APPENDIX}

These tables show hardly any difference between the intervention and the control groups as described in chapter five. Therefore we believe that we might draw the conclusions in the quantitative results described in the manuscript from the full class.

As is illustrated in Table 1 (page 95) the average number of ties is not significantly different between the control group and the two intervention groups. The mean value of ties was lower for giving information and friendships over time in intervention group B, whereas in intervention group $A$, the value of ties was higher for receiving information from other students.

This mixed results in the value of ties, might be the result in the lack of power of the intervention groups compared to the control group. Especially in the second curriculum year, the intervention groups are rather small (just over 40 students). The next Table (2) therefore shows that no difference between the mean number of ties and the value of the ties over time existed between the control group and the intervention groups.

Table 2: No difference is found between the control group and the intervention groups combined.

\begin{tabular}{|l|rr|rr|c|c|}
\hline & \multicolumn{2}{|c|}{ GIVE } & \multicolumn{2}{c}{ GET } & \multicolumn{2}{c|}{ FRIENDS } \\
\hline
\end{tabular}

Correlational analyses (Table 3 ) (all $\rho$ are $p<0.001$ ) shows that the instrumental ties and friendships are significantly related to being involved in an intervention groups. These data need MRQAP analyses (see page 99) to specify how the students in the intervention groups are different in their networks than students in the control group 


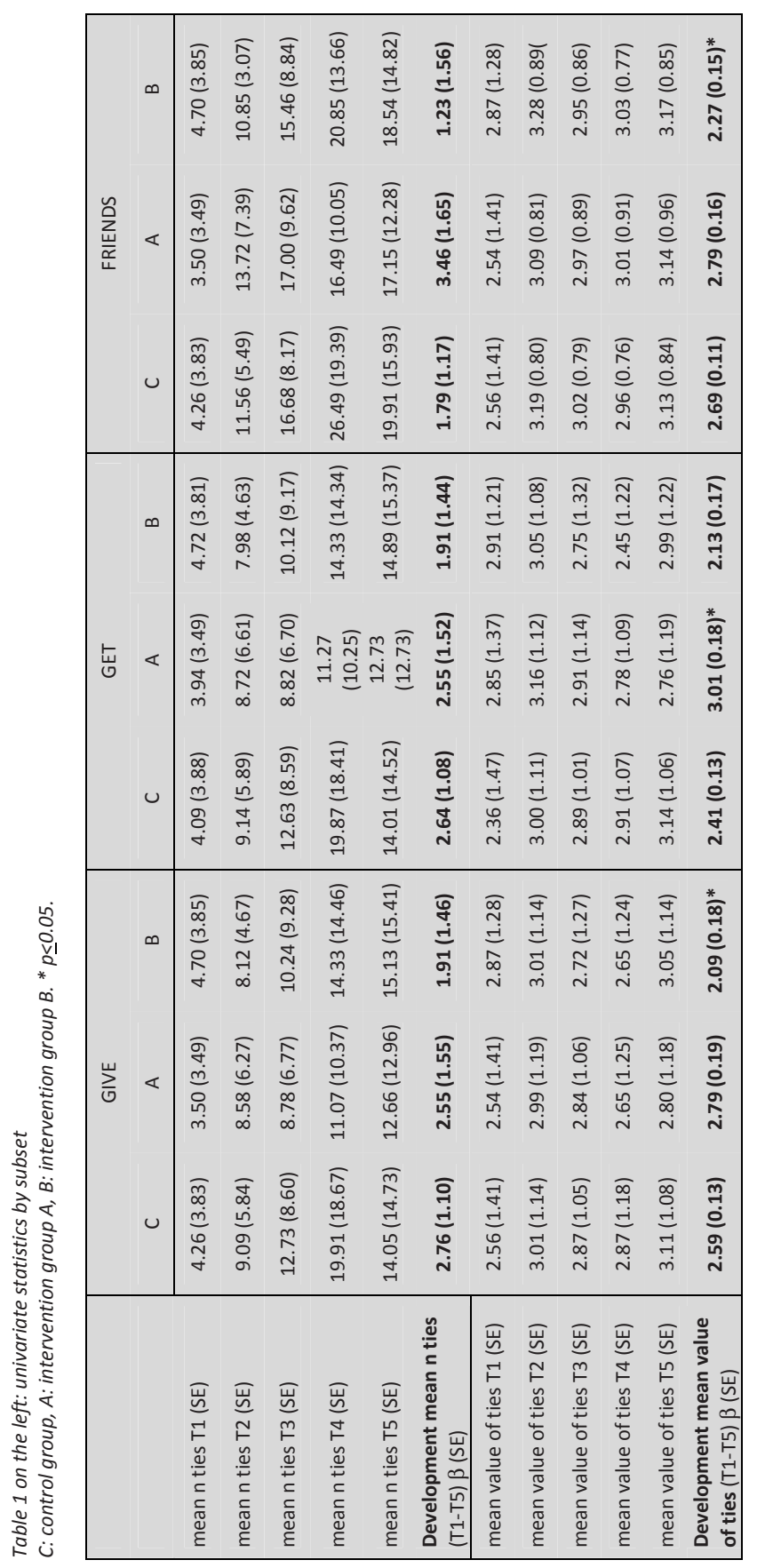




\begin{tabular}{|c|c|c|c|c|c|c|c|c|c|c|c|c|c|c|}
\hline \multirow{7}{*}{ ָั } & & $\begin{array}{l}\frac{n}{0} \\
\frac{0}{w} \\
\frac{\omega}{4}\end{array}$ & নี & $\stackrel{m}{-}$ & $\stackrel{\mathscr{N}}{\stackrel{0}{0}}$ & $\stackrel{\text { ㄱ }}{\circ}$ & न्. & 궁 & O̊. & $\stackrel{m}{7}$ & $\stackrel{m}{\stackrel{7}{0}}$ & $\stackrel{\overrightarrow{1}}{0}$ & न⿱ & $\stackrel{\stackrel{n}{?}}{0}$ \\
\hline & & $\stackrel{ \pm}{\Xi}$ & 궁 & ન્ન & $\underset{\sim}{\sim}$ & $\stackrel{?}{?}$ & : & $\stackrel{?}{?}$ & 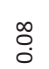 & 궁 & $\underset{\text { ㄱ. }}{\text { ?े }}$ & $\begin{array}{l}\text { o̊ } \\
0 \\
0\end{array}$ & $\stackrel{?}{\rightarrow}$ & $\stackrel{\text { n? }}{0}$ \\
\hline & & $\sum_{i=0}^{\infty}$ & 궁 & ન્ & $\underset{\sim}{\sim}$ & 움 & : & 움 & $\stackrel{\infty}{\circ}$ & $\overrightarrow{7}$ & $\stackrel{7}{7}$ & 움 & : & $\stackrel{n}{\stackrel{n}{0}}$ \\
\hline & & 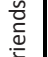 & & $\stackrel{n}{?}$ & $\vec{m}$ & $\stackrel{\text { n }}{\circ}$ & $\stackrel{m}{\circ}$ & 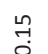 & 웅 & $\stackrel{0}{0}$ & $\stackrel{\text { N }}{\circ}$ & $\stackrel{\pi}{\check{2}}$ & $\stackrel{\pi}{L}$ & $\stackrel{\pi}{x}$ \\
\hline & 吉 & + & N & $\approx$ & $\stackrel{\sim}{\sim}$ & $\sim$ & $F$ & $m$ & の & $m$ & $\stackrel{+}{\circ}$ & $\sigma$ & & \\
\hline & & () & $0^{\circ}$ & 0 & 0 & 0 & 0 & 0 & 0 & 0 & 0 & $\mathrm{~s}$ & 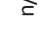 & a \\
\hline & & $\sum_{i=0}^{0}$ & 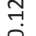 & $\stackrel{m}{\rightarrow}$ & $\stackrel{\mathscr{L}}{\stackrel{2}{n}}$ & $\stackrel{\sim}{7}$ & $\overrightarrow{7}$ & $\stackrel{m}{\stackrel{n}{2}}$ & og & $\stackrel{m}{\rightarrow}$ & 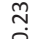 & $\stackrel{\pi}{=}$ & $\stackrel{\pi}{\varepsilon}$ & $\stackrel{\pi}{=}$ \\
\hline \multirow{12}{*}{ ฮృ } & \multirow[b]{6}{*}{$\approx$} & $\begin{array}{l}n \\
\underline{c} \\
\underline{\underline{g}}\end{array}$ & $\stackrel{m}{\longrightarrow}$ & $\approx$ & กุ? & $\hat{m}$ & $\stackrel{\pi}{c}$ & $\stackrel{\pi}{=}$ & $\stackrel{\pi}{=}$ & $\stackrel{\pi}{\varepsilon}$ & $\stackrel{\pi}{=}$ & $\stackrel{\pi}{=}$ & $\stackrel{\pi}{=}$ & $\stackrel{\pi}{x}$ \\
\hline & & + & - & $\neg$ & 은 & ఫ & $\sigma$ & $\pi$ & $\pi$ & $\sigma$ & $\sigma$ & & & \\
\hline & & $\widetilde{0}$ & 0 & 0 & 0 & 0 & $\mathrm{z}$ & $=$ & $\bar{\varepsilon}$ & $\Xi$ & a & $\bar{\imath}$ & $=$ & $\bar{z}$ \\
\hline & & $\sum_{0}^{0}$ & ت궁 & $\overrightarrow{7}$ & $\stackrel{\text { ֻq }}{\circ}$ & m̃ & $\stackrel{\pi}{a}$ & $\stackrel{\tilde{n}}{\underline{n}}$ & $\stackrel{\pi}{\Sigma}$ & $\stackrel{\pi}{a}$ & $\stackrel{\pi}{z}$ & $\stackrel{\pi}{\Omega}$ & $\stackrel{\pi}{\Sigma}$ & $\stackrel{\pi}{[}$ \\
\hline & & $\begin{array}{l}0 \\
\underline{0} \\
\underline{\underline{v}}\end{array}$ & 움 & 웅 & $\tilde{0}$ & $\stackrel{\pi}{x}$ & $\stackrel{\pi}{x}$ & $\stackrel{\pi}{\Sigma}$ & $\stackrel{\pi}{x}$ & $\stackrel{\pi}{x}$ & $\stackrel{\pi}{=}$ & $\stackrel{\pi}{x}$ & $\stackrel{\pi}{=}$ & $\stackrel{\pi}{x}$ \\
\hline & & + & の & a & $a$ & & & & & & & & & \\
\hline & & 5 & 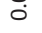 & 0 & 0 & 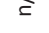 & $=$ & $\Xi$ & $=$ & $\mathrm{I}$ & $=$ & $=$ & $=$ & a \\
\hline & & $\sum_{0}^{0}$ & : & 兽 & 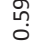 & $\stackrel{\pi}{=}$ & $\stackrel{\pi}{a}$ & $\stackrel{\pi}{\geq}$ & $\stackrel{\pi}{=}$ & $\stackrel{\pi}{\Sigma}$ & $\stackrel{\pi}{\leq}$ & $\stackrel{\pi}{\leq}$ & $\stackrel{\pi}{\Sigma}$ & $\stackrel{\pi}{\varepsilon}$ \\
\hline & & 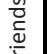 & $\stackrel{0}{0}$ & 望 & $\stackrel{\text { I }}{\circ}$ & $\stackrel{\pi}{x}$ & $\stackrel{\pi}{x}$ & $\stackrel{\pi}{\Sigma}$ & $\stackrel{\pi}{x}$ & $\stackrel{\pi}{\varepsilon}$ & $\stackrel{\pi}{x}$ & $\stackrel{\pi}{\Sigma}$ & $\stackrel{\pi}{=}$ & $\stackrel{\pi}{x}$ \\
\hline & $F$ & $\vec{\alpha}$ & $\bullet$ & n & $\eta$ & $\pi$ & $\pi$ & $\pi$ & $\pi$ & $\sqrt{0}$ & $\pi$ & $\pi$ & $\pi$ & \\
\hline & & & 0 & 0 & 0 & $=$ & & & & $\varepsilon$ & $\varepsilon$ & & $\varepsilon$ & $\varepsilon$ \\
\hline & & ट्रे & : & o. & f. & $\stackrel{\pi}{c}$ & $\stackrel{\pi}{a}$ & $\stackrel{\pi}{[}$ & $\stackrel{\pi}{c}$ & $\stackrel{\pi}{c}$ & $\stackrel{\pi}{\varepsilon}$ & $\stackrel{\pi}{\varepsilon}$ & $\stackrel{\pi}{[}$ & $\stackrel{\pi}{a}$ \\
\hline & & & 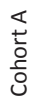 & $\begin{array}{l}\infty \\
\vdots \\
0 \\
\vdots \\
0 \\
0\end{array}$ & $\begin{array}{l}\underset{\infty}{\infty} \\
\vec{\Sigma}\end{array}$ & $\Sigma^{m}$ & $\sum_{\Sigma}^{\nabla}$ & $\sum^{n}$ & $\Sigma^{0}$ & $\stackrel{-1}{\Sigma}$ & $\Sigma$ & $\Sigma^{m}$ & $\Sigma$ & $\sum^{n n}$ \\
\hline & & & & & & & 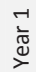 & & & & & 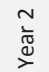 & & \\
\hline
\end{tabular}


MRQAP (regression) analyses (Table 4) show that the added beta-coefficient by being involved in an intervention group is not significant for the instrumental ties. Students' involvement in an intervention group is a significant predictor for friendship networks over time.

Table 4: MRQAP analyses. The dependent variable is shown on the left. The independent variables were the other networks at T1-T5 respectively, the formal groups students were involved in and involvement in either intervention groups.

\begin{tabular}{|c|c|c|c|}
\hline MRQAP & & $\begin{array}{l}\text { Beta-coefficient } \\
\text { Intervention group }\end{array}$ & p-value \\
\hline \multirow[t]{3}{*}{$\mathrm{T} 1$} & Give & 0.000 & 0.996 \\
\hline & Get & 0.002 & 0.113 \\
\hline & Friends & 0.000 & 0.280 \\
\hline \multirow[t]{3}{*}{$\mathrm{T} 2$} & Give & 0.000 & 0.429 \\
\hline & Get & 0.000 & 0.412 \\
\hline & Friends & 0.027 & 0.001 \\
\hline \multirow[t]{3}{*}{ T3 } & Give & 0.000 & 0.437 \\
\hline & Get & 0.000 & 0.410 \\
\hline & Friends & 0.032 & 0.001 \\
\hline \multirow[t]{3}{*}{ T4 } & Give & 0.001 & 0.083 \\
\hline & Get & -0.001 & 0.195 \\
\hline & Friends & 0.043 & 0.001 \\
\hline \multirow[t]{3}{*}{ T5 } & Give & 0.000 & 0.321 \\
\hline & Get & 0.000 & 0.318 \\
\hline & Friends & 0.037 & 0.001 \\
\hline
\end{tabular}





\section{CHAPTER 5}
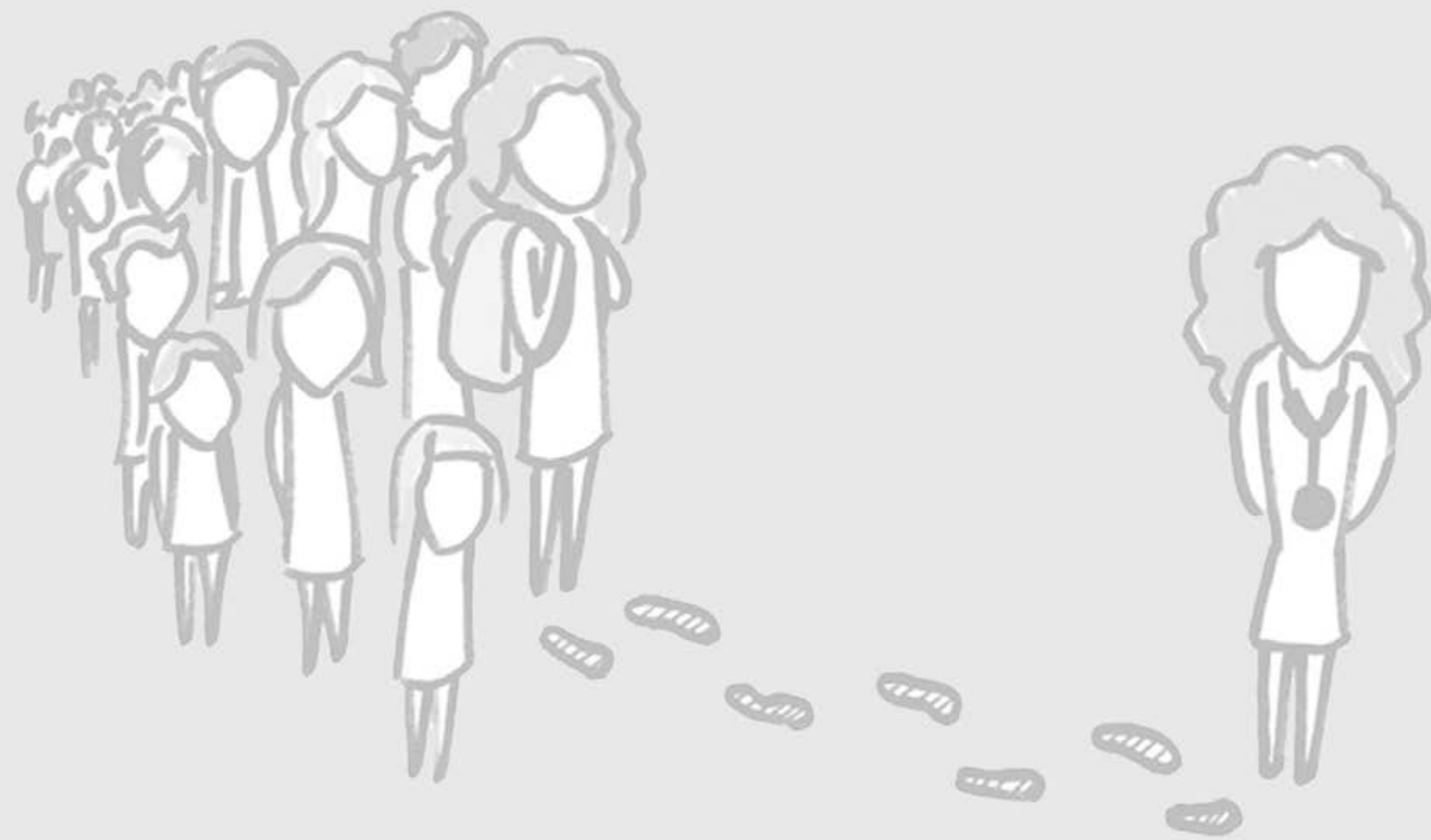


\section{Medical students perceive better learning processes when classes are made to seem small}

J. Hommes ${ }^{1}$, O.A. Arah ${ }^{2}$, W. de Grave ${ }^{1}$, L. Schuwirth ${ }^{3}$, A. Scherpbier ${ }^{1}$, G. Bos ${ }^{4}$

1. Department of Educational Development and Research, Faculty of Health Medicine and Life Sciences, Maastricht University, The Netherlands.

2. Department of Epidemiology, The Fielding School of Public Health, University of California Los Angeles (UCLA), USA.

3. Flinders Innovation and Clinical Education, Flinders Medical School, Flinders University, Adelaide, Australia.

4. University Hospital Maastricht, Department of Internal medicine, Haematology, The Netherlands. 


\section{ABSTRACT}

OBjective

Medical schools struggle with large classes, which might interfere with the effectiveness of learning within small groups due to students being unfamiliar to fellow students. Therefore the aim of this study was to assess the effects of making a large class seem small on the students' collaborative learning processes.

DESIGN

A randomised controlled intervention study was undertaken to make a large class seem small, without the need to reduce the number of students enrolling in the medical programme. The class was divided into subsets: two small subsets $(n=50)$ as the intervention groups; a control group $(n=102)$ was mixed with the remaining students (the non-randomised group $\mathrm{n}^{\sim 100}$ ) to create one large subset.

SETTING

The undergraduate curriculum of the Maastricht Medical School, applying the Problem-Based Learning principles. In this learning context, students learn mainly in tutorial groups, which are composed randomly from a large class every 6-10 weeks.

INTERVENTION The formal group learning activities were organised within the subsets. Students from the intervention groups met frequently within the formal groups. This was in contrast to the students from the large subset who hardly enrolled with the same students in formal activities.

MAIN OUTCOME MEASURES Three outcomes measures assessed students' learning processes over time: learning within formally organised groups, learning with other students in the informal context and perceptions of the intervention.

RESULTS Formal learning processes were perceived more positive in the intervention groups from the second study year on, with a mean increase of $\beta=0.48$ compared to the control group. Informal learning activities occurred almost exclusively within the subsets as defined by the intervention from the first week involved in the medical curriculum (E-I indexes $>-0.69$ ). Interviews tapped negligible negative side effects of the intervention.

CONCLUSIONS Better learning processes can be delivered in large medical schools by making their large classes seem small. 


\section{INTRODUCTION}

Powerful learning environments comply with the cognitive architecture of learning (Konings, Brand-Gruwel, \& van Merrienboer, 2005) combining learning within a meaningful context (contextualism), learning as an active process (constructivism) and learning in groups (collaboration). These learning environments assemble small groups as the units in which learning takes place to 'teach' undergraduate medical students. In such small groups, students are supposed to solve meaningful problems, share information and discuss conflicting ideas (Simons, van der Linden, \& Duffy, 2000). These distinctive steps in the process of learning have shown positive effects on short- and long-term knowledge acquisition (Schmidt, De Grave, De Volder, Moust, \& Patel, 1989; van Blankenstein, Dolmans, van der Vleuten, \& Schmidt, 2009; van Boxtel, van der Linden, \& Kanselaar, 2000; Visschers-Pleijers, Dolmans, Wolfhagen, \& van der Vleuten, 2004). Performing these steps within a small group has been shown more effective than acted by an individual alone (De Grave et al., 1985; van der Linden, Erkens, Schmidt, \& Renshaw, 2000). Furthermore, in the field of medical education positive effects of these group processes on a variety of medical competencies have been shown repeatedly (Michaelsen \& Richards, 2005; Schmidt, 2009; Schmidt, Rotgans, \& Yew, 2011; Slavin, 1996). In accordance with the evidence, many medical schools all over the world have changed their learning context towards powerful learning environments.

Medical schools have grown towards 'mega' classes with commonly over 300 students in European medical schools. This scale enlargement has shown to make teaching large classes difficult (Anderson, 1964; Jenkins, 1991; McConnell \& Sosin, 1984). Although learning in powerful learning contexts still mainly occurs in small groups, it is plausible that the scale enlargement threatens the students' learning processes. Random allocation of students into new groups every few weeks again results in small groups of unfamiliar students. Sharing knowledge in the collaborative process incurs an implicit cost, while the expected returns of relevant new knowledge and/or expertise are uncertain. Some students are therefore less willing to share knowledge than others. Group member familiarity might reduce costs of sharing information among students (Gruenfeld, Mannix, Williams, \& Neale, 1996; Harrison, Mohammed, McGrath, Florey, \& Vanderstoep, 2003). Second, groups must invest time and energy in the collaborative process before the group can become effective (Mathieu, Maynard, Rapp, \& Gilson, 2008). Changing the composition of groups too quickly might prevent groups from reaching the beneficial effects of collaboration in groups. Such suboptimal effectiveness of physicians' medical training increases the need for parsimonious solutions to make medical education more effective.

In medical schools the battle against scale enlargement cannot be won by reducing the number of doctors enrolling in medical schools. Dividing a medical parallel programme into two (or more) sections will result in a duplication of necessary staff 
time (Bridges, 1992). Next, in medical education we strive towards evidenced-based decision making to design the most powerful learning context. Therefore, our study angled this large class debate differently. We conducted a randomised controlled intervention study to test if subdividing a large class into small subsets could facilitate the learning processes positively. This division of a large class in small subsets, which is schematically illustrated in Figure 1, increases the frequency students meet in small groups and hereby increase the time students spend collaborating with one another. More time to collaborate with one another aligns with the group development literature (Mathieu et al., 2008) which has shown to increase the effectiveness of groups.

Our primary aim was to assess the effects of time on quality of the learning processes in the small groups in the medical curriculum. As was briefly expounded in the first paragraph, interaction among students when problem solving, sharing knowledge and discussing medical scenarios are the steps in which learning takes place. However, learners in groups do not necessarily interact when present in the same space at the same time (Johnson \& Johnson, 2002; Roschelle \& Teasley, 1995). Attitudes, motivation and beliefs drive or inhibit interaction within a group. For example, potency beliefs -beliefs that the group will be valuable for one's learning process- is an important predictor for effective learning in a group (Gully, Incalcaterra, Joshi, \& Beaubien, 2002; Stajkovic, Nyberg, \& Lee, 2009). A strong body of evidence shows that effective learning in groups is dependent on the quality of interaction and a variety of attitudes, motivations and beliefs among the group members (Goodman \& Dabbish, 2011; Harrington \& Fine, 2006). Therefore, we borrowed the parameters of effective group learning as the primary outcome measures. In this study we tested if the quality of interaction, the attitudes, motivation and beliefs in the small subsets were perceived more positive compared to the control group.

Students spend the majority of time studying and interacting with other students outside the formally organised activities. Learning in the 'informal' context with other students has been found an important part of the students' learning process (Hommes et al., 2012) and could thus confound our findings related to learning in the formally organised groups (Krackhardt \& Hanson, 1993). Large classes allow students to learn with or from a large number of students. However, large learning networks have been shown to be less effective as it demands much energy to maintain the learning network (Cross \& Thomas, 2008). Therefore our secondary aim was to test whether subsets of the class also directed informal learning with the students in their own subset.

Finally, to be thorough and not miss possible negative side effects of this intervention study on the students' learning process in an actual medical school, the third aim was to explore students perceptions of possible negative and positive effects of the intervention. 


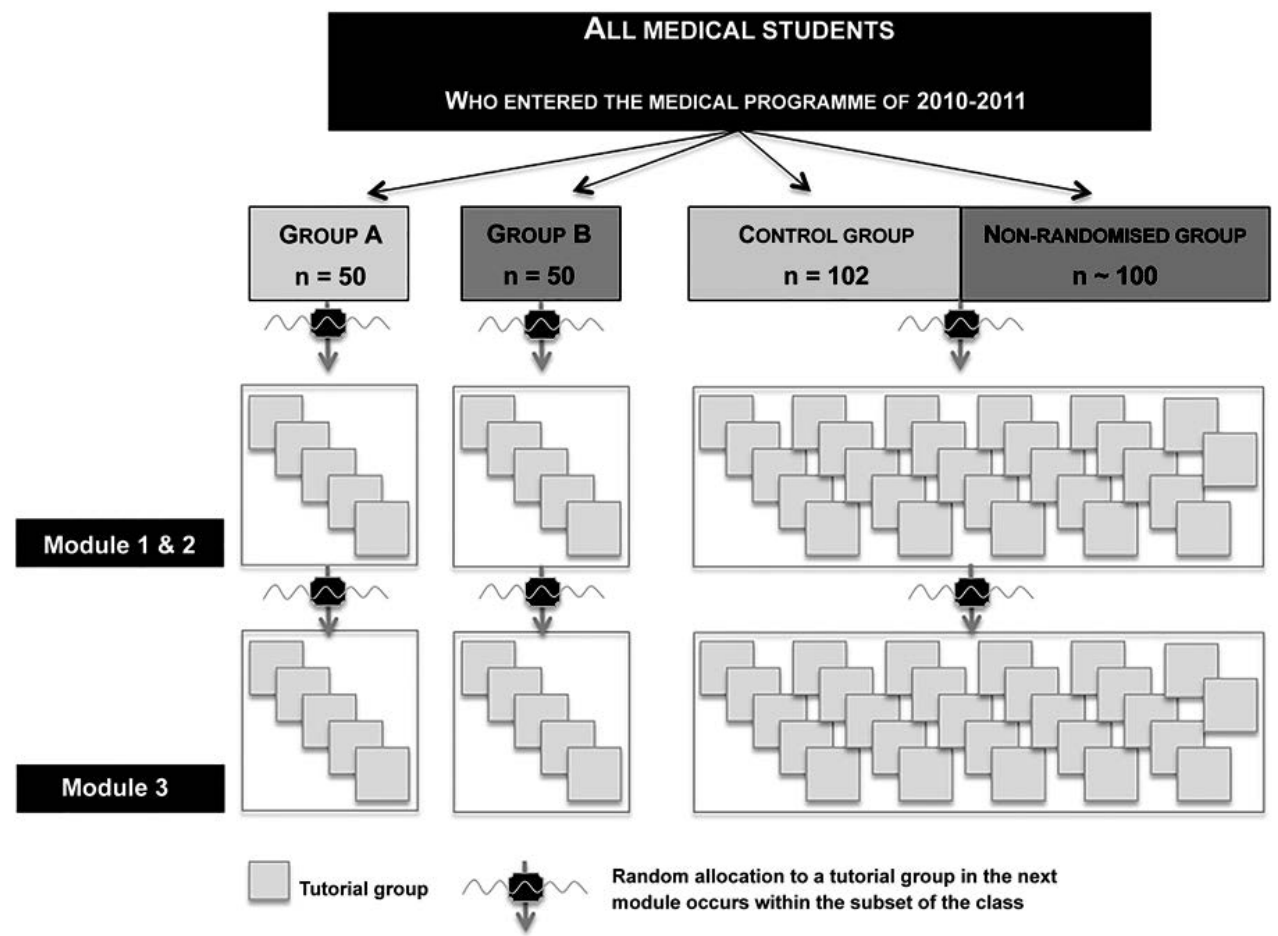

Figure 1: Overview of the randomised controlled trial allocation procedure and intervention

The class of 2010-2011 was randomised into two intervention groups (A and B) with 50 students in each subset and the control group $(n=102)$. The control group was mixed with the non-randomised students representing the large subset of the class. The intervention consisted of allocating students within the subsets of the class to new tutorial groups while progressing through the curriculum. This way, students in the small subsets frequently interacted with the same students over time.

\section{MetHODS}

Research in medical education is exempted from the Medical Ethical Committee in The Netherlands on the ground that this type of research does not intend to answer a research question on health or pathology (aetiology, pathogenesis, symptoms, diagnosis, prevention, results of a treatment) (Center, Downloaded July 2013). As the medical educational domain does not agree with this view, a review board for medical education was designed, but was not yet in function when this research was planned and applied. This did not prevent our research team to apply ethical guidelines for our research. To meet the need for thorough ethical guidelines normally tested in an ethical committee, the students were given the details of the intervention, after which they were asked for informed consent to take part. Students could withdraw at any moment without having to provide a reason. The intervention did not influence the contents of the educational programme at all. For each study (observation), students were again briefed with the goals of the research and asked to participate and provide informed consent to use their data for research 
purposes. Stop criteria were formulated on the basis of achievement, the prerequisite for students to progress through the medical programme. To replace an independent institutional review board the management team of the medical faculty responsible for the quality of education in the medical programme, approved our research proposal and annual feedback on the progress was given.

\section{SETTING \& PARTICIPANTS}

This study was conducted in the first two years of the undergraduate-entry preclinical curriculum in the Maastricht University medical school. This medical school employs a Problem-Based Learning (PBL) approach with small-group tutorials as the backbone of the curriculum in conjunction with practical learning sessions, e.g. gross anatomy laboratory sessions, to complement these groups. The formal activities compose approximately ten hours per week, which leaves plenty of time for informal learning. At its inception in 1974, classes consisted of 34 students. Nowadays, this school enrols approximately 320 students yearly.

Students enrol in a class and participate in a set of modules in chronological order. Recruitment started with enrolment for the new academic year of 2010-2011 (July 2010). One inclusion criterion was used: informed consent to participate in this RCT.

\section{RANDOMISATION AND INTERVENTION}

Of the students enrolling in the undergraduate-entry Maastricht University medical school, 202 students were randomised into three groups: Two intervention groups (A \& B) with 50 students each and the control group (C) consisting of 102 students. For logistical reasons, mainly on the national level, approximately 100 students were not allocated to our medical school before the randomisation of students to tutorial group, which occurs two weeks before the start of the medical programme. Therefore, these students could not participate in the study. The majority of these students still started within the first week of the medical programme. Only eighteen students entered late in the first module. Together with 27 students who did not want to participate in the intervention study, these 'non-randomised' students were mixed with the control group, to generate a large subset of the class.

Students were stratified on their Grade Point Average (GPA) as a proxy to divide weak and strong students evenly over all subsets (Lei, 2010; Moruzi \& Norman, 2002). It was decided to have two intervention groups so that each intervention group could serve as a cross validation for the results of the other group. Randomisation was performed using block randomisation in STATA version 11 (StataCorp, 2010). As is shown in table 1, gender and age did not differ significantly between the intervention groups and the control group. The non-randomised students were slightly but significantly older and had a lower GPA than the control group.

The intervention consisted of allocating students to small groups within the subsets of the class for two years (as illustrated in figure 1). As such, in the first curriculum year, time wise $54.7 \%$ of all formally organised educational events in small groups (clinical skills training sessions and tutorial groups) were organised within the subsets of the class. In the second curriculum year, students were only allocated into the tutorial groups within the subsets of the class, resulting in $39.4 \%$ of all formally 
organised activities was spend within the subsets of the class. To control costs no extra staff time was used in this intervention study. To strengthen students' awareness of being involved in the intervention, three two-hour workshops were organised in which students were actively involved in icebreaker games.

\section{INSTRUMENTS}

\section{LEARNING PROCESSES IN THE FORMAL LEARNING CONTEXT}

A repeated measures study assessed the primary outcome measure, interaction or collaboration among students in the formally organised small groups over time. The Team Learning Beliefs and Behaviour Questionnaire (van den Bossche, Gijselaers, Segers, \& Kirschner, 2006) based on validated scales (Edmondson 1999; Gibson, Randel, \& Early, 2000; Guzzo, Yost, Campbell \& Shea 1993; van Offenbeek 2001; van der Vegt, Emans \& van de Vliert, 1998; Sargent \& Sue-Chan, 2001; Visschers-Pleijers, Dolmans, Wolfhagen \& van der Vleuten 2003) assessed learning processes in these formally organised groups by measuring four parameters of effective group processes (Decuyper, Dochy, \& van den Bossche, 2010): group learning behaviour, feelings of psychological safety, social cohesion (communal attraction to the group and its members), and group potency (the belief that the group is effective). These learning processes were measured on a seven-point scale ranging from (1) 'I do not agree at all' to (7) 'I fully agree'. To assess the developmental aspect of these processes, a longitudinal repeated measures analysis was performed. Figure 2 shows the administration moments over four modules in the two study years. Students were assessed twice per module: in the second week (observation null) and in the penultimate week (observation one).

\section{LEARNING PROCESSES IN THE INFORMAL LEARNING CONTEXT}

The secondary aim was to study informal learning among students, which was quantified by longitudinal social network analyses. Social networks define student learning as interaction between a set of actors or individuals ("nodes") and their interrelationships ("ties"). Three network types assessed social interaction between students; friendships, giving and receiving information related to the module in which students were involved. Friendship networks explore passive information diffusion, while communication networks have a more instrumental nature (e.g. asking explicitly for help on a certain topic) (Ibarra \& Andrews, 1993; Katz, Lazer, Arrow, \& Contractor, 2004). Tie strength, the value of the information that was given or received respectively, or the intensity of the friendship was measured on a Likert scale ranging from 'not valuable' (1) to 'very valuable' (5). A previous study demonstrated validity of this method (Hommes et al., 2012). Five times during the two curriculum years (T1 - T5), students' were asked to indicate with whom they interacted in the informal context (outside all formally organised activities), see figure 2 . 
PeRCePtions OF THE INTERVENTION

Individual interviews were held with students to explore any (other) positive or negative effects of the randomised controlled trial. Two independent trained interviewers conducted $n=39$ and $n=36$ interviews with students from the intervention groups $A$ and $B$ and the control group in the beginning and in the end of the second study year (see figure 2). Students were asked what they noticed from being involved in a small or large subset.

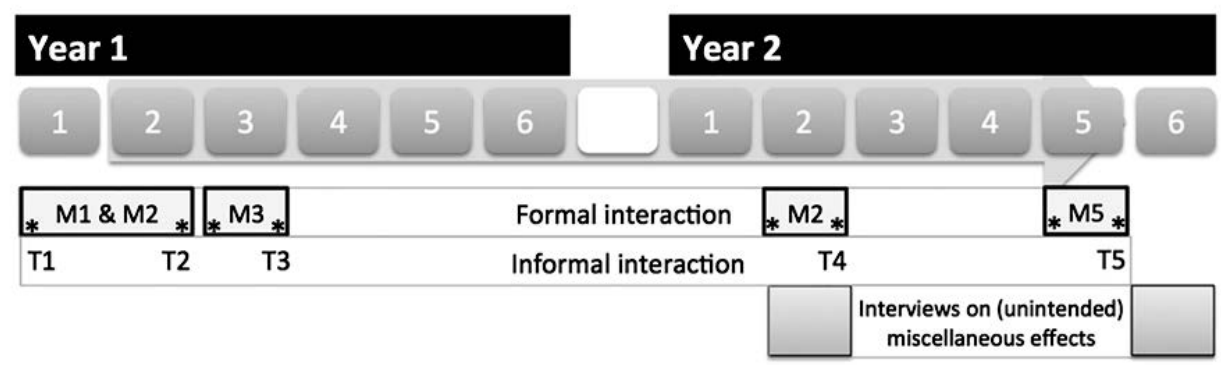

Figure 2: Overview of the instrument assessment over time

Students progressed through six modules every study year. Formal interaction was assessed in the first tutorial group (M1 and M2; since the composition of first two modules did not change), the second tutorial group (M3) and in year two the second and penultimate tutorial groups (M2 and M5 in curriculum year two). The assessment consisted of two observations within the module, indicated as * in the orange boxes. The first observation took place in the second week of the tutorial group and the second in the penultimate week. Informal learning in social networks was assessed during the first three modules in the first year and during two modules in the second study year (T1-T5). Finally, semi-structured interviews assessed the perceptions of the intervention during M2 and M6 of the second curriculum year.

\section{ANALYSES}

LEARNING PROCESSES IN THE FORMAL LEARNING CONTEXT

Per-protocol multilevel cross-classified regression modelling was used to analyse the data, as two observations per students were obtained, while students were involved in tutorial groups, which were assembled from the subsets of the class (Fielding \& Goldstein, 2006). The intervention groups (A and B) were compared to the control group. In the large subset of the class, the control group was mixed with nonrandomised students. Furthermore, the control group and the non-randomised group of students were compared to ensure that the control group was not put in disadvantage. Response rates varied between $87.6 \%$ and $96.6 \%$.

\section{LEARNING PROCESSES IN THE INFORMAL LEARNING CONTEXT}

Response rates varied between $82.2 \%$ and $94.0 \%$. Missing data have considerable negative effects on social network analysis since interpretations of social network relations rely heavily on the assumption that the presence or absence of ties is identified. We dealt with the missing relational data as follows (Gile \& Handcock, 2006), treating the missing ties on the precise estimates of mutuality and other (full) network characteristics to fit from the observed data.

Analyses of social networks started with graphical analysis using Pajek v4G. In order to determine if informal learning occurred within the subsets of the class, Krackhardt 
and Stern's External - Internal index was used in UCINET (v6.439) (1988). The E-I index takes the number of ties to members of other subsets of the group (E), subtracts the number of ties to members within the same subset of the class (I), and divides it by the total number of ties in the network. The resulting index ranges from -1 (all ties are only within the subset) to +1 (all ties are outside the subset of the class).

\section{PERCEPTIONS OF THE INTERVENTION}

Thematic analyses (Braun \& Clarke, 2006) was applied to categorise students perception about positive and negative effects of the intervention. The first author $\mathrm{(JH})$ analysed all transcripts. WdG randomly analysed four transcripts to limit reliance of a single researcher. Comparison showed a high level of agreement. Differences were solved by consensus following qualitative research practice (Kuper, Lingard, \& Levinson, 2008).

\section{RESULTS}

\section{DEMOgRAPHICS AT BASELINE}

Of all randomised students $65.8 \%$ were female and the mean age was 19.2 years at the start of the medical course. Four students chose to discontinue participation in the intervention or control group, during the two academic years. Reasons were: planning problems with clinical skills training sessions $(n=2)$, objections to having exam results analysed $(n=1)$ or personal dislike of some students within the subgroup $(n=1)$. Twenty-seven students were lost to follow-up as can be seen in table 1.

\begin{tabular}{|c|c|c|c|c|}
\hline & $\begin{array}{l}\text { Intervention } \\
\text { group A }\end{array}$ & $\begin{array}{c}\text { Interventio } \\
\mathrm{n} \text { group B }\end{array}$ & $\begin{array}{c}\text { Control } \\
\text { group }\end{array}$ & $\begin{array}{c}\text { Not } \\
\text { randomised } \\
\text { group }\end{array}$ \\
\hline Number of students & $n=50$ & $n=50$ & $n=102$ & $\mathrm{n} \sim 100$ \\
\hline GPA (1-5) & 2.8 & 2.9 & 2.9 & $2.4^{*}$ \\
\hline Gender (\% female) & 64.0 & 70.0 & 64.7 & 57.5 \\
\hline Age & 19.0 & 19.3 & 19.3 & $20 * *$ \\
\hline Lost to follow up & 8 & 4 & 15 & $n / a$ \\
\hline Stop participation & 2 & 1 & 1 & $n / a$ \\
\hline
\end{tabular}




\section{LEARNING PROCESSES IN THE FORMAL LEARNING CONTEXT}

The intervention was expected to take effect when the small groups were randomised to new small groups at least twice. However, to understand and monitor the effects of mixing the control group and the non-randomised group to generate a large subset, we explored what happened in the first two small groups that students were involved in. In Table 2 and the Supplementary materials (appendix) can be found that no significant differences were found between the control group and the non-randomised group.

In the second curriculum year students in the intervention groups reported a higher quality of group interaction at the start of the module than the control group (cf. figure 3 and figures 1-4 in the appendix), confirming our expectations. Effect sizes are shown in tables 2 and table 3 . For example, in the case of psychological safety, students in the intervention groups perceived higher degrees of safety than the control group in Module 2 (M2); [Group A] $\beta=0.47$ (0.21) $p<0.001$, [Group B] $\beta=0.58$ (0.21) $p<0.001$. Similarly, in Module 5 (M5), students in the intervention groups reported a higher degree of safety [Group A]: $\beta=0.37(0.16) p<0.001$, [Group B] $\beta=0.36$ (0.15) $p<0.001$. As for social cohesion, it is clear that students in the intervention groups reported significantly higher cohesion towards the members of the tutorial group at the start and the end of both modules in year two.

The control group was mixed with non-randomised students and could thus be influenced by the latter group of students. Therefore, it is important to note that in all periods, students in the control group did not differ significantly from students in the non-randomised groups. For all results, including the observations in the first year of the medical programme, we refer to the supplementary materials (appendix). 


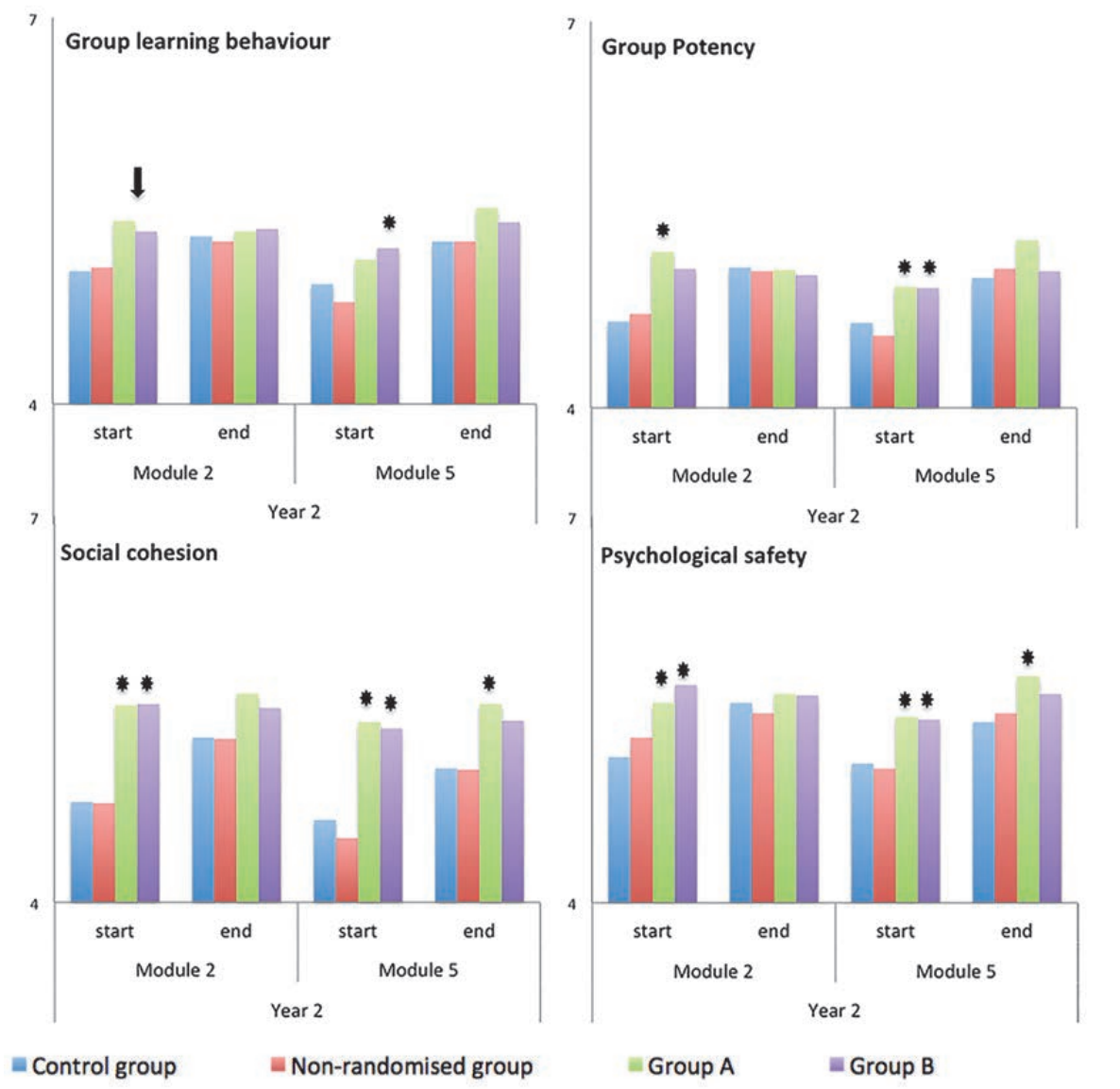

Figure 3: Learning processes in formal groups

his figure depicts mean perceptions of the four parameters for effective group processes. These learning processes were assessed in two modules in the second curriculum year. The * represents a difference from the control group with a pvalue $\leq 0.05$. The arrow represents a significant difference when both intervention groups were combined to improve power and overcome the low number of students in the intervention groups in year 2 (approximately 40 students). Please note that $Y$-axis starts at 4 since this was 'neutral 'on the scale. 
Table 2: Effect sizes of the learning processes in formal groups over time Hierarchical cross-classified data analyses reveal that the intervention groups $A$ and $B$ perceive higher group learning processes in curriculum year 2 compared to the control group (C) at observation 0, the start of the module. GLB: Group learning behaviour, Potency: Group Potency, Cohesion: Social cohesion, Safety: Psychological Safety. Effect sizes are given in regression coefficients, with standard errors between brackets. Obs 0 : starting point in the module. Slope: increase ( $\beta)$ between the start (obs 0 ) and the end of the module (obs 1). $C=$ control group, $A$ \& $B$ are the intervention groups (small subsets), and $n R$ is the non-randomised group of students. * signifies $p$-value $\leq 0.05$.

\begin{tabular}{|c|c|c|c|c|}
\hline & GLB & Potency & Cohesion & Safety \\
\hline \multicolumn{5}{|c|}{ Year 2 - Module 2} \\
\hline Obs 0 (C) & $5.00(.11)$ & $4.65(.12)$ & $4.75(.12)$ & $5.10(.11)$ \\
\hline A & $0.42(.24)$ & $* 0.58(.27)$ & $* 0.78(.24)$ & $* 0.47(.21)$ \\
\hline B & $0.32(.24)$ & $0.42(.26)$ & $* 0.80(.23)$ & $* 0.58(.21)$ \\
\hline $\mathrm{nR}$ & $0.00(.11)$ & $0.04(.11)$ & $-0.02(.12)$ & $0.13(.12)$ \\
\hline SLOPE (C) & $0.31(.09)^{*}$ & $0.44(.10)^{*}$ & $0.55(.10)^{*}$ & $0.45(.10)^{*}$ \\
\hline A & $*^{*}-0.39(.15)$ & *-0.59 (.17) & $*_{-}-0.46(.18)$ & $*_{-0.39}(.17)$ \\
\hline B & $-0.27(.14)$ & $*-0.48(.16)$ & $*_{-} 0.59(.17)$ & $*_{-} 0.52(.16)$ \\
\hline $\mathrm{nR}$ & $-0.17(.12)$ & $-0.19(.13)$ & $-0.11(.14)$ & $*_{-} 0.28(.13)$ \\
\hline \multicolumn{5}{|c|}{ Year 2 - Module 5} \\
\hline Obs 0 (C) & $4.93(.08)$ & $4.66(.08)$ & $4.63(.09)$ & $5.08(.08)$ \\
\hline A & $0.19(.14)$ & $* 0.28(.13)$ & $* 0.77(.19)$ & $* 0.37(.16)$ \\
\hline B & $* 0.28(.14)$ & $* 0.27(.13)$ & *0.73 (.18) & $* 0.36(.15)$ \\
\hline $\mathrm{nR}$ & $*_{-0.20}(.10)$ & $-0.06(.10)$ & $-0.12(.11)$ & $-0.06(.11)$ \\
\hline SLOPE (C) & $0.29(.07)^{*}$ & $0.32(.07)^{*}$ & $0.41(.08)^{*}$ & $0.29(.08)^{*}$ \\
\hline A & $0.10(.12)$ & $0.05(.13)$ & $*-0.27(.15)$ & $0.02(.14)$ \\
\hline B & $-0.10(.12)$ & $-0.20(.13)$ & $*_{-}-0.36(.14)$ & $-0.11(.13)$ \\
\hline $\mathrm{nR}$ & $0.18(.10)$ & $0.11(.10)$ & $0.06(.12)$ & $0.09(.11)$ \\
\hline
\end{tabular}


Table 3: Learning in formal groups over time: a problem of power? Since the subsets of the class ( $A$ and $B$ ) are composed of only approximately 40 students in curriculum year 2, the lack of power could explain why differences between the control group and the subsets of the classes did not reach significance in year 2. Therefore, the intervention groups were combined in the analyses of the modules in the second year. Again, the control group (C) is compared to the intervention groups $(A+B)$ and the non-randomised student group $(n R)$. * signifies $p$-value $\leq 0.05$.

\begin{tabular}{|c|c|c|c|c|}
\hline & GLB & Potency & Cohesion & Safety \\
\hline \multicolumn{5}{|c|}{ Year 2 - Module 2} \\
\hline obs 0 (C) & $5.00(.11)$ & $4.65(.12)$ & $4.75(.11)$ & $5.10(.11)$ \\
\hline$A+B$ & $* 0.37(.18)$ & $* 0.50(.20)$ & $* 0.79(.18)$ & $* 0.53(.16)$ \\
\hline $\mathrm{nR}$ & $0.00(.11)$ & $0.04(.11)$ & $-0.02(.12)$ & $0.13(.12)$ \\
\hline Slope (C) & $0.31(.09)^{*}$ & $0.44(.10)^{*}$ & $0.55(.10)^{*}$ & $0.45(.010)^{*}$ \\
\hline$A+B$ & $*_{-}-0.32(.12)$ & $*_{-0.53(.14)}$ & $*_{-0.53(.14)}$ & $*_{-0.46}(.13)$ \\
\hline $\mathrm{nR}$ & $-0.16(.12)$ & $-0.19(.13)$ & $-0.11(.14)$ & $* 0.28(.13)$ \\
\hline \multicolumn{5}{|c|}{ Year 2 - Module 5} \\
\hline obs 0 (C) & $4.93(.07)$ & $4.66(.07)$ & $4.63(.09)$ & $5.08(.08)$ \\
\hline$A+B$ & $*^{*} 0.24(.11)$ & $* 0.27(.11)$ & $* 0.75(.14)$ & $* 0.36(.12)$ \\
\hline $\mathrm{nR}$ & $-0.20(.10)$ & $-0.07(.10)$ & $-0.12(.11)$ & $-0.06(.11)$ \\
\hline Slope (C) & $0.29(.07)^{*}$ & $0.32(.07)^{*}$ & $0.41(.08)^{*}$ & $0.29(.08)^{*}$ \\
\hline$A+B$ & $-0.00(.09)$ & $-0.08(.10)$ & $*-0.32(.12)$ & $-0.05(.11)$ \\
\hline $\mathrm{nR}$ & $0.18(.09)$ & $0.12(.10)$ & $0.07(.12)$ & $0.09(.11)$ \\
\hline
\end{tabular}

\section{LEARNING PROCESSES IN THE INFORMAL LEARNING CONTEXT}

Graphical illustrations (see figure 4 and the video with the 3D images of the networks) show that students' build informal social networks within the subsets of the class in either one of the two intervention groups or the large subset over two years.

The E-I indexes (table 4) quantify the invisible barriers between the subsets showing that the three subsets hardly share any information external to their own subset of the class. These results demonstrate that a simple change in educational design has strong effects on the students' learning process for (at least) 22 months. 


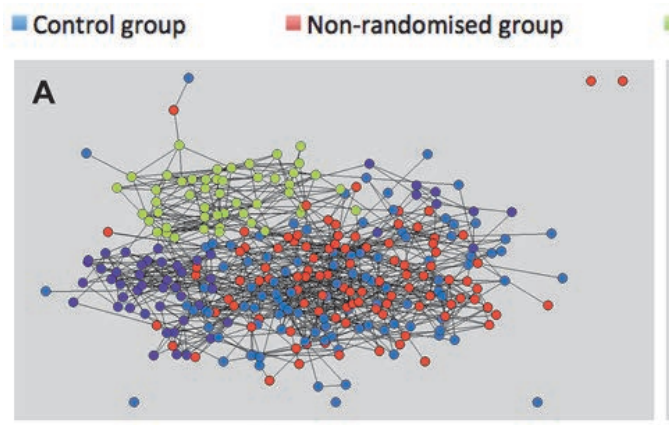

\section{Group A $\quad$ Group B}
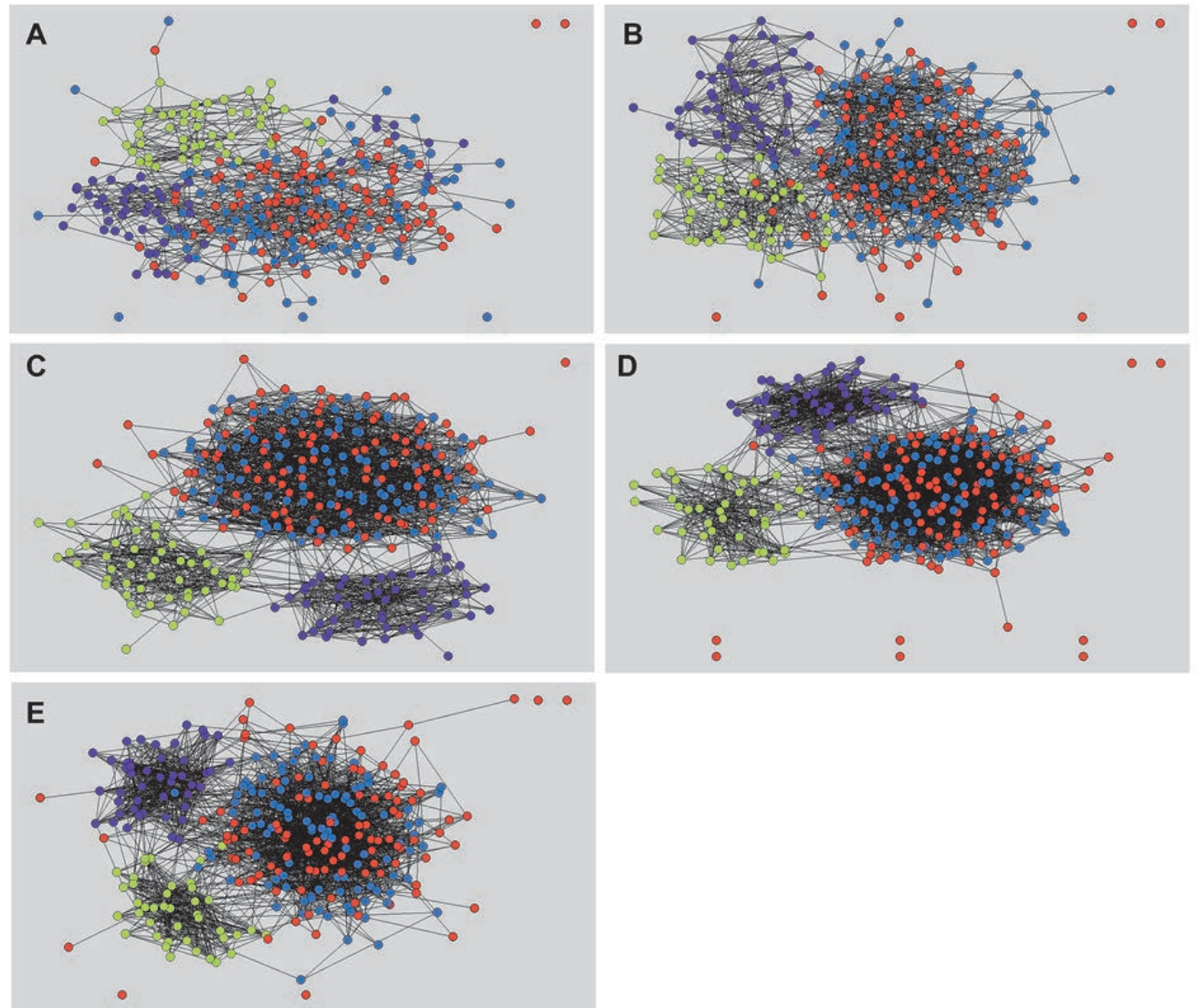

Figure 4: Visualisation of learning among students in the informal learning context over time

These figures illustrate how students' learning in the informal context is arranged within the subsets of the class over time $(T 1-T 5=A-E)$. The nodes (students) are connected by lines, which represent information flow among the students. In these learning networks, the lines indicated that student received information from the other students (GET network). The colour of each node depicts the subset of the class.

Table 4: Students learn primarily within the subsets of the class in the informal context

The $E-I$ indexes show strong internal orientations when interacting in the informal context over time in three networks (friendship, giving and getting module-related information). The large subset is composed of a mixed group of students from the control group and the nonrandomised group. All E-I indexes are significantly different $(p<0.05)$ from $H_{0}$ hypothesis $E=I$.

\begin{tabular}{|l|l|ccccc|}
\hline & & T1 & T2 & T3 & T4 & T5 \\
\hline Friendships & Large subset & -0.90 & -0.93 & -0.96 & -0.95 & -0.93 \\
& Group A & -0.75 & -0.83 & -0.89 & -0.81 & -0.81 \\
& Group B & -0.69 & -0.75 & -0.86 & -0.86 & -0.81 \\
\hline & Large subset & -0.90 & -0.93 & -0.96 & -0.95 & -0.92 \\
Giving & Group A & -0.75 & -0.81 & -0.85 & -0.80 & -0.78 \\
$\begin{array}{l}\text { Module related } \\
\text { information }\end{array}$ & Group B & -0.69 & -0.78 & -0.85 & -0.82 & -0.80 \\
\hline & Large subset & -0.90 & -0.93 & -0.96 & -0.95 & -0.92 \\
Getting & & -0.78 & -0.81 & -0.85 & -0.80 & -0.78 \\
$\begin{array}{l}\text { Module related } \\
\text { information }\end{array}$ & Group A & -0.71 & -0.78 & -0.85 & -0.83 & -0.81 \\
\hline
\end{tabular}




\section{Perceptions of the interVEntion}

Negative influences of the intervention experienced by the 38 students interviewed from the intervention groups (subsets A \& B) were limited to uneasy feelings towards collaboration in future groups in which the majority of students will not be familiar to them, not liking to be more frequently involved with a student whom he or she did not like, and fewer time slots to plan clinical skills training sessions (see table 1). The students in the control group did not perceive any effects of the randomised controlled trial.

Table 5: How 38 students from the intervention groups perceived the intervention

\begin{tabular}{|c|c|c|}
\hline Advantages & $\mathrm{n}$ & $\%$ \\
\hline $\begin{array}{l}\text { I was familiar with the members of tutorial groups which made the } \\
\text { group develop more quickly within the modules (from the end of } \\
\text { year one and onwards) }\end{array}$ & 13 & 34.2 \\
\hline $\begin{array}{l}\text { I was familiar with the members of the tutorial groups, providing } \\
\text { me with feeling that I knew what to expect from the group } \\
\text { (members) }\end{array}$ & 13 & 34.2 \\
\hline $\begin{array}{l}\text { I was familiar with the members of the tutorial groups, which } \\
\text { made collaboration in the group easier }\end{array}$ & 24 & 63.2 \\
\hline $\begin{array}{l}\text { I was familiar with the members of the tutorial groups, which } \\
\text { enabled us to provide and receive feedback to one another }\end{array}$ & 8 & 21.1 \\
\hline $\begin{array}{l}\text { I was familiar with the members in the skills training sessions } \\
\text { which made me feel more comfortable practising skills on one } \\
\text { another }\end{array}$ & 8 & 21.1 \\
\hline $\begin{array}{l}\text { I spent much time with many of the members of the intervention } \\
\text { group which resulted in a close group of friends; this made me feel } \\
\text { 'at home' in the university }\end{array}$ & 5 & 13.2 \\
\hline $\begin{array}{l}\text { We met regularly again in tutorial groups which enabled us to see } \\
\text { one another's development in collaboration competencies }\end{array}$ & 3 & 7.9 \\
\hline \multicolumn{3}{|l|}{ Disadvantages } \\
\hline $\begin{array}{l}\text { There was a limited number of options to plan skills training } \\
\text { sessions }\end{array}$ & 6 & 15.8 \\
\hline I am not familiar to the remaining students of the class & 13 & 34.2 \\
\hline $\begin{array}{l}\text { If I did not like collaborating with another member in the group or } \\
\text { in an assignment, there is a high risk to be involved in a future } \\
\text { group or assignment again }\end{array}$ & 3 & 7.9 \\
\hline $\begin{array}{l}\text { I like meeting new persons every module again, which was not } \\
\text { possible in this intervention group }\end{array}$ & 5 & 13.2 \\
\hline $\begin{array}{l}\text { I was familiar with the members of the future group I was } \\
\text { allocated to. Sometimes I expected bad collaboration from this } \\
\text { group, which did not motivate me to participate in the group }\end{array}$ & 2 & 5.3 \\
\hline
\end{tabular}




\section{Discussion}

This randomised controlled study aimed at improving the students' learning processes in a large class ( $n \sim 320)$. The first outcome measure shows that making a class seem small resulted in more effective learning processes in formally organised groups. These findings align with those from the team-based literature describing that group members need to get to know one another before the group can be considered 'effective' (Decuyper et al., 2010; Mathieu et al., 2008). In other words, group member familiarity is thus an important influence on the quality of collaboration in small groups. Changing the composition of groups in the medical programme to create high member familiarity in these groups indeed induced more effective group learning processes as indicated by the chosen parameters, such as more positive psychological safety, social cohesion, group potency and group learning behaviour. Although it might seem odd to focus on the learning processes, the quality of formal learning processes in small groups is the foundation for learning outcomes such as knowledge retention. Therefore, studying formal learning processes provides a direct assessment of the student learning behaviour.

Moreover this study discovered that the educational design directed informal learning to occur mainly within the subset of the class over 22 months, which might even enhance the effects of the intervention. In organisational sciences, research has shown that large networks need quite some energy to be maintained (Cross \& Thomas, 2008). Therefore big networks are not necessarily effective networks. In contrast, as safety and judgements of expertise are the strongest indicators of successful informal learning from peers (Cross \& Thomas, 2008), it is likely that informal learning in networks is also more effective in these small classes. Alternatively, positive experiences during informal learning could contribute to group learning in the formally organised small groups. Therefore, this intervention study might have created a better context to learn outside formal activities as well. As informal learning is regarded as a choice for students, it has been regarded as difficult to steer this learning process in a variety of disciplines. This study is therefore a very promising example that it is possible for educators to direct informal learning among students as well.

Furthermore, the interviews exploring students' perception of the (side) effects of the intervention show only minor to negligible 'side effects'. Besides the interviews, another indication of positive perceptions of students towards involvement in a small subset was the rather limited drop out rate.

Finally, this study discovered that involvement in a large class had a negative influence on the students learning process. Difficulties in teaching large classes had already been noticed in traditional lecture-based learning contexts (Anderson, 1964; Jenkins, 1991; McConnell \& Sosin, 1984). In these traditional learning contexts the solution to involve all students in the mega-class was to include group-based 
activities in the learning contexts (Murdoch \& Guy, 2002). However, in powerful learning contexts, which are founded upon learning in small groups, the effect of large classes had to our knowledge not been investigated previously.

Time plays a key role in developing students' collaborative learning processes. Although we measured processes representing formal group interaction in five modules over two years we cannot yet define precisely the timeframe needed for students in the intervention arm to start experiencing more positive learning processes than the control group. At the same time, within the modules, it cannot be defined when the control group develops to the same level as the intervention arm. This shows that time is still an unsolved parameter with respect to the students' learning process. Previous studies in team learning recognise groups as dynamic social systems changing over time (Decuyper et al., 2010). Therefore future research in education should focus on the influence of time on groups within and over modules.

In the search for evidence-based practice in medical education, randomised controlled trials are valuable tools to show how education can be improved. Especially since very little studies have applied this research method to show effects of the educational context on learning. The setting of an actual learning context is strength of this study and makes the outcomes much more ecologically valid than controlled (lab) experiments, but it also made the study more complex. A pure experimental design, for example, would not have included a control group mixed with a non-randomised group. However, because it was situated in an actual learning context, the study could not avoid mixing the controls with students that do not want to participate or who could not be included. The most important reason was that it would have been unethical to give the non-participants anything but an optimal 'standard education'. Had we separated out the control group and the nonparticipants then the participants would have been automatically put in their own small subset and thus be similar to the intervention groups. When analysing their results we found that the GPA was lower in the not-randomised group, which indicates that the latter group consisted of 'weaker' students and could affect the students from the control group negatively. However, no differences were found in learning processes between the control group and the not randomised student group in the first and second curriculum years. We can therefore safely conclude that mixing the control group and the not-randomised student group did not weaken the research design and conclusions that were drawn from this study. Moreover, since two intervention groups ( $\&$ \& $)$ were used in one experiment, each replicating the findings of the other, we conclude that the beneficial effect of the intervention is valid and replicable. The validity of our results is strongly founded on the collaborative learning literature aligning to Kane's notion of an argument-based approach to validity (Kane, 1992). Since this research was conducted in an actual learning context, we believe that the results are quite unique and underline the ecologic validity of the results, which is normally a critical downside in pure tightly controlled experimental studies. 
This study was performed in the context of the Maastricht Medical School, a Problem-Based Learning context. We want to argue that the results of this intervention study are also beneficial to other small-group learning contexts. Moreover, increasing the strength of the intervention could further accelerate the positive effects. In this study we manipulated only a part of the educational processes (the tutorial groups) and not all other educational activities (practical, lectures). It is plausible to assume that with a stronger intervention even stronger effects would be caused. In a further step-up, for example linking a student group to subgroups of faculty further improvement of the efficacy of formal and informal learning processes could be achieved, as this study clearly shows that classes need to seem small to reach optimal learning processes. In such study we feel competency development should also be introduced as outcome parameters. Based on the data described in this paper, we advise our medical school and others, which make use of a powerful learning context to change the formal group design and make large classes seem small.

\section{Funding:}

Competing interests:

Data sharing:

Acknowledgements
OAA was supported by Veni grant number 916.96 .059 from the Netherlands Organization for Scientific Research. All authors declare: no support from any organisation for the submitted work; no financial relationships with any organisations that might have an interest in the submitted work in the previous 3 years; no other relationships or activities that could appear to have influenced the submitted work.

No data was used in other manuscripts or published previously.

We thank the students in the class for participating in the longitudinal studies, the board of directors of the Maastricht Medical School for allowing an intervention to take place in a 'live' educational programme for two years, Mrs. Delnooz for her work on organising the allocation of students within the subsets of the class, and all others that have invested time and efforts in this research project to increase the effectiveness of medical educational designs.

\section{REFERENCES}

Anderson, W. T. (1964). Large classes in elementary accounting. The accounting review, 1034-1036.

Braun, V., \& Clarke, V. (2006). Using thematic analysis in psychology. Qualitative research in psychology, 3(2), 77-101. doi: 10.1191/1478088706qp063oa
Bridges, E. M. (1992). Implementing Problem-Based Learning in a Higher Education Context. In E. M. Bridges (Ed.), Problem-Based Learning for administrators. Oregon: ERIC Clearninghouse on Educational Management, University of Oregon.

Center, M. U. M. (Downloaded July 2013). http://www.azm.nl/info/azMorganisatie/MEC/wmo onderzoek/indienenonderzoek1. 
Cross, R., \& Thomas, R. J. (2008). How top talent uses networks and where rising stars get trapped. Organizational Dynamics, 37(2), 165-180.

De Grave, W., Schmidt, H. G., Belie, N. J. J., Moust, J. H. C., De Volder, M. L., \& Kerkhofs, L. M. M. (1985). Effecten van verschillende typen van activatie van voorkennis of recall, gemeten met een aanvultoets (Effects of different types of activation of prior knolwege on recall, measured with a completeion procedure). Paper presented at the Onderwijs Research Dagen, Tilburg.

Decuyper, S., Dochy, F., \& van den Bossche, P. (2010). Grasping the dynamic complexity of team learning: An integrative model for effective team learning in organisations. Educational Research Review, 5, 111133. doi: 10.1016/j.edurev.2010.02.002

Edmondson, A. (1999). Psychological safety and learning behaviour in work teams. Administrative science quarterly, 44, 350-383.

Fielding, A., \& Goldstein, H. (2006). Cross-classified and multiple membership structures in multilevel models: An Introduction and review Education and skills. Nottingham: University of Birmingham.

Gibson, C. B., Randel, A. E., \& Early, P. C. (2000). Understanding group efficacy. Group \& organization management, 25(1), 67-97.

Gile, K., \& Handcock, M. S. (2006). Model-based assessment of the impact of missing data on inference for networks. Center for statistics and the social sciences, (working paper no.66). University of Washington, Seattle.

Goodman, P. S., \& Dabbish, L. A. (2011). Methodological issues in measuring group learning. Small group research, 42, 379-404. doi: $10.1177 / 1046496410385471$

Gruenfeld, D. H., Mannix, E. A., Williams, K. Y., \& Neale, M. A. (1996). Group composition and decision making: How member familiarity and information distribution affect process and performance. Organizational behavior and human decision processes, 67(1), 1-15.

Gully, S. M., Incalcaterra, K. A., Joshi, A., \& Beaubien, J. M. (2002). A meta-analysis of team-efficacy, potency, and performance: interdependence and level of analysis as moderators of observed relationships. Journal of applied psychology, 87(5), 819-832.

Guzzo, R. A., Yost, P. R., Campbell, J. R., \& Shea, G. P. (1993). Potency in teams: Articulating a construct. British journal of social psychology, 32, 87-106.

Harrington, B., \& Fine, G. A. (2006). Where the Action Is: Small Groups and Recent Developments in Sociological Theory. Small group research, 37(1), 419. doi: $10.1177 / 1046496405284356$

Harrison, D. A., Mohammed, S., McGrath, J. E., Florey, A. T., \& Vanderstoep, S. W. (2003). Time matters in team performance: effects of member familitary, entrainment, and task discontinuity on speed and quality. Personnel Psychology, 56(3), 663-669.
Hommes, J., Rienties, B., de Grave, W., Bos, G. Schuwirth, L., \& Scherpbier, A. (2012). Visualising the invisible: A network approach to reveal the informal social side of student learning. Advances in Health Sciences Education, 17(5), 743-757. doi: 10.1007/s10459-012-9349-0

Ibarra, H., \& Andrews, S. B. (1993). Power, Social Influence, and Sense Making: Effects of Network Centrality and Proximity on Employee Perceptions. Administrative Science Quarterly, 38(2), 277-303.

Jenkins, J. J. (1991). Teaching Psychology in Large Classes: Research and Personal Experience. Teaching of psychology, 18(2), 74-80.

Johnson, D., \& Johnson, R. (2002). Social interdependence theory and university instruction: Theory into practice. Swiss journal of psychology, 61(3), 119-129.

Kane, M. T. (1992). An argument-based approach to validation. Psychological bulletin, 112(3), 527-535. doi: 10.1037/0033-2909.112.3.527

Katz, N., Lazer, D., Arrow, H., \& Contractor, N. (2004). Network theory and small groups. Small Group Research, 35(3), 307-332. doi 10.1177/1046496404264941

Konings, K. D., Brand-Gruwel, S., \& van Merrienboer, J. J. G. (2005). Towards more powerful learning environments through combining the perspectives of designers, teachers, and students. British Journal of Educational Psychology, 75, 645-660. doi: 10.1348/000709905X43616

Krackhardt, D., \& Hanson, J. R. (1993). Informal networks: The company behind the chart. Harvard Business Review, July-August, 104-111.

Krackhardt, D., \& Stern, R. N. (1988). Informal networks and organizational crises: An experimental simulation. Social Psychology Quarterly, 51(2), 123140.

Kuper, A., Lingard, L. A., \& Levinson, W. (2008). Practice Qualitative Research: Critically appraising qualitative research. British Medical Journal, 337, 687-692. doi: 10.1136/bmj.a1035

Lei, S. A. (2010). Group composition affecting student interaction and achievement: instructors perspectives. Journal of instructional psychology, 37(4), 317-325.

Mathieu, J., Maynard, M. T., Rapp, T., \& Gilson, L. (2008). Team effectiveness 1997-2007: A review of recent advancements and a glimpse into the future. Journal of Management, 34(3), 410-476. doi: $10.1177 / 0149206308316061$

McConnell, C. R., \& Sosin, K. (1984). Some determinants of student attituteds toward large classes. Research in Economic Education, 181-190.

Michaelsen, L. K., \& Richards, B. (2005). Drawing Conclusions from the Team-Learning Literature in Health-Sciences Education: A Commentary Teaching and learning in medicine, 17(1), 85-88.

Moruzi, C. K., \& Norman, G. R. (2002). Validity of Admissions Measures in Predicting Performance Outcomes: The Contribution of Cognitive and NonCognitive Dimensions. Teaching and learning in medicine, 14(1), 34-42. doi: 10.1207/S15328015TLM1401 9 
Murdoch, B., \& Guy, P. W. (2002). Active learaning in small and large classes. Accounting Education, 11(3), 271-282.

Roschelle, J., \& Teasley, S. D. (1995). The construction of shared knowledge in collaborative problem solving. In C. E. O'Malley (Ed.), Computer supported collaborative learning (pp. 69-197). Berlin: SpringerVerlag.

Sargent, L. D., \& Sue-Chan, C. (2001). Does diversity affect group efficacy? The intervening role of cohesion and task-interdependence Small group research, 32, 426-450.

Schmidt, H. G. (2009). Constructivist, Problem-Based Learning Does Work: A Meta-Analysis of Curricular Comparisons Involving a Single Medical School. Educational psychologist, 44(4), 227-249. doi: 10.1080/00461520903213592

Schmidt, H. G., De Grave, W., De Volder, M. L., Moust, J. H. C., \& Patel, V. L. (1989). Explanatory models in the processing of science text: the role of prior knolwege activation through small-group discussion. Journal of Educational Psychology, 81, 610-619.

Schmidt, H. G., Rotgans, J. I., \& Yew, E. H. J. (2011). The process of Problem-Based Learning: what works and why. Medical Education, 45, 792-806. doi: 10.1111/j.1365-2923.2011.04035.x

Simons, R.-J., van der Linden, J., \& Duffy, T. (2000). New learning. Dordrecht, the Netherlands: Kluwer Academic Publishers.

Slavin, R. E. (1996). Research on cooperative learning and achievement: What we know, what we need to know. Contemporary educational psychology, 21, 43-69.

Stajkovic, A. D., Nyberg, A. J., \& Lee, D. (2009). Collective efficacy, group potency, and group performance: Meta-analyses of their relationships and test of a mediation model. Journal of applied psychology, 94(3), 814-828.

StataCorp, L. (2010). Stata (Version 11.1). Texas, USA: Stata Corporation. van Blankenstein, F. M., Dolmans, D. H. J. M., van der Vleuten, C. P. M., \& Schmidt, H. G. (2009). Which cognitive processes support learning during smallgroup discussion? The role of providing explanations and listening to others. Instructional Science, 32(2), 1-16. doi: 10.1007/s11251-0099124-7

van Boxtel, C., van der Linden, J., \& Kanselaar, G. (2000). Collaborative learning tasks and the elaboration of conceptual knowledge. Learning and instruction, 10, 311-330.

van den Bossche, P., Gijselaers, W. H., Segers, M., \& Kirschner, P. A. (2006). Social and cognitive factors driving teamwork in collaborative learning environments: Team learning beliefs and behaviors. Small Group Research, 37(5), 490-521. doi: $0.1177 / 1046496406292938$

van der Linden, J., Erkens, G., Schmidt, H. G., \& Renshaw, P. (2000). Collaborative learning. London: Kluwer Academic Publishers.

van der Vegt, G., Emans, B., \& van de Vliert, E. (1998). Motivating effects of task and outcome interdependence in work teams. Group \& organization management, 23(2), 124-143.

van Offenbeek, M. (2001). Processes and outcomes of team learning. European journal of work and organizational psychology, 10(3), 303-317.

Visschers-Pleijers, A. J. S. F., Dolmans, D. H. J. M., Wolfhagen, H. A. P., \& van der Vleuten, C. P. M. (2003). Development and validation of $a$ questionnaire to identify interactions that promote deep learning in PBL. Paper presented at the 10th Euopean conference of research on learning and instruction, Padova, Italy.

Visschers-Pleijers, A. J. S. F., Dolmans, D. H. J. M., Wolfhagen, H. A. P., \& van der Vleuten, C. P. M. (2004). Exploration of a method to analyze group interactions in problem-based learning. Medical Teacher, 26(5), 471-478. doi: $10.1080 / 01421590410001679064$ 


\section{SUPPLEMENTARY MATERIALS (APPENDIX)}

These figures depicts mean perceptions of the four parameters for effective group processes. These learning processes were assessed in two modules in the first and second curriculum year, observed twice per module. The intervention was expected to take effect when the small groups were randomised to new small groups at least twice. However, to understand and monitor the effects of mixing the control group and the non-randomised group to generate a large subset, we explored what happened in the first two small groups that students were involved in.

The * represents a significant difference from the control group with a $p$-value $\leq 0.05$. The arrow represents a significant difference when both intervention groups are added to counterbalance the lack of power due to a low number of students in the small subsets in year 2 (circa 40 students). Please note that $Y$-axis starts at 4 since this was 'neutral 'on the scale.
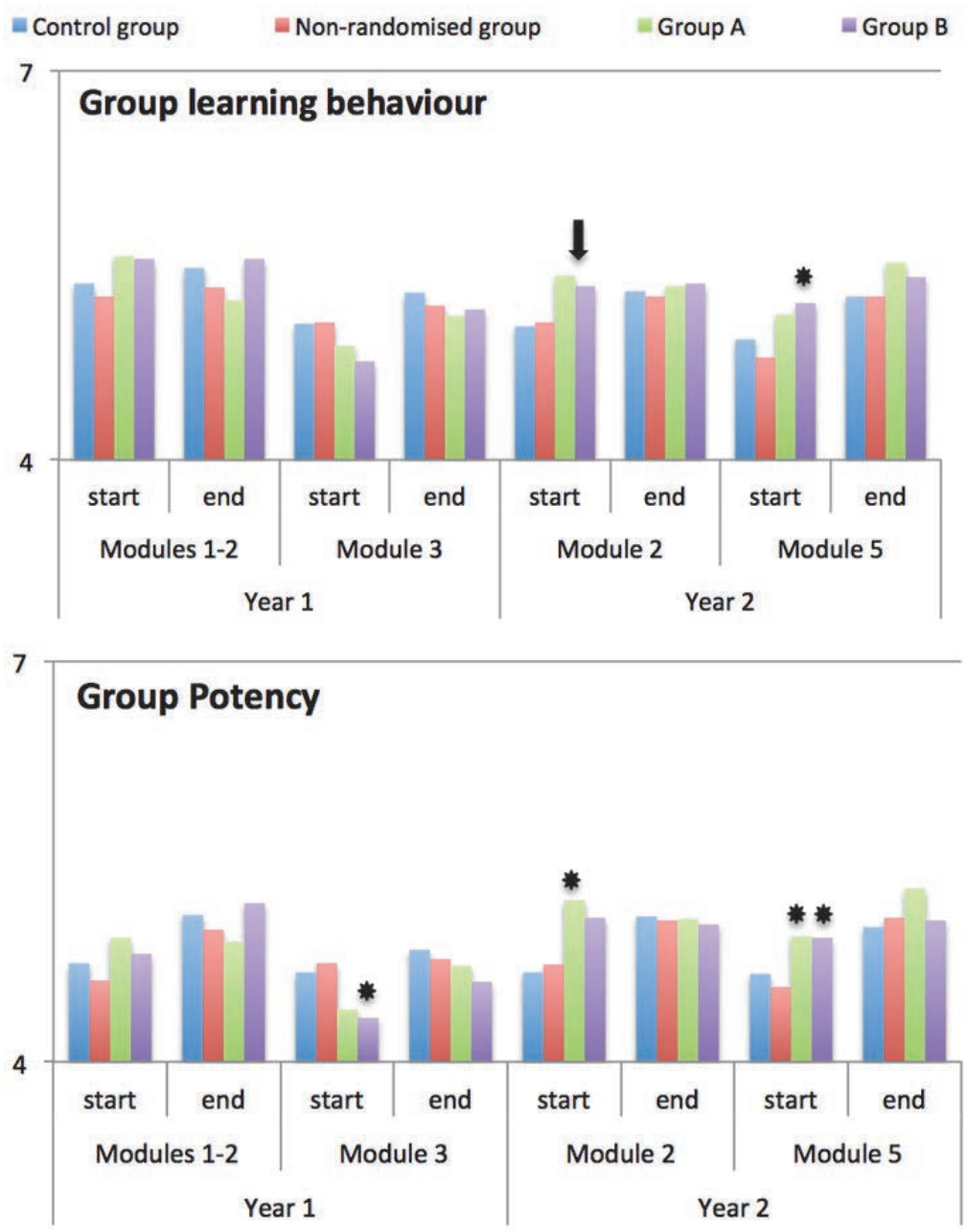

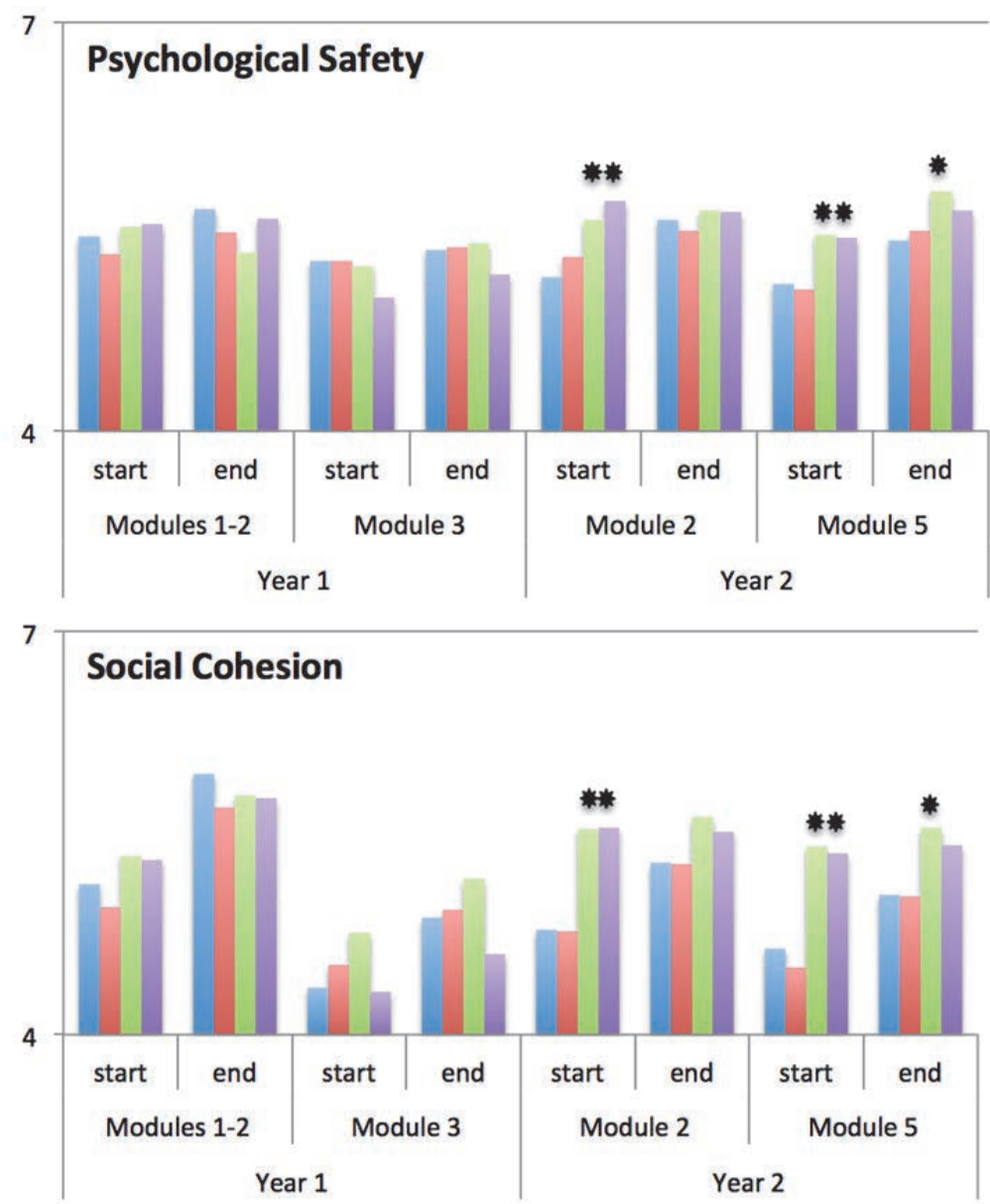

Table 1: Effect sizes of learning in small groups in the formal context two curriculum years GLB: Group learning behaviour, Potency: Group Potency, Cohesion: Social cohesion, Safety: Psychological Safety. Effect sizes are given in regression coefficients, with standard errors between brackets. Obs 0 : starting point in the module. Slope: increase ( $\beta$ ) between the start (obs 0 ) and the end of the module (obs 1 ). $C=$ control group, $A \& B$ are the intervention groups (small subsets), and $n R$ is the non-randomised group of students. ${ }^{*}$ signifies $p$-value $\leq 0.05$. 


\begin{tabular}{|c|c|c|c|c|}
\hline & GLB & Potency & Cohesion & Safety \\
\hline \multicolumn{5}{|c|}{ Year 1 - Module 1 \& 2} \\
\hline Obs 0 (C) & $5.34(.10)$ & $4.72(.10)$ & $5.08(.11)$ & $5.40(.10)$ \\
\hline A & $0.25(.20)$ & $0.21(.20)$ & $0.25(.20)$ & $0.12(.19)$ \\
\hline B & $0.19(.20)$ & $0.08(.20)$ & $0.16(.20)$ & $0.10(.10)$ \\
\hline $\mathrm{nR}$ & $-0.04(.10)$ & $-0.08(.10)$ & $-0.12(.14)$ & $-0.06(.10)$ \\
\hline SLOPE (C) & $0.04(.09)$ & $0.29(.13)^{*}$ & $0.76(.12)^{*}$ & $0.14(.09)$ \\
\hline A & $*_{-0.39}(.16)$ & $-0.31(.25)$ & $-0.31(.22)$ & $*_{-} 0.34(.15)$ \\
\hline B & $-0.03(.16)$ & $0.10(.25)$ & $-0.27(.22)$ & $-0.08(.15)$ \\
\hline $\mathrm{nR}$ & $0.02(.12)$ & $0.11(.12)$ & $0.01(.00)$ & $0.02(.12)$ \\
\hline \multicolumn{5}{|c|}{ Year 1 - Module 3} \\
\hline Obs 0 (C) & 5.03 & $4.66(.08)$ & $4.35(.12)$ & $5.25(.08)$ \\
\hline A & $-0.15(.16)$ & $-0.16(.16)$ & $0.40(.23)$ & $-0.03(.14)$ \\
\hline B & $-0.25(.16)$ & $*_{-0.31(.16)}$ & $-0.01(.23)$ & $-0.25(.14)$ \\
\hline $\mathrm{nR}$ & $0.02(.10)$ & $-0.08(.11)$ & $0.13(.13)$ & $-0.02(.11)$ \\
\hline SLOPE (C) & $0.26(.07)^{*}$ & $0.19(.08)^{*}$ & $0.54(.10)^{*}$ & $0.09(.08)$ \\
\hline A & $-0.03(.12)$ & $0.03(.14)$ & $-0.13(.17)$ & $0.07(.13)$ \\
\hline B & $0.13(.13)$ & $0.07(.14)$ & $-0.27(.17)$ & $0.06(.14)$ \\
\hline $\mathrm{nR}$ & $-0.13(.10)$ & $-0.14(.11)$ & $-0.12(.14)$ & $0.02(.11)$ \\
\hline \multicolumn{5}{|c|}{ Year 2 - Module 2} \\
\hline Obs 0 (C) & $5.00(.11)$ & $4.65(.12)$ & $4.75(.12)$ & $5.10(.11)$ \\
\hline A & $0.42(.24)$ & $* 0.58(.27)$ & $* 0.78(.24)$ & $* 0.47(.21)$ \\
\hline B & $0.32(.24)$ & $0.42(.26)$ & $* 0.80(.23)$ & $* 0.58(.21)$ \\
\hline$n R$ & $0.00(.11)$ & $0.04(.11)$ & $-0.02(.12)$ & $0.13(.12)$ \\
\hline SLOPE (C) & $0.31(.09)^{*}$ & $0.44(.10)^{*}$ & $0.55(.10)^{*}$ & $0.45(.10)^{*}$ \\
\hline$A$ & $*-0.39(.15)$ & $*-0.59(.17)$ & $*_{-0.46(.18)}$ & $*_{-0.39(.17)}$ \\
\hline B & $-0.27(.14)$ & $*_{-0.48}(.16)$ & $*_{-0.59}(.17)$ & $*_{-} 0.52(.16)$ \\
\hline $\mathrm{nR}$ & $-0.17(.12)$ & $-0.19(.13)$ & $-0.11(.14)$ & $*_{-0.28}(.13)$ \\
\hline \multicolumn{5}{|c|}{ Year 2 - Module 5} \\
\hline Obs 0 (C) & $4.93(.08)$ & $4.66(.08)$ & $4.63(.09)$ & $5.08(.08)$ \\
\hline A & $0.19(.14)$ & $* 0.28(.13)$ & *0.77 (.19) & $* 0.37(.16)$ \\
\hline B & $* 0.28(.14)$ & ${ }^{*} 0.27(.13)$ & $* 0.73(.18)$ & $* 0.36(.15)$ \\
\hline $\mathrm{nR}$ & $*_{-}-0.20(.10)$ & $-0.06(.10)$ & $-0.12(.11)$ & $-0.06(.11)$ \\
\hline SLOPE (C) & $0.29(.07)^{*}$ & $0.32(.07)^{*}$ & $0.41(.08)^{*}$ & $0.29(.08)^{*}$ \\
\hline A & $0.10(.12)$ & $0.05(.13)$ & $*_{-0.27(.15)}$ & $0.02(.14)$ \\
\hline B & $-0.10(.12)$ & $-0.20(.13)$ & $*_{-0.36}(.14)$ & $-0.11(.13)$ \\
\hline $\mathrm{nR}$ & $0.18(.10)$ & $0.11(.10)$ & $0.06(.12)$ & $0.09(.11)$ \\
\hline
\end{tabular}




\section{CHAPTER 6}
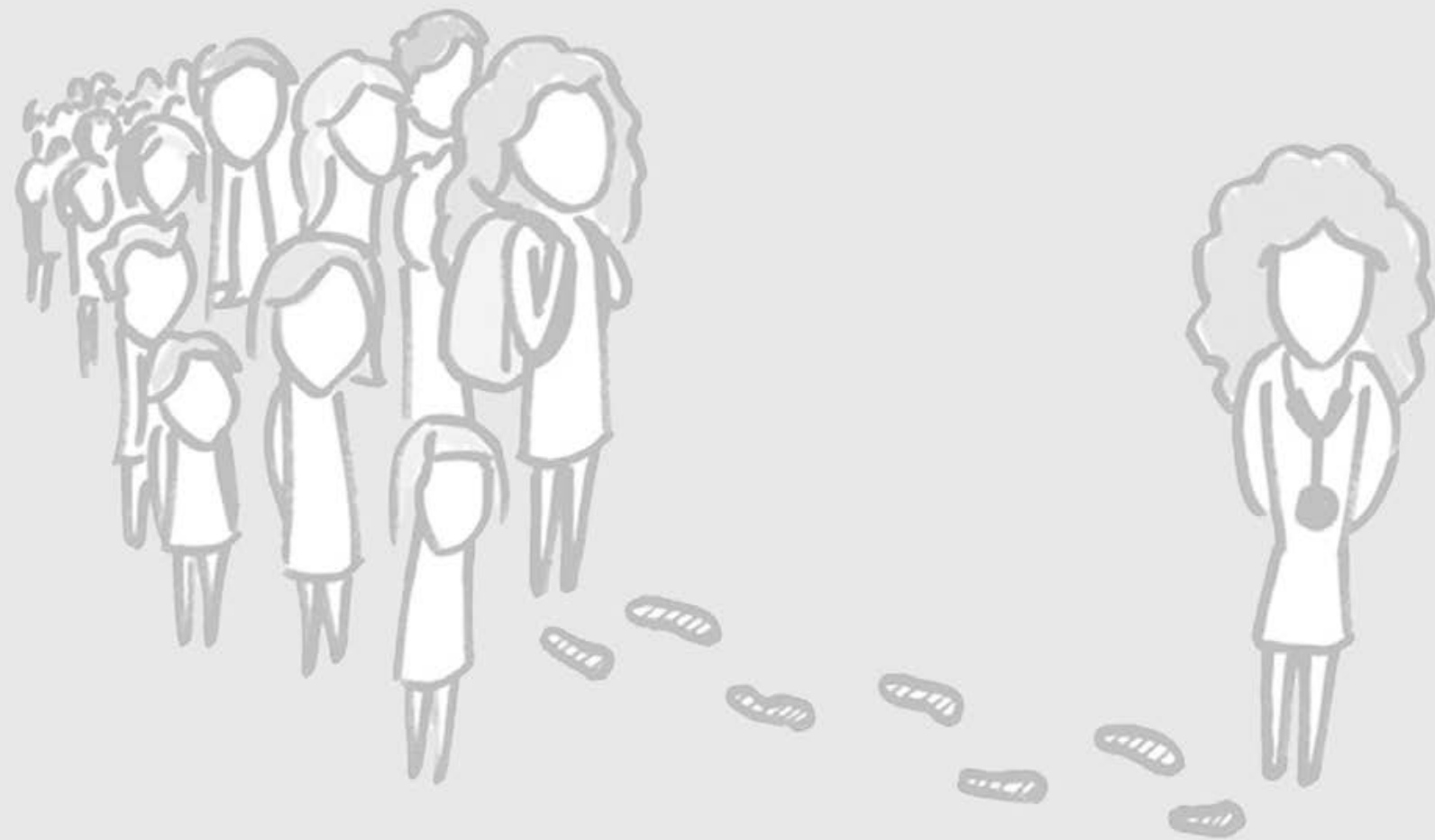


\section{General discussion}

To improve the education of our future doctors we sought to increase the effectiveness of powerful learning contexts. To reach this goal, we first needed to improve the understanding of learning processes at the micro-level. In this dissertation, we focussed on the social process of learning among students. We included the variable 'time' as in 'how collaboration develops over time'. This is an important facet of collaborative learning because time may play a complex and counter-intuitive role in the development of the effectiveness of collaboration in groups. Previous research has explored the elements of learning (the group learning processes) in a group but how time influences and contributes to interaction between these key elements was still largely unknown. We continued deepening our understanding about the social process of learning by unravelling the structure of groups. Our research, both in formally organised and informally self-organised groups emphasized similarities in how students learn through interaction with other students in both contexts. For example, feelings of psychological safety are of primary importance for learning in both the formal and informal learning environments. Both contexts are tightly interwoven and complement one another. For example, convergence of mental models is more rapidly reached when students spend more time learning together informally. Therefore, our studies show that the divide between formal and informal learning is highly artificial, and that both contribute towards the process of (social) learning. It is important to bear in mind that educational research should not only focus on how formally organised groups learn and ignore the informal context.

For consideration of the macro-level of social learning, our final study shows that learning processes among students can be positively influenced. The success of making classes appear small might indicate the need to build communities to shape the social learning context for students. This is in sharp contrast with the development of the current world in which borders seem to have faded through the use of the worldwide web (YouTube, Facebook) and modern-day technology such as cell phones.

\section{RESULTS OF THIS DISSERTATION}

In chapter two we focussed on development of group learning processes over time in formally organised learning groups (tutorial groups). This quantitative study based on six observations in three modules distributed in the course of 1,5 curriculum years, showed that a varying combination of group processes developed within each module and over the three observed periods. Furthermore, groups appeared to develop their group-learning processes over and over again each time the group 
composition changed. The subsequent qualitative study illustrated the developments of psychological safety, interdependence, potency, group learning behaviour, social and task cohesion. Some of these processes were tightly interwoven with each other and occurred rather early in the module (social cohesion and safety for example), while other processes emerged only later in the modules. Two new processes were observed: 'transactive memory' and 'convergence in mental models'. These two emerged only later in the module(s) and - in turn - induced all other processes. These data support the experience or common knowledge that tutorial or small collaborative groups develop over time when students learn together, just like teams or groups in other contexts (Mathieu, Maynard, Rapp, \& Gilson, 2008). Various models of development have been developed to understand and 'stage' the development in groups, including both linear and cyclical models (Carabajal, LaPointe, \& Gunawardena, 2008; Fransen, Weinberger, \& Kirschner, 2013; Mennecke, Hoffer, \& Wynne, 1992). The qualitative data suggest that a non-sequential development model approaches the changes over time best, supporting the hypothesis of Fransen et al. (2013). In other words, processes appear to exist in a certain (not necessarily fixed) order and the context, experience, time, feedback, etcetera influence how the processes further develop or influence one another. The most important conclusion of this mixed methods study is that time indeed plays an important role on group processes. This implies that further research should take into account the factor time when exploring group processes.

In chapter three and four, we have focussed on informal learning through interaction between students. Inspired by other disciplines, mostly organizational sciences, which acknowledge interaction outside groups as a pivotal part of a learning process, we used a social network study to explore the importance of informal learning with other students in medical education. We represented informal learning among students as a social network of students with passive relations (friendship) and instrumental relations (giving and receiving medicine-related information). In chapter three we demonstrated that medical students who took up a more central position in a social network (having most ties to other students or who interacted most with other students) were the students who achieved highest results in their study. Path analyses further revealed that motivation and academic integration were less important than informal social interaction on learning. Although not described in chapter four, the longitudinal study on social networks, we replicated the finding that social networks increased learning among the students; supporting the results found in chapter three.

In chapter four we expanded our investigation into informal learning through interaction among students and explored why and how students developed their informal social networks over time. Also, we explored the influence of formal group structures on informal learning over time, as this is the variable that can be addressed in curriculum organisation. The results of the longitudinal social network analyses and interviews showed that, at the start of the medical programme, formal group composition plays an important role in the determination with which peers students interact. However, in the second study year students interacted almost 
exclusively with students who were not part of their formal groups. In other words, students had developed a personal network. Alignment in character and physical proximity resulted in connections between people. However, the most important predictor factor for sharing information were reciprocal relations; emphasizing the importance of member familiarity to reduce the necessary investment for sharing information (Gruenfeld, Mannix, Williams, \& Neale, 1996; Harrison, Mohammed, McGrath, Florey, \& Vanderstoep, 2003).

In the final study, described in the fifth chapter, we sought to improve the effectiveness of the group learning process by a simple change in the organisation of the curriculum. Often class sizes are large and may be over 300 students per year. If students are randomly allocated to small groups every module again, this will cause them to encounter new peers every 6-10 weeks, with whom these students have to collaborate intensely for a short period of time. An open, pragmatic, randomized controlled intervention study was undertaken to make a large class appear small. The class was divided into two intervention groups of 50 students and a control group of 102 students. The remaining students were mixed with the control group and composed a single large subset. From these subsets, the tutorial groups, and in the first curriculum year, the skills trainings were composed. Students in the intervention group would thus interact more frequently with the same students while students in the large subset would have a very low probability of having to collaborate with the same peers. The primary outcome measures were the group learning processes in tutorial groups. Students in the (small) intervention groups did not need to repeatedly develop their collaboration in their tutorial groups as opposed to the control group, who still required development of their collaboration over time each module again. Because informal interaction is such an important variable in the students' learning processes, the informal social networks were included in this study. It was shown that students almost exclusively interacted with students within their subset. Thus, informal interaction was not a confounder in this study. Quite the contrary, it suggests that a simple change in design has far-reaching consequences for the students learning process, even beyond the boundaries of the formally organised educational processes. Finally, interviews suggested that students experienced negligible negative side effects of the intervention. Therefore, it is safe to conclude that students have better learning processes when involved in small subsets.

\section{ChAllenges \& DIRECTIONS FOR FUtURE RESEARCH}

This dissertation addressed questions concerning the optimal method to collaborate and how this situation is best achieved. Although these questions have been elaborated in this dissertation, future studies need to be done. For example, is there a need to be a balance between dialogue (common ground) and discourse (constructive cognitive conflict) in a group to learn most in the group? How can 
students, teachers and the context facilitate the group to become more effective? This dissertation was the first to focus on informal learning in medical education. In this dissertation we have not focused on what is a 'good' social network to learn with. Furthermore, the informal and formal learning processes might be quite different in other contexts. For example, in the graduate medical curriculum or post-doctoral curriculum medical students, trainees or consultants might rely on informal learning more strongly than in the pre-clinical curriculum. Moreover, the divide between formal and informal learning is probably less clear in the whole educational continuum than is assumed in this manuscript. Therefore, future studies in various phases of the medical education could help to uncover how medical doctors learn and explore areas for improvement or facilitation this process of learning. A good start has been made by Wagter et al (2012). This team visualized informal learning networks in the workplace to understand how inter-professional collaboration occurs in an Intensive Care Unit.

In this dissertation we focused on learning processes. A valuable addition to gaining understanding of learning is to combine processes and outcome measures. One of the first problems that need to be solved, is to clearly define group learning outcomes in collaborative learning (Goodman \& Dabbish, 2011). Besides cognitive outcome measures such as achievement on knowledge tests or better medical skills, other competences should be included such as collaborative skills, motivational and social gains.

Methodological challenges need to be overcome when researching groups over time. In longitudinal studies, timing is important. While collecting longitudinal data sets, the timing of these observations may influence the results (Roe, 2008). For example, when understanding how a group collaborates it might be of crucial importance to include all group sessions. If a researcher needs to choose which sessions can be measured or observed, timing is essential to measure collaboration over time. The process of developing better ways to perform longitudinal research and analysis still continues (Ballard, Tschan, \& Waller, 2008). For example, in social network analyses longitudinal data sets are rather time-consuming and difficult to analyse. Hopefully new software programmes will help to ease longitudinal data analysis in longitudinal social network studies.

Moreover, in qualitative research, biases may play a role when students are asked for their perception over a long retrospective period. Besides self-reports, observational studies could provide rather interesting details in what students actually do when learning together. However, also at present longitudinal observational studies in a natural context without influencing the students' behaviour remain a challenge. Modern-day video techniques might facilitate data gathering and analysis (Goldman, Pea, Baron, \& Derry, 2007). 


\section{Practical implications \& VALIDATION}

The process of gaining understanding into the collaborative learning process has revealed interesting details on formal and informal learning in a Problem-Based Learning context. Above all, collaborative learning is a social and dynamic process that is still under development. In chapter five it was clearly shown how learning processes increase when classes appear small. This intervention was purely based on allowing students more time for interaction with the same set of students. Of course, other methods to increase the quality of interaction among students might be applied; for example by teaching students more about group dynamics and how to deal with problems in the group. An increase in the quality of informal interaction might be achieved by analysing who are the students with weak networks. Besides the students, the tutors are important facilitators of learning in small collaborative groups. The quality of collaboration might be increased by providing students with tutors for a longer period of time (Curet \& Mennin, 2003), a higher quality of scaffolding by the tutors or facilitation of reflexive learning based on the performance of the group (Gabelica, van den Bossche, Segers, \& Gijselaers, 2012). Finally, as students are directed by tests what and how they learn (Al-Kadri, 2012), outcomes of the medical programme are rather important to direct how students learn the required medical competences.

Overall, this dissertation emphasised the importance to include time in the design of Powerful Learning Environments. We hope that current curriculum designers are able to include this in their (medical) programmes to increase student learning. 


\section{REFERENCES}

Al-Kadri, H. M. (2012). Does Assessment Drive Students' Learning? Clinical Context Assessment and Students' Approaches to Learning. (PhD), Maastricht University, Maastricht.

Ballard, D. I., Tschan, F., \& Waller, M. J. (2008). All in the timing: considering time at multiple stages of group research. Small group research, 39(3), 328-351.

Carabajal, K., LaPointe, D., \& Gunawardena, C. N. (2008) Group development in online distance learning groups. In M. G. Moore (Ed.), Handbook of distance education (2nd ed., pp. 137-148). Mahwah, New Jersey: Lawrence Erlbaum Assocates Inc.

Curet, M. J., \& Mennin, S. P. (2003). The effect of longterm vs shortterm tutors on the quality of the tutotiral process and student performance. Advances in Health Sciences Education, 8, 117-126.

Fransen, J., Weinberger, A., \& Kirschner, P. A. (2013). Team Effectiveness and Team Development in CSCL. Educational psychologist, 48(1), 9-24. doi: 10.1080/00461520.2012.747947

Gabelica, C., van den Bossche, P., Segers, M., \& Gijselaers, W. (2012). Feedback, a powerful level in teams: A review. Educational Research Review, 7(2), 123-144.

Goldman, R., Pea, R., Baron, B., \& Derry, S. J. (2007). Video research in the learning sciences. Mahwah, NJ: Lawrence Erlbaum Associates.
Gruenfeld, D. H., Mannix, E. A., Williams, K. Y., \& Neale, M. A. (1996). Group composition and decision making: How member familiarity and information distribution affect process and performance. Organizational behavior and human decision processes, 67(1), 1-15.

Harrison, D. A., Mohammed, S., McGrath, J. E., Florey, A. T., \& Vanderstoep, S. W. (2003). Time matters in team performance: effects of member familitary, entrainment, and task discontinuity on speed and quality. Personnel Psychology, 56(3), 663-669.

Mathieu, J., Maynard, M. T., Rapp, T., \& Gilson, L. (2008). Team effectiveness 1997-2007: A review of recent advancements and a glimpse into the future. Journal of Management, 34(3), 410-476. doi: $10.1177 / 0149206308316061$

Mennecke, B. E., Hoffer, J. A., \& Wynne, B. E. (1992). The implications of group development and history for group support system theory and practice. Small group research, 23, 524-572. doi: $10.1177 / 1046496492234005$

Roe, R. A. (2008). Time in Applied psychology. European psychologist, 13(1), 37-52. doi: 10.1027/10169040.13.1.37

Wagter, J. M., van de Bunt, G., Honing, M., Eckenhausen, M., \& Scherpbier, A. (2012). Informal interprofessional learning: Visualizing the clinical workplace. Journal of interprofessional care, 26, 173-182. doi: 10.3109/13561820.2012.656773 



\section{CHAPTER 7}
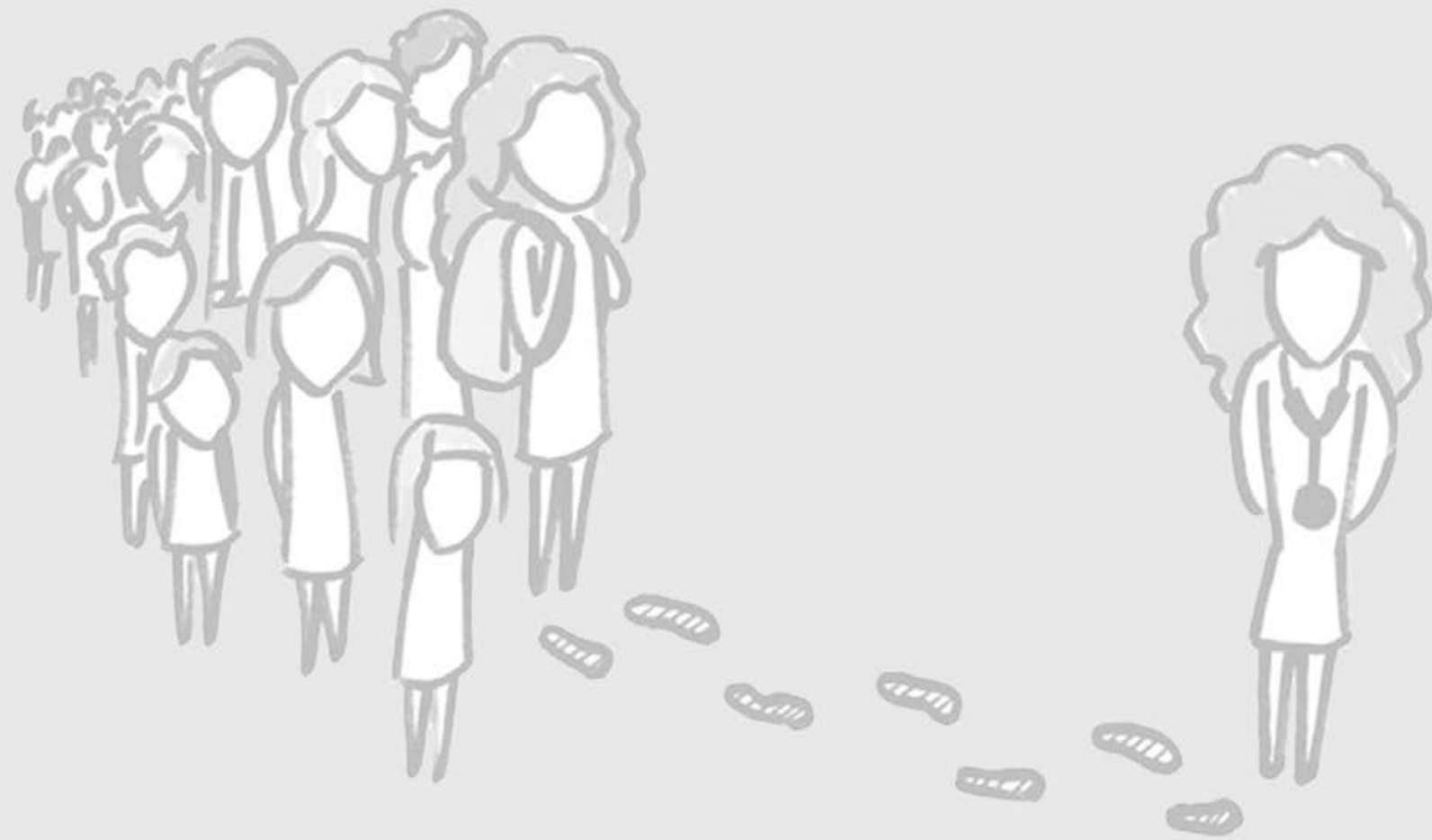


\section{Summary}

This dissertation explores collaborative learning. Previous research showed that collaboration among students in small groups is more effective than rather traditional types of learning environments in which the teacher holds the central position in the classroom. More effective learning is described as better cognition, such as more knowledge, better translation of knowledge but also better achievement, higher motivation to do difficult tasks and more social relations gained from the learning environment. Although this student-centred learning context is promising, in practice, problems were experienced as well, for example social loafing or free riding amongst students. Problems in the collaborative process have been depicted as the cause. Therefore, questions remain how students learn collaboratively and how to improve collaboration among students to make this learning context more effective. In this dissertation these two quests were addressed. In chapter two we investigated how groups of students assembled by the university changed over time. In this study we found that students needed to learn how to learn in a small group every time they changed group composition. There was no linear improvement over time, in such way that we did not observe that students became more experienced in collaboration when having collaborated in quite some groups over time. Various group processes were perceived important, among others knowing a fellow students' expertise. Another important process was 'knowing how a fellow student collaborates'. Development of learning in groups should be seen as a complex not-sequential process instead of a linear process.

The third and fourth chapters cover learning with others students when not involved in activities organised by the university. This type of learning is called 'informal' learning such as meeting in the library and study with fellow students. In the end of the first curriculum year it was found that learning with fellow students in the informal context is rather important for the overall learning process. A second longitudinal study found that students developed a social network of students with whom they learn. In the second curriculum year this network decreased in size. Students perceived that somewhere in the second curriculum year they had developed an optimal network to learn. The influence of the medical school on the composition of these learning networks decreased progressively over time. The members of the first tutorial group remained in the network.

Finally, we wanted to improve the learning environment in practice. These previous studies clearly emphasiz that students need to know one another to optimally collaborate in small groups. At the moment this study was undertaken, the class consisted of approximately 320 students who were randomised every module again towards a small group. Due to the large class size the chance is rather small to meet and collaborate with a fellow student again in one of the future modules. Therefore we subdivided the class of 2010-2011 in three subsets: two small subsets of 50 students each and own large subset with the remaining students (220). The students were assembled in small groups within their subset. In the first curriculum year, also 
the clinical skills trainings were composed from the subsets. This way, students in the small subsets frequently met one another in formal activities. In contrast, the control group, the large subset, met 'new' or 'unfamiliar' students every module again. This study observed that in the second curriculum year, students did not need to develop again in the small groups. Students also learned in the informal context mostly within their subset, enlarging the effect of the intervention. Finally, students perceived negligible side effects. Therefore, medical education can become more effective by making classes seem small. 


\section{Samenvatting}

Dit proefschrift gaat over leren in groepen. Eerder onderzoek heeft laten zien dat samenwerkend leren van studenten in kleine groepen effectiever is dan leren in meer traditionele vormen van onderwijs waarin de leraar centraal staat. 'Beter' leren neemt de vorm aan van cognitieve uitkomsten, zoals meer kennis, betere vertaling van kennis naar de praktijk, maar ook betere prestaties, meer motivatie om moeilijke taken uit te voeren en meer sociale contacten die opgedaan worden in de leeromgeving. Alhoewel deze onderwijsvorm dus veelbelovend is, komen er in de praktijk ook problemen voor, zoals studenten die meeliften op de kennis van anderen. Uiteindelijk is bekend dat een heel aantal groepen niet goed functioneren. Zodoende blijven er dus veel vragen over hoe groepen samenwerkend leren toepassen en hoe we dit kunnen stimuleren of verbeteren in de praktijk zodat studenten meer leren. In dit proefschrift exploreren we het leren in groepen.

In hoofdstuk twee hebben we bestudeerd hoe groepen studenten, samengesteld door de universiteit, veranderen door de tijd heen. In de universiteit wisselen studenten elk blok van groep samenstelling. In dit onderzoek blijkt dat studenten in elke groep opnieuw moesten leren om samen te leren. $\mathrm{Er}$ was geen lineaire verbetering over de tijd te bemerken waaruit blijkt dat studenten beter konden samenwerken wanneer ze meer ervaring hadden opgedaan in het samenwerken. Er bleken verschillende groepsprocessen van groot belang te zijn in het samenwerkend leren, waaronder het weten waar een collega student expert in is. Een ander belangrijk concept was het weten hoe collega studenten participeren in groepen. Ontwikkeling van samenwerking in groepen moet gezien worden als complex en nietsequentieel in plaats van lineair.

Het derde en vierde hoofdstuk beslaat het leren met collega studenten buiten de activiteiten die de faculteit had georganiseerd, ook wel informeel leren genaamd, zoals samen in de bibliotheek af te spreken en te studeren. Aan het einde van het eerste jaar bleek dat het leren in de informele leeromgeving zeer belangrijk was in het leerproces van de student. Een tweede longitudinale studie liet zien dat studenten een netwerk opbouwen die steeds groter werd. In het tweede jaar van de geneeskunde opleiding nam het netwerk in grootte af. Studenten lichtte in interviews toe dat ongeveer in het tweede jaar er een optimaal netwerk was ontstaan waarin men goed samen kon leren. De invloed van de faculteit op de samenstelling van het netwerk van studenten vervaagde met het verstrijken van de tijd. Alleen de eerste onderwijsgroepssamenstelling was bepalend wie in je netwerk aanwezig blijft.

Tenslotte wilden we graag het (groeps)onderwijs verbeteren in de praktijk. Uit de voorgaande studies komt duidelijk naar voren dat studenten elkaar moesten kennen om optimaal gebruik te maken van elkaar in de tutorgroepen. Op dit moment wordt de totale geneeskunde jaargroep van zo'n 320 studenten steeds willekeurig elk blok opnieuw ingedeeld in een tutorgroep. Hierdoor is de kans zeer klein dat een student een collega opnieuw tegenkomt in een volgend blok. Vandaar dat we het cohort in 
2010-2011 hebben gesplitst in drie groepen: twee kleine subjaargroepen van 50 studenten en een grote jaargroep van de overige studenten (220). De studenten werden twee jaar lang binnen hun subjaargroep ingedeeld in de tutorgroepen en in het eerste jaar ook in vaardigheidstrainingen. Daardoor kwamen studenten in de kleine jaargroepen steeds dezelfde studenten tegen. In de controle groep, de grote jaargroep, kwamen de studenten voornamelijk 'nieuwe' of 'onbekende' studenten tegen. Uit deze studie bleek dat in het tweede jaar, studenten zich niet meer hoefden te ontwikkelen tot een "goed" functionerende tutorgroep. Daarnaast bleek dat studenten vrijwel alleen binnen de subjaargroep samen leerden buiten de onderwijsgroepen of andere formele activiteiten om. Tenslotte ervaarden studenten in de kleine subjaargroepen weinig nadelen. Kortom, grote jaargroepen opdelen in kleinere subgroepen kan het samenwerkend leerproces verbeteren in de praktijk, waardoor medisch studenten gefaciliteerd worden in hun proces om dokter te worden. 



\section{CHAPTER 8}

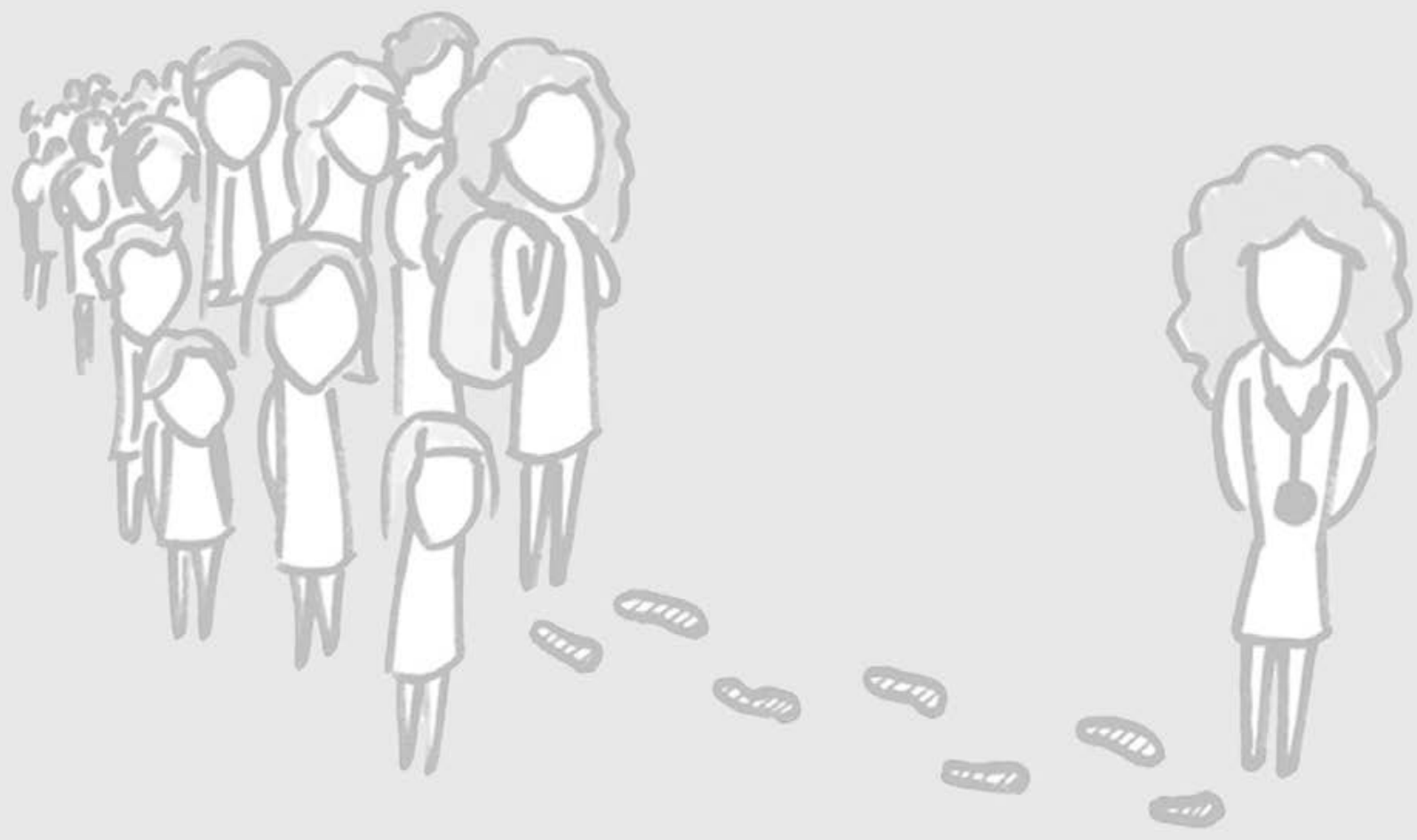




\section{Dankwoord}

The very substance of the ambitious is merely the shadow of a dream. Mijn dank gaat uiteraard als eerste uit naar mijn promotieteam die met veel ambitie dit project heeft begeleid. Goede ideeën prikkelden dit promotieonderzoek, maar de keerzijde bleek onze hoge verwachtingen. 'Dit gaat jullie nooit lukken' hebben we meermaals gehoord. Mijn lof gaat uit naar jullie die een risicovol project hebben willen begeleiden. Daarnaast mijn dank voor jullie enthousiasme, het vertrouwen dat ik het project mocht dirigeren ondanks mijn naïviteit in de onderzoekswereld en eigenwijze karakter, de strenge woorden als grootse ideeën in de lucht bleven hangen maar tegelijkertijd de vrijheid om groots te blijven denken. Ik ben altijd trots en dankbaar geweest om met jullie vieren in een team samen te werken met ieder een geheel andere kijk in het medisch onderwijs en een drukke agenda.

Professor Bos, beste Gerard; het duurde ongeveer een jaar voordat ik je ambitie in het onderwijs kon begrijpen. Je leek het eerste jaar in het Management Team streng en nors. Pas na een aantal maanden zag ik je enthousiasme om alles uit de kast te halen om een Harvard aan de Maas te ontwikkelen. Je zorgde ervoor dat dit project voldoende steun kreeg en behield. Bedankt voor je verassende, soms frustrerend maar altijd realistische kijk op de resultaten en impact van de onderzoeken op de (toekomstige) werkvloer.

Doctor de Grave, beste Willem; je onophoudelijke enthousiasme daar ben ik je zeer dankbaar voor. Je was altijd bereikbaar om 'even' te brainstormen. Menige avond trof ik je als enige aanwezige in de UNS 60 met een gezellig muziekje om nog even te vergaderen. Als je op vakantie ging liet je het me dit alvast vooraf weten zodat ik mijn feedback en vergader sessies met je kon afstemmen. Je interesse in nieuwe methodes zoals sociale netwerken, maar ook de uitgebreide literatuur uit andere disciplines zorgden ervoor dat ik altijd inspiratie kreeg.

Professor Scherpbier, beste Albert; we kennen elkaar uit het Management Team van de faculteit. Als toenmalige directeur van de medische faculteit stelde je me voor dat het tijd was om te kiezen. Als we een experiment in het onderwijs wilden uitvoeren, dan kon het niet anders dan het uit te voeren als onderdeel van een promotie onderzoek. Er zijn maar weinig professoren die het aandurven om medisch studenten te laten promoveren. En ondanks je promoties naar uiteindelijk de decaan, ben je toch altijd in staat om feedback te geven en overzicht te houden. Fijn dat je af en toe bleef controleren wat ik nu wilde als er allerlei discussies werden gevoerd over de mail. Wat kon ik me nog meer wensen?

Professor Schuwirth, beste Lambert; als de expert in toetsing durfde je het aan om onderzoek naar groepsprocessen te doen met een medisch student die naast dit onderzoek ook een master deed. Bedankt voor het vertrouwen in de moeilijke 
beginperiode van het project. Na drie maanden alleen maar lezen en brainstormen bleek dat je gelijk had. Je vrolijkheid, oprechtheid en geweldige manier van synoniemen verzinnen om theoretische kaders te verduidelijken, hebben me geïnspireerd. Toen je naar Australië verhuisde was je fysiek ver weg, maar ondertussen bleef je meedenken. Veel dank voor de nauwkeurigheid waarmee je de manuscripten heb gelezen. Het is een vaardigheid om jaloers op te worden.

Geachte leden van de promotiecommissie; professor Dolmans, professor de Laat, professor Dornan, professor Jaarsma, professor Gijselaers. Zeer veel dank voor het kritisch lezen van het manuscript en de positieve beoordeling van het proefschrift. Daarnaast veel dank voor de inspiratie die ik heb gekregen van jullie eigen onderzoeken.

Geachte mede-auteurs, natuurlijk konden deze studies niet verricht worden zonder jullie.

Bart Rienties promoveerde net toen ik startte met mijn onderzoek. Je bent ook zo'n enthousiasteling met grootse ideeën in het onderzoek naar het leren tussen studenten. Sociale netwerken is een methode die ons verbind, maar er zijn nog zoveel ideeën nog niet geëxploreerd. No-nonsense is hoe jij je onderzoek doet. Bedankt voor je enthousiasme, gezelligheid en inspiratie.

Piet van den Bossche bleek een expert in groepsprocessen van samenwerkend leren. Heel veel dank voor je inspiratie en vele feedback sessies voordat ons manuscript dusdanig goed in elkaar zat totdat we allemaal tevreden waren.

Professor Arah, beste Onyi, heel veel dank dat ik een paar maanden naar UCLA mocht komen om mijn vaardigheden in de epidemiologie te verbeteren. Je 'master classes' begonnen als een les Chinees, maar eindigde in daadwerkelijk begrip in de materie. Bedankt voor je wijsheid en gastvrijheid.

Uiteraard was dit onderzoek niet mogelijk geweest zonder de steun en het vele werk van het voormalige Management \& Organisatie Team: Pauline Vluggen, Professor Oude Egbrink en Professor Kooman. Daarnaast, de ondersteuning vanuit de faculteit, in het speciaal Paul, Guus en Marjo.

Nicky, Lilian en Marie-Louise, heel veel dank voor al jullie hulp met de vele enveloppen uitdelen, ontvangen en dingen klaarleggen voor deze onderzoeken. Onze communicatie verliep helaas vaak middels 'post-its'. Ondanks deze fragmentarische communicatie bleek dit vlekkeloos te werken. Verder ook veel dank aan de studentassistenten Madelon, Max, Rachel, Guus en Suzanne die ontzettend veel hebben gedaan om dit onderzoek mogelijk te maken. 
Collega's van O\&O, heel veel dank voor de inspiratie en gezelligheid. Af en aan was ik een tijdje aanwezig, dan weer lange tijd afwezig. Desondanks voelde ik me een deel van de groep. Zeker tijdens congressen resulteerde het in een zeer gezellige en inspirerende tijd. Zeer veel dank en tot binnenkort bij de volgende promoties.

Kamergenootjes, Ingrid, je was de eerste van ons vieren die in 2012 promoveerde. Jonne, Mariette en ik volgen je nu op de voet. We hebben allemaal een andere onderzoeksinteresse en verschillend in karakter. Echter, onze nieuwsgierigheid en de passie voor onze onderzoeken zijn niet te evenaren. Zeer veel dank voor jullie gezelligheid, de steun en inspiratie. Heerlijk dat we voorlopig allemaal toch in de buurt blijven zodat we onze etentjes kunnen blijven houden.

Paranimfen, Juul en Mariëlle, beide vonden jullie het verrassend dat ik jullie heb gevraagd voor deze rol. Soms vroeg ik me af of ik niet beter kunnen redeneren als jullie; 'Onderzoek doen is vooral heel veel werk, dus waarom zou je het doen?' Desondanks blijf ik een idealist en ben ik blij met jullie visie die me met beide benen op de grond houden. Juultje, je hebt vele rollen vervuld in vrijwel alle onderzoeken vooral de interviews. Heel veel dank voor je flexibiliteit, je nuancering, je vrije denkvermogen, je enthousiasme en kunde in het interviewen, maar bovenal onze vriendschap die bestaat sinds het verlaten van de middelbare school. Mariëlle, jij en ik lijken vrijwel niet op elkaar, wat gek genoeg onze aantrekkingskracht is in onze vriendschap. Heel veel dank voor je pure en eerlijke oordeelsvermogen. Je bent een enorme steun geweest op moeilijke momenten of wanneer er belangrijke beslissingen genomen dienden te worden. Uiteraard zorgde je ook voor een fijne tijd naast de universiteit en het ziekenhuis.

Familie, het zijn druk bewogen jaren geweest. Er zijn weer veel bergen beklommen en ik prijs mij dan ook erg gelukkig jullie er allemaal zijn om dit feest te kunnen vieren. Bedankt voor het geduld als ik het te druk had met de studie, het onderzoek of later het 'werk'. Veel dank voor jullie steun en luisterend oor als ik een klaaggezang of juist een succesverhaal wilde afsteken.

I was so blessed meeting the Finlan family, who invited me into their home and made me part of their family. I miss all Sunday dinners which are such example of enjoying the important things in life: friends, family and amazing food. I hope to see you soon again.

Vrienden, te veel om afzonderlijk te noemen. Jullie zijn onmisbaar in mijn leven. Bedankt voor de gezellige avonden, weekenden en vakanties. We zijn langzaam uitgewaaierd naar de rest van het Nederland of zelfs hierbuiten; gelukkig zijn we in staat om elkaar regelmatig op te zoeken. Ik hoop dat dit kan blijven bestaan.

Tenslotte wil ik nog stilstaan voor de openhartigheid en enthousiasme van de studenten die dit onderzoek mogelijk gemaakt hebben. Ik wens jullie allen een mooie carrière als dokter. 


\section{CHAPTER 9}
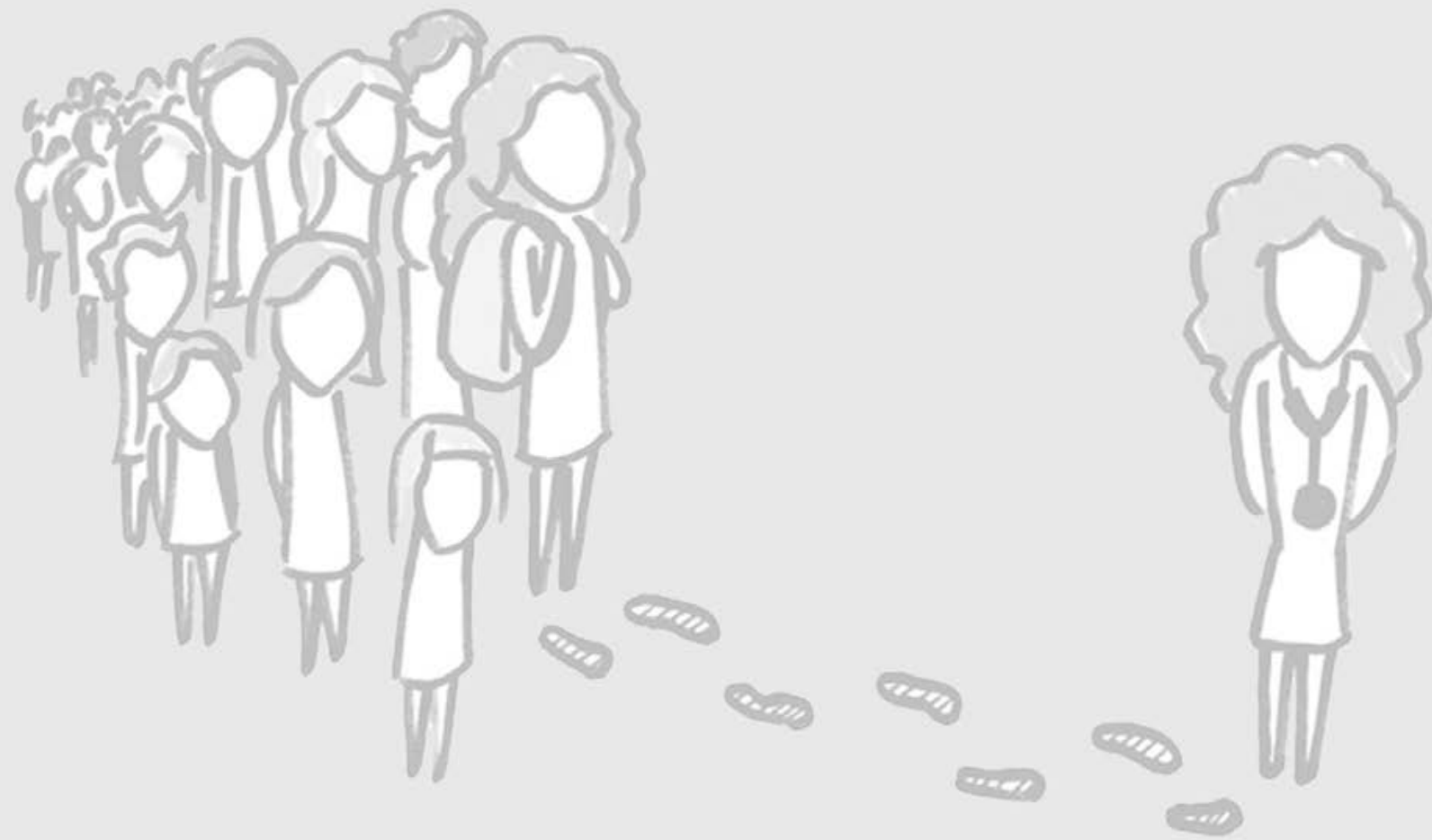


\section{Curriculum vitae}

Social learning is my second nature being born in 1986 in Gorinchem the Netherlands amidst a family with two brothers and two sisters. The Montessori school left its prints spending 12 years in both the primary \& secondary education learning with peers in Maastricht. After finishing high school in 2004 I applied for the Rotary Exchange Programme and went on exchange to Upstate New York, in the United States of America. During this year I learned the 'American way of life' and went to a traditional teacher centred high school. This made me decide to choose a studentcentred university for my medical studies instead of aspiring to my desire to explore a new city.

My first steps in the world of research were made in the second curriculum year when I was asked to do research for the Skillslab 'why students prepare' with my fellow student Marlien Aalbers guided by Maarten Verwijnen \& Jan-Joost Rethans. At the same time I was accepted to the Honours programme Research and started research on disorders in social cognition in patients (and relatives) with psychosis in the department of Social Psychiatry with Dagmar Versmissen, Ruud van Winkel \& Jim van Os.

As a student I was active in the student government in a variety of evaluation committees. I represented students in the Management Team of the Medical School. In this team, the idea was born to improve the Maastricht PBL system. With Gerard Bos and supported by Albert Scherpbier we designed a first research proposal. Lambert Schuwirth accepted the challenge to guide the project and Willem de Grave joined the team when we realised we needed an expert on group processes. Due to the support of the educational office I was able to pursue a master in Medicine and at the same time conduct a PhD project. As part of the PhD project I explored epidemiology visiting Professor Arah at the University of Southern California, Los Angeles in the summer of 2012.

In October 2012 I graduated in Medicine at the Maastricht University Medical School. From January 2013 I worked in the department of Plastic \& Reconstructive surgery, Venlo. In November 2013 I started a residency-training programme in the field of Plastic, Reconstructive \& Hand Surgery in Maastricht.

\section{SCIENTIFIC PUBLICATIONS IN PEER-REVIEWED JOURNALS}

Smeets, F., Lataster, T. de Gracia Dominguez, M., Hommes, J. Lieb, R, Wittchen, H., van Os, J. (2010) Evidence that onset of psychosis in the population reflects early hallucinatory experiences that through environmental risks and affective dysregulation become complicated by delusions. Schizophrenia Bulletin, October 28, p.1-12.

Hommes, J., Krabbendam, L., Versmissen, D., Kircher, T., van Os, J., van Winkel, R. (2012) Self-monitoring as a familial vulnerability marker for psychosis: an analysis of patients, unaffected siblings and healthy controls. Psychological medicine, 42, 
p235-245.

Hommes, J., Rienties, B., de Grave, W., Bos, G., Schuwirth, L., Scherpbier, A. (2012) Visualizing the invisible; a network approach to reveal the impact of informal social interaction on student learning. Advances in Health Science professionals Education 17 (5) p743-757.

Aalbers MW*, Hommes J*, Rethans JJ, Imbos T, Muijtjens AM, Verwijnen MG. (2013) Why should I prepare? a mixed method study exploring the motives of medical undergraduate students to prepare for clinical skills training sessions. BMC Medical Education. 22;13:27

* these authors contributed equally.

Bates, E., Hommes, J., Duvivier, R., Taylor, D. (2013) AMEE Guide 84: Student involvement in Problem-Based Learning (PBL). Medical Teacher, $X X(X X), p X X$

Hommes J, van den Bossche P, de Grave W, Bos G, Schuwirth L, Scherpbier A. (2013) Understanding the effects of time on collaborative learning processes in a Problem Based Learning setting: a mixed methods study. Accepted in Advances in Health Sciences Education.

\section{Proceedings AND BOOK CHAPTERS}

Hernandez Nenclares, N., Rienties, B., Van den Bossche, P., \& Hommes, J. (2011) Redesigning the classroom to enhance knowledge spillovers: the role of friendship versus group work. In B. Rienties, S. Reeb-Gruber, P. Daly \& P. Van den Bossche (Eds.), Proceedings of the 18th EDINEB Conference From Innovation to Crème de la Crème Education! (pp. 262 - 270). Lyons: FEBA ERD Press.

Rienties, B. Hernandez Nenclares, N., Hommes, J. Veermans, K. (2013) Understanding emerging knowledge spillovers in small-group learning settings: a networked learning perspective. In: Developing Theory, Design and Experience of Networked Learning. Hodgson, V; McConnell, D.; de Laat, M. (Eds.) 2013, Springer book series on networked learning.

\section{Presentations}

Aalbers, M, Hommes, J., Rethans, J., Verwijnen, M. (2007) Waarom bereiden studenten zich voor? Nederlandse Vereniging voor Medisch Onderwijs congres in Egmond aan Zee, The Netherlands.

Hommes, J., Aalbers, M.,Rethans, J., Verwijnen, M. (2008) Daarom bereiden studenten zich voor! Nederlandse Vereniging voor Medisch Onderwijs congres in Egmond aan Zee, The Netherlands.

Hommes, J., Aalbers, M.,Rethans, J., Verwijnen, M. (2008) That's why students prepare! The NETWORK Towards Unity For Health conference, Kampala, Uganda.

Hommes, J., Rienties, B., de Grave, W., Bos, G., Schuwirth, L, Scherpbier, A. (2011) Social networks increase student learning. AMEE - An international Association for Medical Education, Vienna, Austria.

Rienties, B., Veermans, K. Hommes J. (2012) Dynamic social network analysis to understand knowledge spillovers in small group learning settings: a networked learning perspective. The 8th International Conference on Networked Learning. Maastricht, the Netherlands, 2-4th of April 2012. 
Hommes, J. (2013) PhD report: How relations, time \& size matter in medical education. AMEE - international Association for Medical Education, Prague, Tsjech Republic.

Hommes, J. Rienties, B., de Grave, W., Bos, G, Schuwirth, L, Scherpbier, A. (2013) A longitudinal analysis of knowledge spillovers in PBL to explore with whom students learn. EARLI: European Association for Research on Learning and Instruction, Munich, Germany.

Hommes, J., van de Bossche, de Grave, W., Bos, G, Schuwirth, L, Scherpbier (2013) Understanding the effects of time on collaborative learning processes in ProblemBased Learning. EARLI: European Association for Research on Learning and Instruction, Munich, Germany. 


\section{CHAPTER 10}

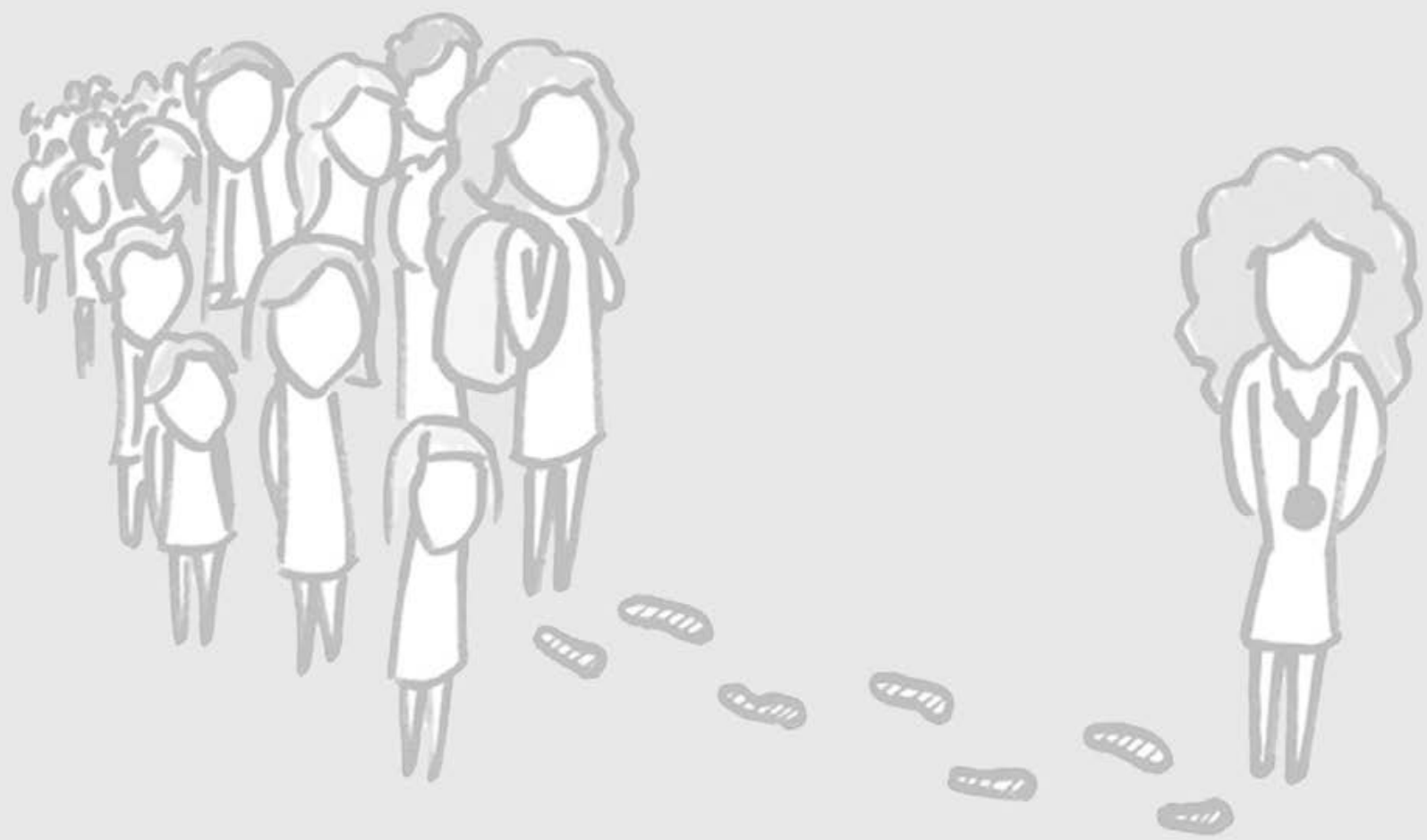




\section{SHE Dissertation Series}

The SHE Dissertation Series publishes dissertations of PhD candidates from the School of Health Professions Education (SHE) who defended their PhD theses at Maastricht University. The most recent ones are listed below. For more information go to: www.maastrichtuniversity.nl/she.

van der Zwet, J. (30.1.2014) Identity, Interaction and Power. Explaining the affordances of doctor-student interaction during clerkships.

Kamp, R.J.A.. (28-11-2013) Peer Feedback to Enhance Learning in Problem-Based Tutorial Groups.

Junod Perron, N. (24-10-2013) Towards a learner-centered approach to postgraduate communications skills teaching,

Pratidina Susilo, A. (24-10-2013) Learning to be the Patient Advocate The Development of a Communication Skills Course to Enhance Nurses' Contribution to the Informed Consent Process.

Alves de Lima, A. (23-10-2013) Assessment of clinical competence: Reliability, Validity, Feasibility and Educational Impact of the mini-CEX.

Sibbald, M. (09-10-2013) Is that your final answer? How doctors should check decisions.

Ladhani, Z. (05-07-2013) Competency based education and professional competencies: a study of institutional structures, perspectives and practices in Pakistan.

Jippes, M. (01-02-2013) Culture matters in medical schools: How values shape a successful curriculum change.

Duvivier, R. J. (12-12-2012) Teaching and Learning Clinical Skills. Mastering the Art of Medicine.

De Feijter, J.M. (09-11-2012) Learning from error to improve patient safety.

Prescott, L. (09-11-2012) Ensuring the Competence of Dental Practitioners through the Development of a Workplace-Based System of Assessment.

Cilliers, F.J. (05-09-2012) The Pre-assessment Learning Effects of Consequential Assessment: Modelling how the Examination Game is Played.

Spanjers, I. A.E. (05-07-2012) Segmentation of Animations: Explaining the Effects on the Learning Process and Learning Outcomes.

Al-Kadri, H.M.F. (28-06-2012) Does Assessment Drive Students' Learning?

Leppink, J. (20-06-2012) Propositional manipulation for conceptual understanding of statistics.

Van Zundert, M.J. (04-05-2012) Conditions of Peer Assessment for Complex Learning.

Claramita, M. (30-03-2012) Doctor-patient communication in a culturally hierarchical context of Southeast Asia: A partnership approach.

Kleijnen, J.C.B.M. (21-03-2012) Internal quality management and organizational values in higher education. 
Persoon, M.C. (19-01-2012) Learning in Urology; The influence of simulators and human factors.

Pawlikowska, T.R.B. (21-12-2011) Patient Enablement; A Living Dialogue.

Sok Ying Liaw, (14-12-2011) Rescuing A Patient In Deteriorating Situations (RAPIDS): A programmatic approach in developing and evaluating a simulation-based educational program.

Singaram, V.S. (7-12-2011) Exploring the Impact of Diversity Factors on ProblemBased Collaborative Learning.

Balslev, T. (24-11-2011) Learning to diagnose using patient video cases in paediatrics: Perceptive and cognitive processes.

Widyandana, D. (19-10-2011) Integrating Pre-clinical skills training in skills laboratory and primary health care centers to prepare medical students for their clerkships.

Durning, S.J. (09-09-2011) Exploring the Influence of Contextual Factors of the Clinical Encounter on Clinical Reasoning Success (Unraveling context specificity.

Govaerts, M.J.B. (08-09-2011) Climbing the Pyramid;Towards Understanding Performance Assessment.

Stalmeijer, R. E. (07-07-2011) Evaluating Clinical Teaching through Cognitive Apprenticeship.

Malling, B.V.G. (01-07-2011) Managing word-based postgraduate medical education in clinical departments.

Veldhuijzen, J.W. (17-06-2011) Challenging the patient-centred paradigm: designing feasible guidelines for doctor patient communication.

Van Blankenstein, F. (18-05-2011) Elaboration during problem-based, small group discussion: A new approach to study collaborative learning.

Van Mook, W. (13-05-2011) Teaching and assessment of professional behavior: Rhetoric and reality.

De Leng, B. (8-12-2009). Wired for learning. How computers can support interaction in small group learning in higher education.

Maiorova, T. (29-05-2009). The role of gender in medical specialty choice and general practice preferences.

Bokken, L. (04-03-2009). Innovative use of simulated patients for educational purposes.

Wagenaar, A. (18-09-2008). Learning in internships. What and how students learn from experience.

Driessen, E. (25-06-2008). Educating the self-critical doctor. Using portfolio to stimulate and assess medical students' reflection.

Derkx, H. (18-06-2008). For your ears only. Quality of telephone triage at out-ofhours centres in the Netherlands.

Niessen, Th. (30-11-2007). Emerging epistemologies: making sense of teaching practice.

Budé, L. (05-10-2007). On the improvement of students' conceptual understanding in statistics education. 
Niemantsverdriet, S. (26-07-2007). Learning from international internships: A reconstruction in the medical domain.

Marambe, K. (20-06-2007). Patterns of student learning in medical education - A Sri Lankan study in traditional curriculum.

Pleijers, A. (19-01-2007). Tutorial group discussion in problem-based learning.

Sargeant, J. (21-09-2006). Multi-source feedback for physician learning and change.

Dornan, T. (12-06-2006). Experience-based learning.

Wass, V. (12-05-2006). The assessment of clinical competence in high stakes examinations.

Prince, K. (21-04-2006). Problem-based learning as a preparation for professional practice. 



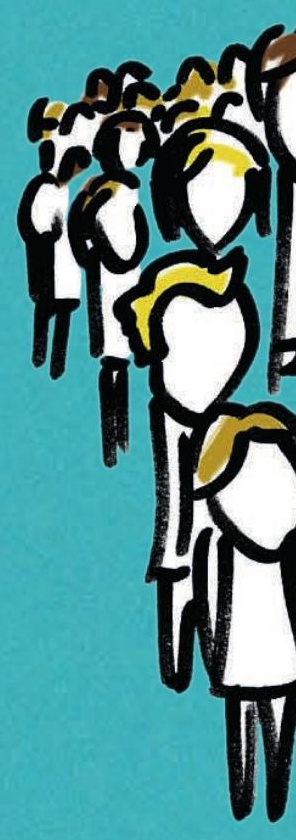

